\title{
Is nanostructuring sufficient to get catalytically active Au?
}

\author{
vorgelegt von \\ M. Sc. \\ Alexander Klyushin \\ geb. in Arkhangelsk, Russland \\ Von der Fakultät II - Mathematik und Naturwissenschaften \\ der Technischen Universität Berlin \\ zur Erlangung des akademischen Grades \\ Doktor der Naturwissenschaften \\ Dr. rer. nat. \\ genehmigte Dissertation
}

Promotionsausschuss:

Vorsitzender: Prof. Dr. Thorsten Ressler

Berichter/Gutachter: Prof. Dr. Robert Schlög1

Berichter/Gutachter: Prof. Dr. Mario Dähne

Berichter/Gutachter: Prof. Dr. Ronald Imbihl

Tag der wissenschaftlichen Aussprache: 24. September 2015

Berlin 2015 

На дне терпения оседает золото.

Имам Шамиль

Gold settles at the bottom of patience.

Imam Shamil. 


\section{Acknowledgement.}

I would like to thank many people for their support and help during my $\mathrm{PhD}$ thesis. First of all, I would like to thank my advisor, Prof. Dr. Robert Schlögl, Director of the Department of Inorganic Chemistry at the Fritz-Haber-Institute of Max-Planck-Society, for his guidance, invaluable support and encouragement throughout my $\mathrm{PhD}$ project. I would like to particularly acknowledge the members of the doctoral board, Prof. Dr. Mario Dähne and Prof. Dr. Ronald Imbihl, who gladly accepted to invest their valuable time in reviewing this work. Additional gratitude goes to Prof. Dr. Peter Strasser for taking the chair of the examination board.

I am also deeply grateful to Dr. Axel Knop-Gericke, leader of Electronic structure group, for his supervision, input and invaluable advice during my study. I shall also thank all members of Electronic structure group for all time that we spent together in the labs, conferences, meetings and events.

I am highly grateful and indebted to Dr. Tulio Rocha for introduce me into the utilization of the NAP-XPS setup and for providing me comprehensive overview of the research topic. Together with Dr. Mark Greiner their fruitful discussion and ideas during and after beamtimes were invaluable in past years.

I thank BESSY II/HZB for the allocation of synchrotron radiation beamtime. And of course, without efforts of Dr. Michael Hävecker, Dr. Raoul Blume and Birgitt Zada the ISSIS beamline operation would be impossible. With this respect, I am truly grateful to the technical support offered by Eugen Stotz in set-up construction.

Further acknowledgment goes to microscopy group, especially to Dr. Marc Willinger, Dr. Thomas Lunkenbein, Dr. Xing Huang, Dr. Manfred Schuster, Gisela Weinberg and Zhu-Jun Wang, for the amazing TEM and SEM images of Au-based catalysts. I shall also thank Dr. Matthias Friedrich for all catalytic tests of various samples at 1 bar pressure. I would also like to extend my gratitude to Dr. Rosa Arrigo, Dr. Zailai Xie, Dr. Yi Youngmi, Dr. Olaf Timpe and Xuan Li for the efforts made in sample synthesis.

Moreover, I would like to thank all my labmates, colleagues, and project partners for every piece of contribution that lead to the success of this work: Prof. Dr. Valerii Bukhtiyarov (Boreskov Institute of Catalysis, Russia), Dr. Andrey 
Bukhtiyarov (Boreskov Institute of Catalysis, Russia), Dr. Igor Prosvirin (Boreskov Institute of Catalysis, Russia), Dr. Detre Teschner, Dr. Ramzi Farra, Dr. Juan Velasco-Vélez, Verena Pfeifer, Maike Hashagen, Norbert Pfänder.

Last but not least important, I would like to thank my parents for their encouragement and support despite the distance. Finally, I would like to express my deepest gratitude to my wife for endless patience and belief in me during $\mathrm{PhD}$ study. 


\section{Table of Content}

List of Abbreviations .................................................. iii

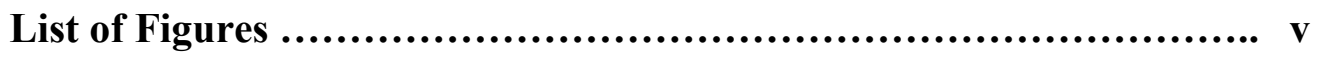

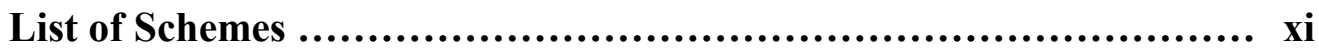

List of Tables ....................................................... xii

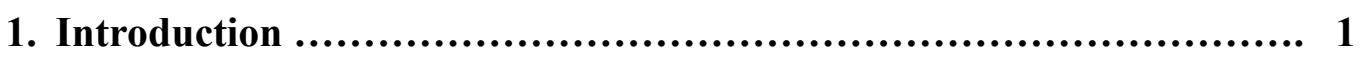

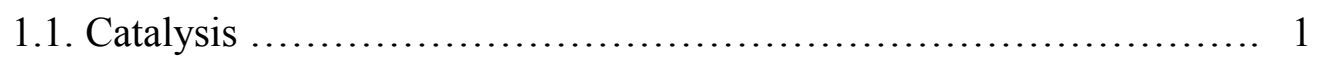

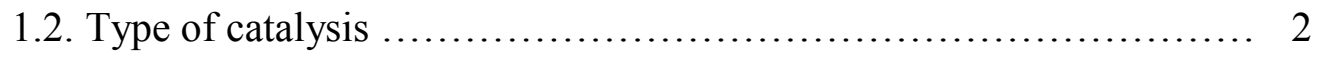

1.3. Mechanisms in gas/solid heterogeneous catalysis ................. 3

1.4. X-ray photoelectron spectroscopy for investigation catalytic process .. 4

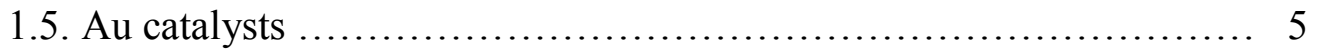

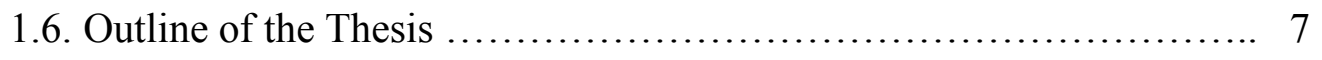

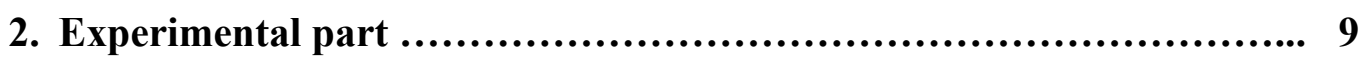

2.1. Beamline ............................................... 9

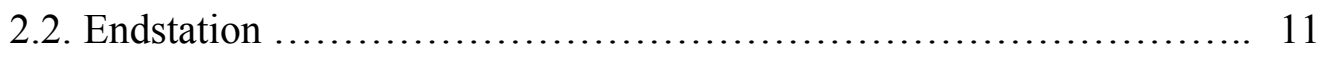

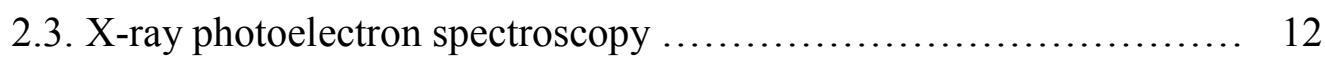

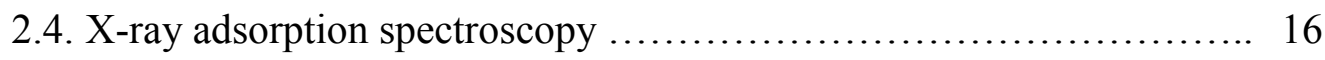

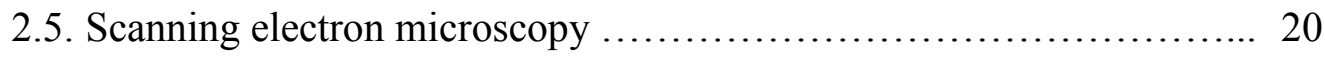

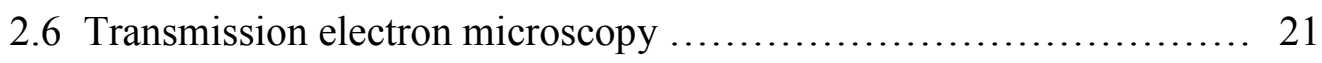

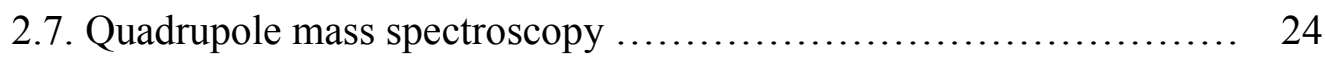

2.8. Reactor for $\mathrm{CO}$ oxidation at atmospheric pressure $\ldots \ldots \ldots \ldots \ldots \ldots . \ldots 25$

2.9. XPS measurement performance ............................ 26 


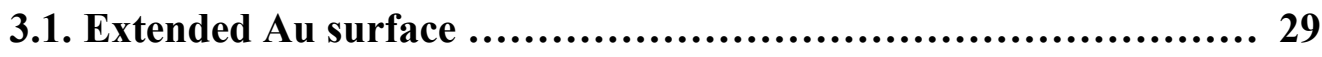

3.1.1. Clean and oxidized $\mathrm{Au}$ foil............................ 29

3.1.2. CO oxidation on $\mathrm{Au}$ foil ............................... 40

3.1.3. Clean and oxidized Au powder ......................... 41

3.1.4. CO oxidation on Au powder ........................... 43

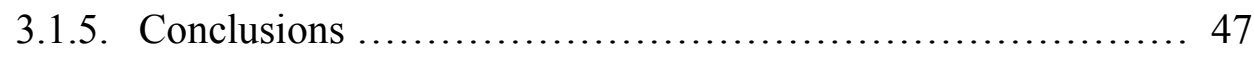

3.2. Au nanoparticles on oxygen-free support ....................... 49

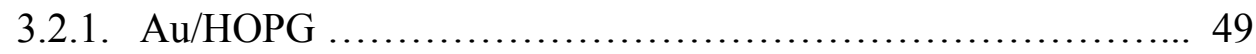

3.2.2. $\mathrm{Au} / \mathrm{N}-\mathrm{CNTs}$ and $\mathrm{Au} / \mathrm{O}-\mathrm{CNTs} \ldots \ldots \ldots \ldots \ldots \ldots \ldots \ldots \ldots \ldots \ldots$

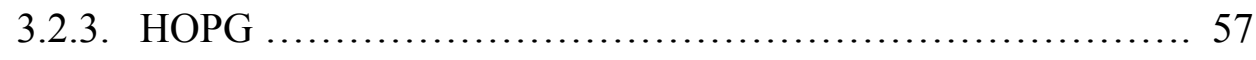

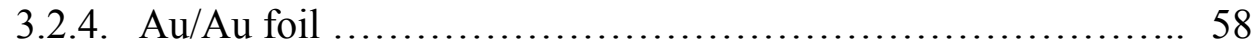

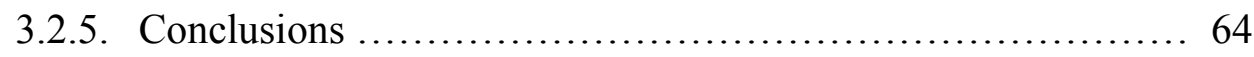

3.3. Au nanoparticles on oxide support ............................. 65

3.3.1. $\mathrm{Au} / \mathrm{Fe}_{2} \mathrm{O}_{3}-\mathrm{PC}$ (photo-induced decomposition of an Au-azidocomplex to generate zero-valence Au-species) .............. 65

3.3.2 $\mathrm{Au} / \mathrm{Fe}_{2} \mathrm{O}_{3}-\mathrm{C}$ (co-precipitation) and $\mathrm{Au} / \mathrm{TiO}_{2}-\mathrm{DP}$ (deposition-

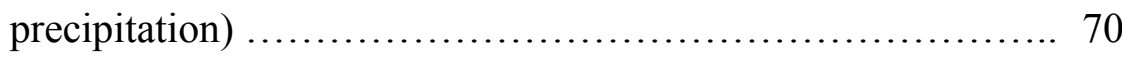

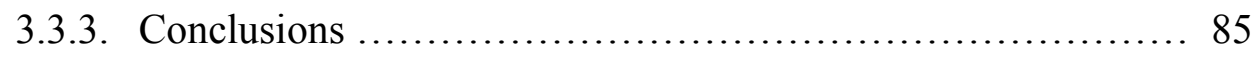

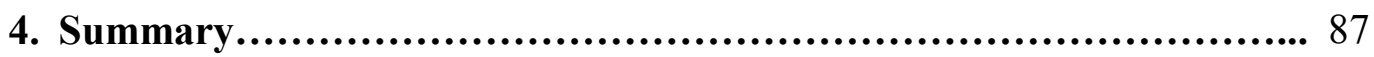

Bibliography....................................................... 90

Statement on the contributions to the publications in this thesis ....... 98 


\section{List of Abbreviations}

\begin{tabular}{|c|c|}
\hline $\mathrm{Au} / \mathrm{Fe}_{2} \mathrm{O}_{3}-\mathrm{C}$ & $\mathrm{Au} / \mathrm{Fe}_{2} \mathrm{O}_{3}$ synthesized by co-precipitation method \\
\hline $\mathrm{Au} / \mathrm{TiO}_{2}-\mathrm{DP}$ & $\mathrm{Au} / \mathrm{TiO}_{2}$ synthesized by deposition-precipitation method \\
\hline $\mathrm{Au} / \mathrm{Fe}_{2} \mathrm{O}_{3}-\mathrm{PC}$ & $\begin{array}{l}\mathrm{Au} / \mathrm{Fe}_{2} \mathrm{O}_{3} \text { synthesized by photo-induced decomposition of a } \mathrm{Au}- \\
\text { azido-complex to generate zero-valence } \mathrm{Au} \text {-species method }\end{array}$ \\
\hline $\mathbf{B E}$ & Binding Energy \\
\hline BESSY II/HZB & $\begin{array}{l}\text { Berliner Elektronenspeicherring für Synchrotronstrahlung/ } \\
\text { Helmholtz-Zentrum-Berlin }\end{array}$ \\
\hline CNT & Carbon Nanotube \\
\hline DFT & Density Functional Theory \\
\hline EDX & Energy-Dispersive X-ray Spectroscopy \\
\hline EELS & Electron Energy Loss Spectroscopy \\
\hline E-SEM & Environmental Scanning Electron Microscopy \\
\hline ESCA & Electron Spectroscopy for Chemical Analysis \\
\hline EXAFS & Extended X-ray Absorption Fine Structure \\
\hline ISISS & Innovative Station for In-Situ Spectroscopy \\
\hline FWHM & Full Width at Half Maximum \\
\hline HOPG & Highly Oriented Pyrolytic Graphite \\
\hline HV & High Vacuum \\
\hline IMFP & Inelastic Mean Free Path \\
\hline KE & Kinetic Energy \\
\hline N-CNT & Nitrogen-functionalized Carbon Nanotube \\
\hline NAP & Near Ambient Pressure \\
\hline NEXAFS & Near-Edge X-ray Absorption Fine Structure \\
\hline $\mathbf{N P}$ & Nanoparticle \\
\hline O-CNT & Oxygen-functionalized Carbon Nanotube \\
\hline PROX & Preferential Oxidation \\
\hline QMS & Quadruple Mass Separation \\
\hline RT & Room Temperature \\
\hline SEM & Scanning Electron Microscopy \\
\hline SMSI & Strong Metal Support Interaction \\
\hline
\end{tabular}


STEM

TEM

ToS

UHV

UV

$\mathrm{UV} / \mathrm{Vis}$

VB

wt $\%$

XANES

XAS

XP

XPS
Scanning Transmission Electron Microscopy

Transmission Electron Microscopy

Time on Stream

Ultrahigh Vacuum

Ultra Violet

Ultraviolet-visible

Valence Band

Weight Percent

X-ray Absorption Near-Edge Structure

X-ray Absorption Spectroscopy

X-ray Photoelectron

X-ray Photoelectron Spectroscopy 


\section{List of Figures.}

Figure 2.1 The optical layout of ISISS beamline ...................... 9

Figure 2.2 Sketch demonstrating the main components of NAP-XPS set-up ... 11

Figure 2.3 Electron trajectories inside a differentially pumped aperture system a) without electrostatic lenses, b) with electrostatic focusing lenses included. Electrons are assumed to enter from the left

Figure 2.4 Several ways to subtract background ....................... 15

Figure 2.5 XANES and EXAFS at Fe K-edge ............................ 17

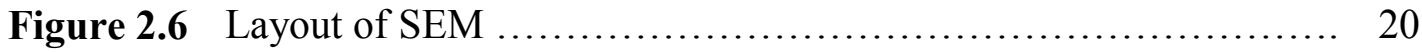

Figure 2.7 The scheme of specimen chamber in E-SEM .................. 21

Figure 2.8 Cross-section and layout of TEM .......................... 22

Figure 2.9 Possible signals available in TEM ............................ 23

Figure 2.10 End-on view of quadrupole mass spectrometer................. 24

Figure 2.11 Stability diagram for quadrupole mass spectrometer............. 25

Figure 2.12 Sapphire sample holder with a stainless steel back-plate and a lid

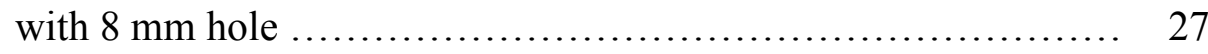

Figure 3.1 Survey photoelectron spectrum of clean $\mathrm{Au}$ foil ................. 29

Figure 3.2 Fitting of NAP (a) $\mathrm{Au} 4 \mathrm{f}_{7 / 2}$ and (b) $\mathrm{O} 1 \mathrm{~s}$ photoelectron spectra (using $150 \mathrm{eV}$ kinetic energy photoelectrons) from gold foil at $100^{\circ} \mathrm{C}$ (i) before (ii) during and (iii) after $\mathrm{O}_{3}$ treatment at $0.3 \mathrm{mbar} \quad 30$

Figure 3.3 Valence band spectra in UHV (bottom), in ozone (middle) and difference spectrum between ozone and UHV environments (top) measured at hv $=130 \mathrm{eV}$

Figure 3.4 $\mathrm{Au} 4 \mathrm{f}$ photoelectron spectra $(\mathrm{h} v=270 \mathrm{eV})$ from gold foil during heating (A) and cooling (B) at various temperatures measured at $0.3 \mathrm{mbar}$ and $\mathrm{CO} / \mathrm{O}_{2}+\mathrm{O}_{3}=1 / 80$ 
Figure 3.5 NAP-XP $\mathrm{Au} \quad 4 \mathrm{f}_{7 / 2}$ spectra (using $150 \mathrm{eV}$ kinetic energy photoelectrons) of a gold foil at $100^{\circ} \mathrm{C}$ before (black dash line), during (red dot line), after (blue solid) $\mathrm{O}_{3}$ treatment at $0.3 \mathrm{mbar}$ and difference spectrum between $\mathrm{Au} 4 \mathrm{f}_{7 / 2}$ after and before $\mathrm{O}_{3}$ treatment

Figure 3.6 $\mathrm{Au} 4 \mathrm{f}_{7 / 2}$ photoelectron spectra $(\mathrm{h} v=270 \mathrm{eV})$ of a gold foil at $100^{\circ} \mathrm{C}$ in UHV after ozone treatment

Figure 3.7 Ex-situ SEM image of a $\mathrm{Au}$ foil after $\mathrm{O}_{3}(0.3$ mbar $)$ treatment at $100^{\circ} \mathrm{C}$ showing ridges only in areas that were exposed to $\mathrm{O}_{3}$ (region A). On the left side, where the surface was covered by the sample holder lid, no ridges are observed (region B)

Figure 3.8 NAP-XPS depth profile (a) $\mathrm{Au} 4 \mathrm{f}_{7 / 2}$ and (b) $\mathrm{O} 1 \mathrm{~s}$ as obtained from a gold foil during $\mathrm{O}_{3}(0.3 \mathrm{mbar})$ treatment at $100^{\circ} \mathrm{C}$ for increasing kinetic energies of photoelectrons, i.e. decreasing surface sensitivity. Spectra were measured at $175 \mathrm{eV}$ (cyan line), $350 \mathrm{eV}$ (magenta line), $600 \mathrm{eV}$ (dark yellow line) and $1000 \mathrm{eV}$ (purple line) kinetic energy of photoelectrons

Figure 3.9 The area ratios between cationic $\mathrm{Au} 4 \mathrm{f}_{7 / 2}$ and $\mathrm{Au}^{0} 4 \mathrm{f}_{7 / 2}$ (red dots), $\mathrm{O} 1 \mathrm{~s}$ and $\mathrm{Au}^{0} 4 \mathrm{f}_{7 / 2}$ (blue squares) XPS peak as function of inelastic mean free path (IMPF) of Au. Fitting results, assuming an oxide over-layer completely (solid line) and 60\% (dash-dot line) covering the Au surface

Figure 3.10 $\mathrm{O} K$-edge absorption spectra measured in Auger yield mode in $\mathrm{O}_{3}+\mathrm{O}_{2}$ at 0.3 mbar and $100^{\circ} \mathrm{C}$

Figure 3.11 The change of the reaction mixture $\left(\mathrm{CO} / \mathrm{O}_{2}+\mathrm{O}_{3}=1 / 20\right)$ with time a) without $\mathrm{Au}$ foil and $\mathrm{b}$ ) using $\mathrm{Au}$ foil as catalyst at $0.3 \mathrm{mbar}$ and $100{ }^{\circ} \mathrm{C}$.

Figure 3.12 Evolution of $\mathrm{Au} 4 \mathrm{f}(\mathrm{A})$ and $\mathrm{O}$ 1s (B) photoelectron spectra (using $700 \mathrm{eV}$ kinetic energy photoelectrons) from gold foil at $0.3 \mathrm{mbar}$ and $100^{\circ} \mathrm{C}$ in reaction mixture $\left(\mathrm{CO} / \mathrm{O}_{2}+\mathrm{O}_{3}=1 / 20\right)$ with time 
Figure 3.13 $\mathrm{Au} 4 \mathrm{f}(\mathrm{A})$ and $\mathrm{O} 1 \mathrm{~s}(\mathrm{~B})$ photoelectron spectra (using $150 \mathrm{eV}$ kinetic energy photoelectrons) of a gold powder at $100^{\circ} \mathrm{C}$ in $\mathrm{UHV}$ (bottom) and ozone (0.3 mbar) (top)

Figure 3.14 SEM image before (left) and after (right) $\mathrm{O}_{3}(0.3 \mathrm{mbar})$ treatment at $100^{\circ} \mathrm{C}$ showing restructuring of gold powder

Figure 3.15 The changes of the reaction mixture $\left(\mathrm{CO} / \mathrm{O}_{2}+\mathrm{O}_{3}=1 / 80\right)$ with time using $\mathrm{Au}$ powder as catalyst at $0.3 \mathrm{mbar}$ and $100^{\circ} \mathrm{C}$

Figure 3.16 In-situ Au 4f (left) and O 1s (right) photoelectron spectra (using $150 \mathrm{eV}$ kinetic energy photoelectrons) of gold powder at $100^{\circ} \mathrm{C}$ during $\mathrm{CO}$ oxidation at $0.3 \mathrm{mbar}$

Figure 3.17 $\mathrm{CO}$ oxidation on Au powder at $0.3 \mathrm{mbar}$ and different temperature 44

Figure 3.18 $\mathrm{Au} 4 \mathrm{f}$ photoelectron spectra $(\mathrm{h} v=270 \mathrm{eV})$ from gold powder during heating (A) and cooling (B) at various temperatures measured at 0.3 mbar and $\mathrm{CO} / \mathrm{O}_{2}+\mathrm{O}_{3}=1 / 80$

Figure 3.19 $\mathrm{CO}$ oxidation $\left(\mathrm{CO} / \mathrm{O}_{2}+\mathrm{O}_{3}=1 / 80\right)$ on $\mathrm{Au}$ powder with and without $\mathrm{O}_{3}$ at 0.3 mbar and $100^{\circ} \mathrm{C}$

Figure 3.20 Gas mixture changes while removing $\mathrm{Au}$ powder out of the chamber

Figure 3.21 NAP (a) Au 4f, (b) O 1s and (c) C 1s XP spectra of Au/HOPG (i) in UHV at RT, (ii) under $\mathrm{O}_{3}$ at $0.3 \mathrm{mbar}, 100{ }^{\circ} \mathrm{C}$ and (iii) under $\mathrm{CO}$ and $\mathrm{O}_{2}\left(\mathrm{CO}: \mathrm{O}_{2}=1: 75\right)$ atmosphere at $0.3 \mathrm{mbar}$, RT

Figure 3.22 SEM image of $\mathrm{Au} / \mathrm{HOPG}$ a) before and b) after $\mathrm{O}_{3}$ treatment at $250{ }^{\circ} \mathrm{C}$ and $\mathrm{CO}$ oxidation at 0.3 mbar. Images were colorized in order to highlight the differences between the two samples

Figure 3.23 QMS data (CO: $\left.\mathrm{O}_{2}=1: 75\right)$ of $\mathrm{Au} / \mathrm{HOPG}$ a) before and b) after $\mathrm{O}_{3}$ treatment at 0.3 mbar and RT 53

Figure 3.24 TEM image of large Au particle supported on N-CNT 55

Figure 3.25 STEM image of fresh $\mathrm{Au} / \mathrm{N}-\mathrm{CNTs}$ 55

Figure 3.26 STEM images of fresh $\mathrm{Au} / \mathrm{O}-\mathrm{CNTs}$ 56

Figure 3.27 QMS data $\left(\mathrm{CO}: \mathrm{O}_{2}=1: 75\right)$ of $\left.\mathrm{Au} / \mathrm{O}-\mathrm{CNTs} \mathrm{A}\right)$ before and $\left.\mathrm{B}\right)$ after $\mathrm{O}_{3}$ treatment at 0.3 mbar and $\mathrm{RT}$ 56 
Figure 3.28 QMS data $\left(\mathrm{CO}: \mathrm{O}_{2}=2: 1\right)$ of a) $\mathrm{Au} / \mathrm{N}-\mathrm{CNTs}$ and b) $\mathrm{Au} / \mathrm{O}-\mathrm{CNTs}$ at 1 bar without any pretreatment

Figure 3.29 QMS data $\left(\mathrm{CO}: \mathrm{O}_{2}=1: 75\right)$ of HOPG A) before and $\left.\mathrm{B}\right)$ after $\mathrm{O}_{3}$ treatment at 0.3 mbar and RT

Figure 3.30 NAP (a) Au 4f, (b) O 1s and (c) C 1s XP spectra of Au/Au foil (i) in UHV at RT, (ii) under $\mathrm{O}_{3}$ at $0.3 \mathrm{mbar}, 150{ }^{\circ} \mathrm{C}$, (iii) under $\mathrm{O}_{2}$ after $\mathrm{O}_{3}$ treatment at 0.3 mbar, $\mathrm{RT}$ and (iv) under $\mathrm{CO}$ and $\mathrm{O}_{2}$ atmosphere $\left(\mathrm{CO}: \mathrm{O}_{2}=1: 75\right)$ at 0.3 mbar, $\mathrm{RT}$.

Figure 3.31 SEM images of $\mathrm{Au} / \mathrm{Au}$ foil a) before and b) after $\mathrm{O}_{3}$ treatment at 0.3 mbar. Images were colorized in order to highlight the differences between the two samples

Figure 3.32 QMS data $\left(\mathrm{CO}: \mathrm{O}_{2}=1: 2\right)$ of $\mathrm{Au} / \mathrm{Au}$ foil a) before and $\left.\mathrm{b}\right)$ after $\mathrm{O}_{3}$ treatment at 0.3 mbar and $\mathrm{RT}$

Figure 3.33 NAP (a) Au 4f $f_{7 / 2}$, (b) $\mathrm{O} 1 \mathrm{~s}$ and (c) C 1s XP spectra of $\mathrm{Au} / \mathrm{Au}$ foil under $\mathrm{CO}$ reaction $\left(\mathrm{CO}: \mathrm{O}_{2}=1: 2\right)$ after $\mathrm{O}_{3}$ treatment at 0.3 mbar, RT (i) after $10 \mathrm{~min}$, (ii) $60 \mathrm{~min}$ and (iii) $120 \mathrm{~min}$

Figure 3.34 TEM images of $\mathrm{Au} / \mathrm{Fe}_{2} \mathrm{O}_{3}-\mathrm{PC}(\mathrm{A})$ before and (B) after annealing in $\mathrm{O}_{2}$ at $300{ }^{\circ} \mathrm{C}$ and $\mathrm{CO}$ oxidation $\left(\mathrm{CO}: \mathrm{O}_{2}=1: 2\right)$ at $0.3 \mathrm{mbar}$ and $300{ }^{\circ} \mathrm{C}$. Images were colorized in order to highlight the differences between the two samples

Figure 3.35 (A) $\mathrm{Au} 4 \mathrm{f}$, (B) $\mathrm{O} 1 \mathrm{~s}$ and (C) $\mathrm{C} 1 \mathrm{~s} \mathrm{XP}$ spectra of $\mathrm{Au} / \mathrm{Fe}_{2} \mathrm{O}_{3}-\mathrm{PC}$ at 0.3 mbar (i) in $\mathrm{O}_{2}$ during annealing, (ii) in $\mathrm{CO}+\mathrm{O}_{2}\left(\mathrm{CO}: \mathrm{O}_{2}=1: 2\right)$ at $300{ }^{\circ} \mathrm{C}$ and (iii) in $\mathrm{CO}+\mathrm{O}_{2} \quad\left(\mathrm{CO}: \mathrm{O}_{2}=1: 2\right)$ at $100{ }^{\circ} \mathrm{C}$. Photoelectrons with $160 \mathrm{eV}$ kinetic energy were used to collect the $\mathrm{O} 1 \mathrm{~s}$ and C 1s spectra, and photoelectrons with $900 \mathrm{eV}$ kinetic energy were used to collect the $\mathrm{Au} 4 \mathrm{f}$ spectra

Figure 3.36 $\mathrm{CO}_{2}$ production of $\mathrm{Au} / \mathrm{Fe}_{2} \mathrm{O}_{3}-\mathrm{PC}$ in $\mathrm{CO}$-reactor at 1 bar and $\mathrm{CO}: \mathrm{O}_{2}=1: 2$

Figure 3.37 $\mathrm{CO}_{2}$ production of $\mathrm{Au} / \mathrm{Fe}_{2} \mathrm{O}_{3}-\mathrm{C}$ in NAP-XPS chamber at 0.3 mbar 70

Figure 3.38 $\mathrm{CO}_{2}$ production of $\mathrm{Au} / \mathrm{TiO}_{2}$-DP in NAP-XPS chamber at 0.3 mbar 71

Figure 3.39 $\mathrm{CO}_{2}$ production of pure $\mathrm{Fe}_{2} \mathrm{O}_{3}$ in $\mathrm{CO}$-reactor at 1 bar $\left(\mathrm{CO}: \mathrm{O}_{2}=1: 2\right)$ and $373 \mathrm{~K}$ 
Figure 3.40 $\mathrm{CO}_{2}$ production of pure $\mathrm{TiO}_{2}$ in $\mathrm{CO}$-reactor at 1 bar $\left(\mathrm{CO}: \mathrm{O}_{2}=1: 2\right)$ and $373 \mathrm{~K}$

Figure 3.41 $\mathrm{CO}_{2}$ production of $\mathrm{Au} / \mathrm{Fe}_{2} \mathrm{O}_{3}-\mathrm{C}$ in $\mathrm{CO}$-reactor at 1 bar $\left(\mathrm{CO}: \mathrm{O}_{2}=1: 2\right)$ and $373 \mathrm{~K}$

Figure 3.42 $\mathrm{CO}_{2}$ production of $\mathrm{Au} / \mathrm{TiO}_{2}-\mathrm{DP}$ in $\mathrm{CO}$-reactor at 1 bar $\left(\mathrm{CO}: \mathrm{O}_{2}=1: 2\right)$ and $373 \mathrm{~K}$

Figure 3.43 (A) $\mathrm{Au} 4 \mathrm{f}$, (B) $\mathrm{O} 1 \mathrm{~s}$ and (C) $\mathrm{C} 1 \mathrm{~s}$ XP spectra of $\mathrm{Au} / \mathrm{Fe}_{2} \mathrm{O}_{3}-\mathrm{C}$ before (top panel) and after (bottom panel) $\mathrm{CO}$ oxidation $\left(\mathrm{CO}: \mathrm{O}_{2}=1: 2\right)$ at 0.3 mbar and $100{ }^{\circ} \mathrm{C}$. Photoelectrons with $160 \mathrm{eV}$ kinetic energy were used to collect $\mathrm{O} 1 \mathrm{~s}$ and $\mathrm{C} 1 \mathrm{~s}$ spectra and photoelectrons with $900 \mathrm{eV}$ kinetic energy were used to collect $\mathrm{Au}$ 4f spectra

Figure 3.44 (A) $\mathrm{Au} 4 \mathrm{f}$, (B) $\mathrm{O} 1 \mathrm{~s}$ and (C) $\mathrm{C} 1 \mathrm{~s} \mathrm{XP}$ spectra of $\mathrm{Au} / \mathrm{TiO}_{2}-\mathrm{DP}$ before (top panel) and after (low panel) CO oxidation $\left(\mathrm{CO}: \mathrm{O}_{2}=1: 2\right)$ at 0.3 mbar and $100{ }^{\circ} \mathrm{C}$. Photoelectrons with $160 \mathrm{eV}$ kinetic energy were used to collect $\mathrm{O}$ 1s, C 1s spectra and photoelectrons with $720 \mathrm{eV}$ kinetic energy were used to collect $\mathrm{Au}$ $4 \mathrm{f}$ spectra

Figure 3.45 TEM images of $\mathrm{Au} / \mathrm{TiO}_{2}-\mathrm{DP}$ (A) before and (B) after $\mathrm{CO}$ oxidation $\left(\mathrm{CO}: \mathrm{O}_{2}=1: 2\right)$ at 0.3 mbar and $100^{\circ} \mathrm{C}$. The insets in (A) and (B) represent power spectra of the Au nanoparticles. Images were colorized in order to highlight the differences between the two samples

Figure 3.46 TEM image of $\mathrm{Au} / \mathrm{Fe}_{2} \mathrm{O}_{3}-\mathrm{C}$ after $\mathrm{CO}$ oxidation at 0.3 mbar $\left(\mathrm{CO}: \mathrm{O}_{2}=1: 2\right)$ and $100^{\circ} \mathrm{C}$. Image was colorized in order to highlight the differences between $\mathrm{Au}$ and $\mathrm{Fe}_{2} \mathrm{O}_{3}$

Figure 3.47 EELS spectra of $\mathrm{Au} / \mathrm{TiO}_{2}$-DP after $\mathrm{CO}$ oxidation at 0.3 mbar $\left(\mathrm{CO}: \mathrm{O}_{2}=1: 2\right)$ and $100^{\circ} \mathrm{C}$. The inset represents a TEM image of a single $\mathrm{Au}$ NP in front of the aperture

Figure 3.48 Arrhenius plot of $\mathrm{Au} / \mathrm{TiO}_{2}-\mathrm{DP}$ (blue line) and $\mathrm{Au} / \mathrm{Fe}_{2} \mathrm{O}_{3}-\mathrm{C}$ (red line) 
Figure 4.1 $\mathrm{Au}$ 4f XP spectrum and TEM image of sample synthesized by deposition-precipitation (left) and photochemical decomposition of intermediate gold-azido complex (right) method 


\section{List of Schemes.}

Scheme 1.1. Langmuir-Hinshelwood reaction mechanism ................ 3

Scheme 1.2. Eley-Rideal reaction mechanism $\ldots \ldots \ldots \ldots \ldots \ldots \ldots \ldots \ldots \ldots \ldots, 3$

Scheme 1.3. Mars-van Krevelen reaction mechanism ....................... 4

Scheme 2.1. Schematic representation of a) XPS, b) XAS and c) Auger processes ................................................. 19

Scheme 2.2. Scheme of reactor for CO oxidation at atmospheric pressure ..... 26

Figure 3.1. Suggested $\mathrm{CO}$ oxidation pathway on $\mathrm{Au} / \mathrm{TiO}_{2} \ldots \ldots \ldots \ldots \ldots$ 


\section{List of Tables.}

Table 3.1. Fitting parameters of $\mathrm{Au} 4 \mathrm{f}$ spectrum of $\mathrm{Au}$ foil ................ 31

Table 3.2. Surface composition of $\mathrm{Au} / \mathrm{HOPG}$ at different conditions ........ 51

Table 3.3. Fitting parameters of $\mathrm{Au} 4 \mathrm{f}_{7 / 2}$ spectra of $\mathrm{Au} / \mathrm{Au}$ foil ............. 59

Table 3.4. Fitting parameters of $\mathrm{O} 1 \mathrm{~s}$ spectra of $\mathrm{Au} / \mathrm{Au}$ foil $\ldots \ldots \ldots \ldots \ldots \ldots 60$

Table 3.5. Surface composition of $\mathrm{Au} / \mathrm{Au}$ foil at different conditions ....... 61

Table 3.6. Fitting parameters of $\mathrm{Au} 4 f_{7 / 2}$ and $\mathrm{O} 1 \mathrm{~s}$ spectra of $\mathrm{Au} / \mathrm{Fe}_{2} \mathrm{O}_{3}-\mathrm{PC} \ldots 67$

Table 3.7. Fitting parameters of $\mathrm{Au} 4 \mathrm{f}_{7 / 2}$ and $\mathrm{O} 1$ s spectra of $\mathrm{Au} / \mathrm{Fe}_{2} \mathrm{O}_{3}-\mathrm{C} \ldots 75$

Table 3.8. Surface composition of $\mathrm{Au} / \mathrm{Fe}_{2} \mathrm{O}_{3}-\mathrm{C}$ before and after $\mathrm{CO}$

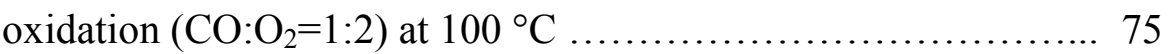

Table 3.9. Fitting parameters of $\mathrm{Au} 4 \mathrm{f}_{7 / 2}$ and $\mathrm{O} 1$ s spectra of $\mathrm{Au} / \mathrm{TiO}_{2}$-DP. 77

Table 3.10. Surface composition of $\mathrm{Au} / \mathrm{TiO}_{2}-\mathrm{DP}$ before and after $\mathrm{CO}$

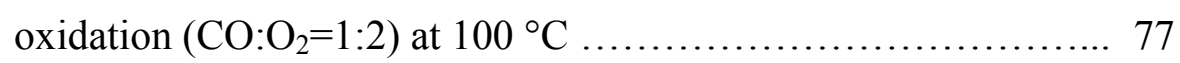

Table 3.11. Main finding of Au NPs supported on transition metal oxides .... 81

Table 3.12. Activation energies for $\mathrm{CO}$ oxidation and specific surface area of $\mathrm{Au} / \mathrm{Fe}_{2} \mathrm{O}_{3}$ and $\mathrm{Au} / \mathrm{TiO}_{2}$ prepared by different methods ........... 84

Table 4.1. $\quad \mathrm{CO}$ oxidation on Au-based catalysts ........................... 88 


\section{Introduction.}

\subsection{Catalysis.}

The word catalysis is derived from latinized form of Greek noun $\kappa \alpha \tau \alpha \dot{\lambda} v \sigma \iota \varsigma$,

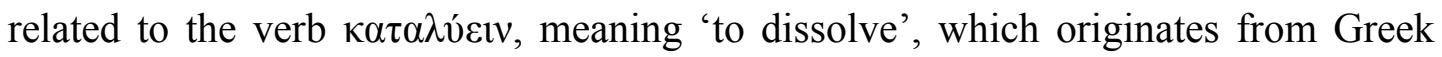

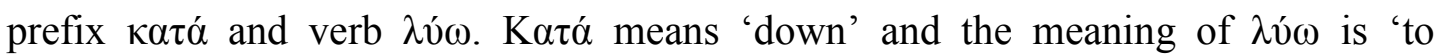
loosen'. The term catalysis was coined in 1836 by Swedish scientist Jöns Jakob Berzelius, who noted that certain chemicals speed up a reaction. He wrote: "I shall therefore call it the catalytic power of substances, and the decomposition by means of this power catalysis, just as we use the word analysis to denote the separation of the component parts of bodies by means of ordinary chemical process. Catalytic power actually means that substances are able to awake affinities which are asleep at this temperature by their mere presence and not by their own affinity" [1]. The development of experimental and theoretical techniques and the accumulated results allowed Nobel Prize winner Friedrich Wilhelm Ostwald to define a catalyst as " $a$ substance that increases the rate at which a chemical system approaches equilibrium, without being consumed in the process." Nevertheless, the position of equilibrium attained in the presence of a catalyst is the same as that ultimately arrived at in its absence [2]. It is only the difference between initial and final states that determines a free energy change - and hence the position of equilibrium - not whether a catalyst was used to bring about the change.

According to the equation proposed by Svante Arrhenius, the reaction rate constant $\mathbf{k}$ is defined as follows:

$$
k=A \exp \left(-E_{a} / R T\right)
$$

Where, $\mathbf{A}$ is the pre-exponential factor, which is proportional to the collision number between unlike molecules according collision theory, $\mathbf{E}_{\mathbf{a}}$ is the activation energy, $\mathbf{R}$ is the gas constant and $\mathbf{T}$ is the temperature. Therefore, the effect of a catalyst on a chemical reaction is to increase its rate, in other words to increase its rate constant. Thus we can conclude that a catalyst acts by decreasing the activation energy of the reaction. A catalytic reaction happens via the adsorption of a molecule on the catalyst 
surface, forming a transition state with a resulting loss of translational freedom. This means that catalytic reactions proceed by a new energetically favorable pathway.

\subsection{Types of catalysis.}

There are three main forms of catalysis: homogeneous, heterogeneous, and enzymatic or biocatalysis. We briefly discuss these types of catalysis in this section.

Biological catalysts called enzymes, are complex organic molecules usually consisting of proteins, which form a lyophilic colloid. Enzymes are neither homogeneous nor heterogeneous catalysts, but sometimes in between. They are extremely efficient catalysts, for example nitrogenase enzymes convert nitrogen from the air to ammonia at ambient temperature [3], while the Haber-Bosch process requires temperature above $400{ }^{\circ} \mathrm{C}[4,5]$. Biocatalysts occur widely in our life. Over 150 biocatalytic processes are running today: the enzymes are employed in food and drink industries. Over the past century the application of biocatalysts has especially increased in the pharmaceutical industry.

In homogeneous catalysis, the catalyst and the reactants are in the same phase, and no phase boundary exists. The main advantages of homogeneous catalysis are high activity and selectivity, the main disadvantage is the complexity of catalyst separation and recovery. However, about $10 \%$ by volume of all industrial catalytic processes occurs on homogeneous catalysts. One important industrial example of homogeneous catalysis is the hydroformation reaction, in which $\mathrm{CO}$ and $\mathrm{H}_{2}$ molecules are added to alkene [6].

In heterogeneous catalysis, the catalyst is in a different phase from the reactants. The catalytic reaction takes place at the catalyst border (surface), where the reaction mixture is temporarily adsorbed. Nowadays, heterogeneous catalysis plays an important role in our life, in particular, in the petrochemical and bulk chemistry industries and in the energy storage cycles, via converting electrical energy into chemical energy. Examples of heterogeneous catalysis include such reactions as methanol synthesis on $\mathrm{Cu} / \mathrm{ZnO} / \mathrm{Al}_{2} \mathrm{O}_{3}$ [7] and Fischer-Tropsch synthesis on $\mathrm{Co}$ and $\mathrm{Fe}[8]$. 


\subsection{Mechanisms in gas/solid heterogeneous catalysis.}

In this work we focus on heterogeneous catalysis in the gas/solid system, therefore the following chapter will briefly discuss different reaction mechanisms. In all mechanisms of heterogeneous catalysis there is one common feature, at least one of the reactants is adsorbed on the catalyst.

The Langmuir-Hinshelwood model describes the most common situation in heterogeneous catalysis [9]. This mechanism assumes that both reactants are first adsorbed on the catalyst surface, then migrate to each other and react (Scheme. 1.1). The products are afterwards desorbed from the catalyst back to the gas phase.

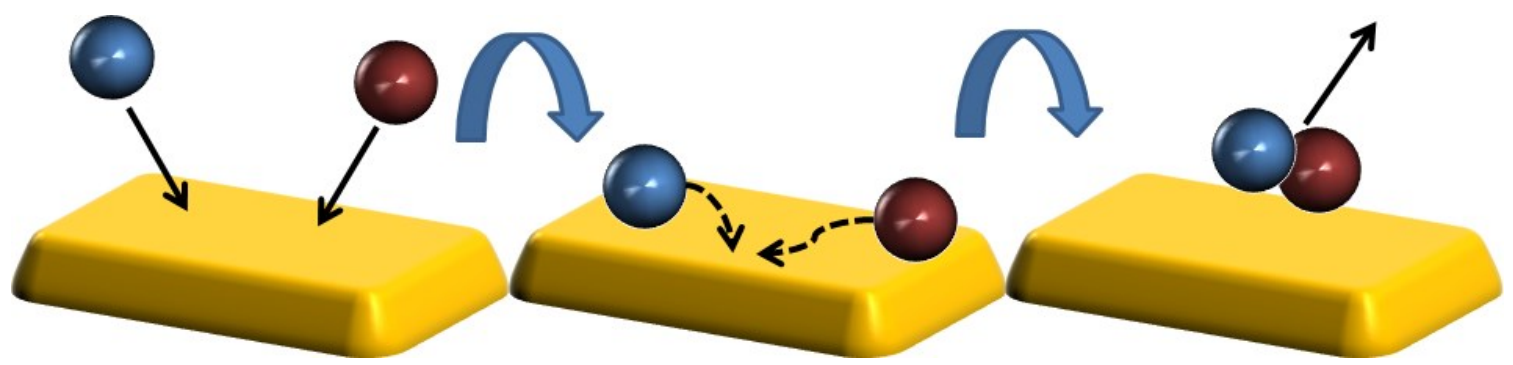

Scheme 1.1 Langmuir-Hinshelwood reaction mechanism.

In the Eley-Rideal mechanism only one reactant is directly chemisorbed on the catalyst. The reaction takes place between reactant from the gas phase and an adsorbed one (Scheme 1.2). The Eley-Rideal mechanism well describes the kinetics of the hydrogen-deuterium reaction [10].

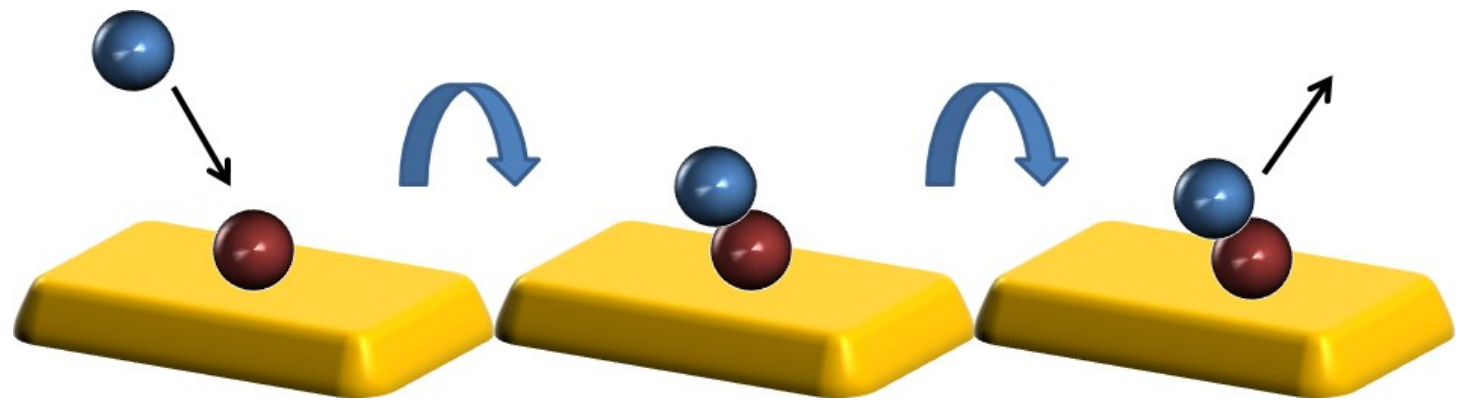

Scheme 1.2. Eley-Rideal reaction mechanism.

The third mechanism is assigned as Mars-van Krevelen mechanism and applies to oxidation reactions on oxides, which are easily reducible. The oxidation occurs between adsorbed reactant and lattice oxygen, which is later replaced by dissociated 
molecular oxygen or by the bulk (Scheme 1.3). An example of the Mars-van Krevelen mechanism is $\mathrm{CO}$ oxidation under high oxygen pressure on $\mathrm{Pt}$ [11].

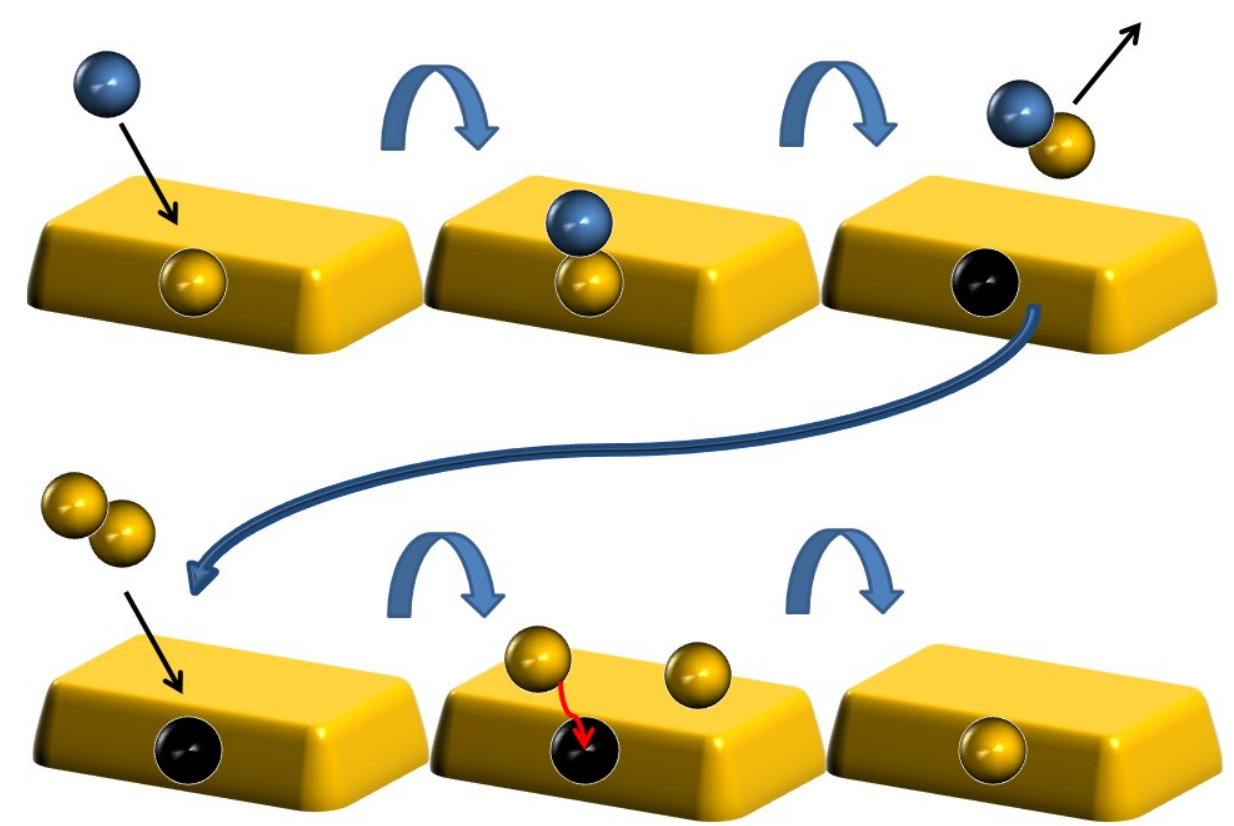

Scheme 1.3. Mars-van Krevelen reaction mechanism.

\subsection{X-ray photoelectron spectroscopy for investigation of catalytic process.}

Model systems have been investigated under well-defined ultrahigh vacuum (UHV) conditions with different methods using surface science approach, which allows applying simplified version of catalysts and reaction [12-15]. Such investigation have provided information about elementary steps of reaction on the surface, changes of electronic and geometric structure of the surface when atoms and molecules are presented, surface dynamics, the role of defects, etc. Theoretical calculations [16] have been used to guide the experiments [17].

The major disadvantage of the surface science approach is that catalysts are investigated far from realistic operating conditions. Surface science studies focus on the catalytic behavior of well-structured (single crystal, alloy, oxide) samples, while catalysts are complex multicomponent materials, this leads to the so-called "material gap". There exists as well a "pressure gap", because operating pressure in catalytic reactors are orders of magnitude higher than in the UHV chambers. The pressure 
influences the morphology of catalysts, dynamics and reaction mechanism because of the chemical potential of the reactant.

The preparation of nanostructured supported model catalysts bridges the "material gap" [18-20]. Meanwhile the first attempts to bridge "pressure gap" were ex-situ experiments, where sample were directly transferred between reactor and UHV chamber. This strategy helps find correlation between catalytic activity in the reactor and the structure before and after reaction [21]. The main disadvantage of $e x-$ situ measurements is that they cannot give insights into metastable species formed just under reaction conditions, which might be very relevant for the catalytic process [22].

The understanding of the interaction of a catalyst's surface with gas atmospheres plays a key role in a detailed description of catalytic processes. X-ray photoelectron spectroscopy (XPS) is well-known method for the characterization of surfaces under high vacuum, but the application of XPS at elevated pressures started more than 40 years ago. However, a spectroscopic characterization of the reacting surface under ambient condition is challenging, because emitted electrons are scattered by gas under operating pressures. The Fritz-Haber-Institut der Max-PlanckGesellschaft in collaboration with the group of M. Salmeron (Berkley) developed a set-up suitable to record photoelectron spectra in the presence of a reacting gas. Nowadays the operating pressure in the setup is up to 10 mbar. The detailed description of the set-up is in the section 2.2.

\subsection{Au catalysts.}

The noble character of bulk Au has been well known for centuries. Corrosion and oxidation resistance are the hallmarks of $\mathrm{Au}$, with these properties being exploited in many technological and everyday applications, such as dentistry, jewelry and electronics. Gold owes its unusual properties for its unique electronic structure. Gold is the $79^{\text {th }}$ element in periodic table with electronic configuration $1 s^{2} 2 s^{2} 2 p^{6} 3 s^{2} 3 p^{6} 4 s^{2} 3 d^{10} 4 p^{6} 5 s^{2} 4 d^{10} 5 p^{6} 4 f^{14} 5 d^{10} 6 s^{1}$. It lies in the 11 th group of the

periodic table along with silver and copper, which are well known catalysts in ethylene epoxidation and methanol synthesis. 
Having excellent catalysts in its neighborhood, it is obvious that scientists tried to use $\mathrm{Au}$ as catalyst too. Most of the tests showed inactivity of $\mathrm{Au}$, but it is not surprising as they were done with macroscopic Au (wires, powders and foils). Nevertheless, some hints that gold is not always inert were found, for example, Michael Faraday found that $\mathrm{Au}$ presents catalyzed hydrogen oxidation at room temperature [23]. Therefore, gold has long been ignored for catalytic purposes due to the inert nature of bulk Au until 1980's.

In 1989, impressive demonstrations that gold's noble characteristics spectacularly vanish as the dimensions of the material are reduced to the nanometer scale were provided by Haruta and co-workers [24], who found Au nanoparticles supported on transition metal oxides to have a high catalytic activity in $\mathrm{CO}$ and $\mathrm{H}_{2}$ oxidation, even at low temperatures. This pioneering work has prompted Au catalysis to become a very active research field in recent years, but the nature of active sites on gold is still under debate in the literature [25]. The huge difference between the catalytic behaviors of extended $\mathrm{Au}$ surfaces and supported nanoscopic $\mathrm{Au}$ has emerged in numerous studies, which came to partly contradictory conclusions. One of the most common conclusions is that the way in which gold acts catalytically is substantially different from that adopted for metals of the platinum group [26].

Supported Au-based catalysts have shown activity for epoxidation of olefins [27,28], water-gas-shift reactions [29,30], C-C coupling reactions [31], liquid-phase oxidation of alcohols [32], selective reduction of NO by hydrocarbons in presence of high oxygen concentrations [33,34], preferential oxidation (PROX) of $\mathrm{CO}$ in a hydrogen atmosphere [35,36], selective oxidation of hydrocarbons [37], epoxidation of propene [38], selective hydrogenation of acetylene to ethylene [39] and of 1,3butadiene to butene [40] and $\mathrm{CO}$ oxidation [41]. Also plenty of metal oxide supports, like $\mathrm{CeO}_{2}$ [42], $\mathrm{TiO}_{2}$ [43-45], $\mathrm{ZrO}_{2}$ [46], $\mathrm{Al}_{2} \mathrm{O}_{3}$ [47], $\mathrm{Fe}_{2} \mathrm{O}_{3}$ [48], $\mathrm{FeO}$ [49], were tested and some common factors affecting catalytic behavior, such as particle size [50], method of preparation [51], pretreatment [52], oxidation state of Au [53], were found.

Nano-structured $\mathrm{Au}$, supported on transition metal oxides, is a highly efficient oxidation catalyst; however, the mechanism of these reactions is still the focus of intense debate in the literature. For instance, edge sites and changes in the electronic 
structure of $\mathrm{Au}$, due to its interaction with the support, have been suggested to be important factors in establishing activity [25]. Furthermore, the activity of $\mathrm{Au}$ in $\mathrm{CO}$ oxidation increases in the presence of water [41,54]. Several works have clearly shown that $\mathrm{CO}$ can be readily oxidized to $\mathrm{CO}_{2}$, at any kind of Au surface, if a source of atomic oxygen is present [25]. Ozone $\left(\mathrm{O}_{3}\right), \mathrm{N}_{2} \mathrm{O}$, and $\mathrm{O}_{2}$ plasma have been used as sources of atomic oxygen to show that even extended surfaces of Au single-crystals can be catalytically active towards $\mathrm{CO}$ oxidation [55]. For high-performance, supported, nano-structured Au catalysts, it has been debated whether or not oxygen atoms are obtained by direct $\mathrm{O}_{2}$ dissociation at the $\mathrm{Au}$ clusters or provided by the oxide support [56]. Based on DFT calculations [57], it was proposed that lowcoordinated atoms on Au clusters play a central role in molecular oxygen activation. Contrary to the case of extended Au surfaces, adsorbed $\mathrm{O}$ on Au clusters is stable relative to $\mathrm{O}_{2}$ in the gas phase. In turn, recent theoretical and experimental investigations show that $\mathrm{Au}$ perimeter atoms can be active sites in $\mathrm{CO}$ oxidation reaction. The interpretation of the results combines the role of low coordinated $\mathrm{Au}$ atoms and interaction with the support. However, the role of the support for the catalytic reaction is still under discussion and the identification of the nature of active sites requires a systematic study of Au-based catalysts.

\subsection{Outline of the Thesis.}

Effective catalyst design based on a rational approach requires knowledge of the relationship between the electronic and morphological features of a catalyst and their roles in the catalytic reaction pathway. Such an understanding can only be obtained by analyzing catalysts under working conditions. A systematical study of the effects of different strategies of $\mathrm{Au}$ activation by comparing the activity, morphology and electronic structure before, after and during $\mathrm{CO}$ oxidation allows understanding what makes Au less noble. Therefore, it is necessary to apply various techniques such as X-ray photoelectron spectroscopy, X-ray absorption spectroscopy, scanning and transmission microscopies, mass-spectroscopy and electron energy-loss spectroscopy in order to gain a deeper insight into the complex physical and chemical properties of Au. 
The thesis is composed of four cumulative chapters. After the introduction presented in Chapter 1, the basics of techniques used in the present work are described in Chapter 2. Chapter 3 consists of three subchapters, which describe the major finding of the thesis. The subchapters are adopted from publications that cover the results obtained during this doctoral thesis. In subchapter 3.1 the oxidation mechanism of $\mathrm{Au}$ is discussed using multiple in-situ and ex-situ techniques. Also the catalytic performance of extended $\mathrm{Au}$ surfaces was investigated in details. The catalytic properties of $\mathrm{Au}$ nanoparticle on oxygen-free support (highly oriented pyrolytic graphite, functionalized carbon nanotubes and $\mathrm{Au}$ foil) as well as their electronic and surface structures are investigated in subchapter 3.2. Subchapter 3.3 describes $\mathrm{Au}$ nanoparticles on transition metal oxides synthesized by precipitation and photochemical decomposition of intermediate gold-azido complex methods. Special attention is paid to the investigation of interaction between $\mathrm{Au}$ and transition metal oxides by surface sensitive techniques. Finally, the main findings are summarized in Chapter 4. 


\section{Experimental part.}

\subsection{Beamline.}

The experiments were performed at ISISS (Innovative Station for In-Situ Spectroscopy) beamline at the electron storage ring BESSY II/HZB (Berliner Elektronenspeicherring für Synchrotronstrahlung/Helmholtz-Zentrum-Berlin), Berlin, Germany.

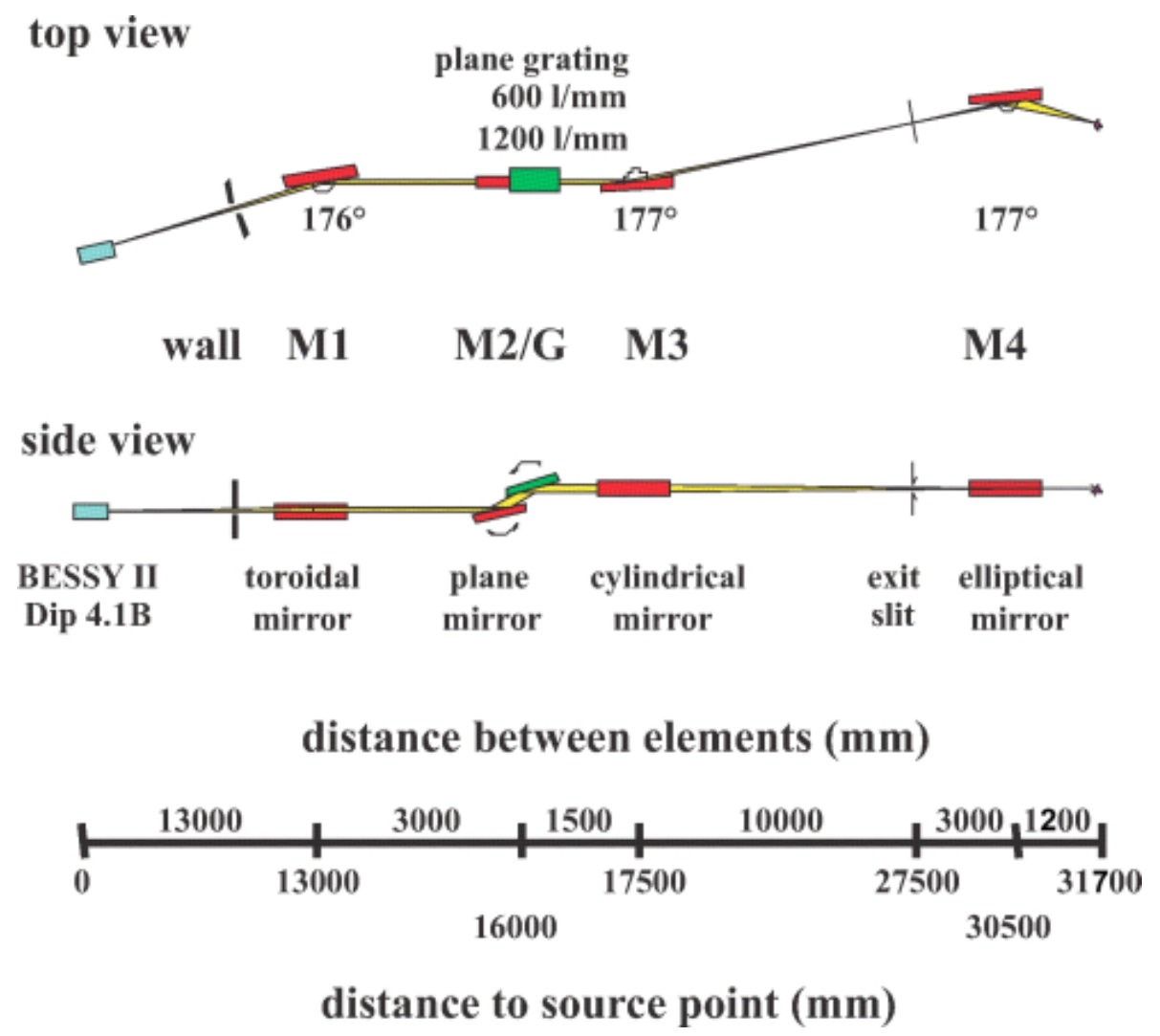

Figure 2.1. The optical layout of ISISS beamline

The optical layout of the beamline is shown in Figure 2.1. The beamline is located at the third generation synchrotron radiation source. Synchrotron radiation is generated by electrons with energy of $1.7 \mathrm{GeV}$ in the bending magnet of the storage ring. The orbit of electrons (circumference of the storage ring is a $240 \mathrm{~m}$ ) is stable and it makes possible to abandon an entrance slit of monochromatization system. The beam is collimated in the vertical plane by the toroidal mirror (M1), which center is $13 \mathrm{~m}$ away from the light source. The mirror is placed in an ultrahigh vacuum 
chamber and is equipped with three adjustment devices allowing the necessary precision of angles and linear movement. A water cooling system is used to eliminate heating of the mirror by incident radiation. Downstream of M1, the beam enters the chamber of monochromator, containing planar mirror M2 and planar grating G. The design provides the ability to change gratings (1200 and $600 \mathrm{l} / \mathrm{mm}$ ) without breaking the vacuum in the system. Their rotation is necessary for the wavelength changing, for the effective use of the entire surface of the optical element and for the reduction of intensity loss. The monochromator chamber is equipped with two optical angle encoders for accurate determination of the rotation angle of the mirror and grating, the signal from which is sent to the control computer. Such an arrangement of optical elements can significantly increase the energy resolution and effectively suppress the higher-order spectrum, as well as provide high beam intensity without additional movements of the optical elements in the entire operating range. In this design, the fix focus constant $c=(\cos \beta / \cos \alpha)(\alpha$ : angle of incidence, $\beta$ : angle of diffraction relative to the grating normal, respectively) is kept constant during the scanning of the photon energy.

Monochromatized radiation enters the next chamber with a cylindrical mirror M3, which focuses light on the exit slit. The photoionization chamber is the next one (not shown in Figure 2.1). It is designed to record photoionization spectra of various gases to determine the spectral resolution and calibration of the monochromator wavelength. The chamber operates as a gas cell when the inlet and outlet valves are closed. In the inlet valve there is a polyamide window with $120 \mathrm{~nm}$ thick, which maintains pressure to 5 mbar. Gas comes into the cell through a leak valve simultaneously with continuous differential pumping through a turbo pump.

The beam enters the last chamber with elliptical mirror M4. The photon beam is re-focused after the exit slit to ensure a high brilliant X-ray spot at the sample position. The spot size is typically $150 \mu \mathrm{m} \times 100 \mu \mathrm{m}(\mathrm{h} \times \mathrm{v})$. The intensity of the photon flux at the location of the sample is determined from the photoemission current of gold foil, taking into account the quantum yield. The beamline is optimized to deliver photons in the energy range between $80 \mathrm{eV}-2000 \mathrm{eV}$ with a high photon flux of up to $6 \times 10^{10}$ photons/ sec/ $0.1 \mathrm{~A}$ ring current. 


\subsection{Endstation.}

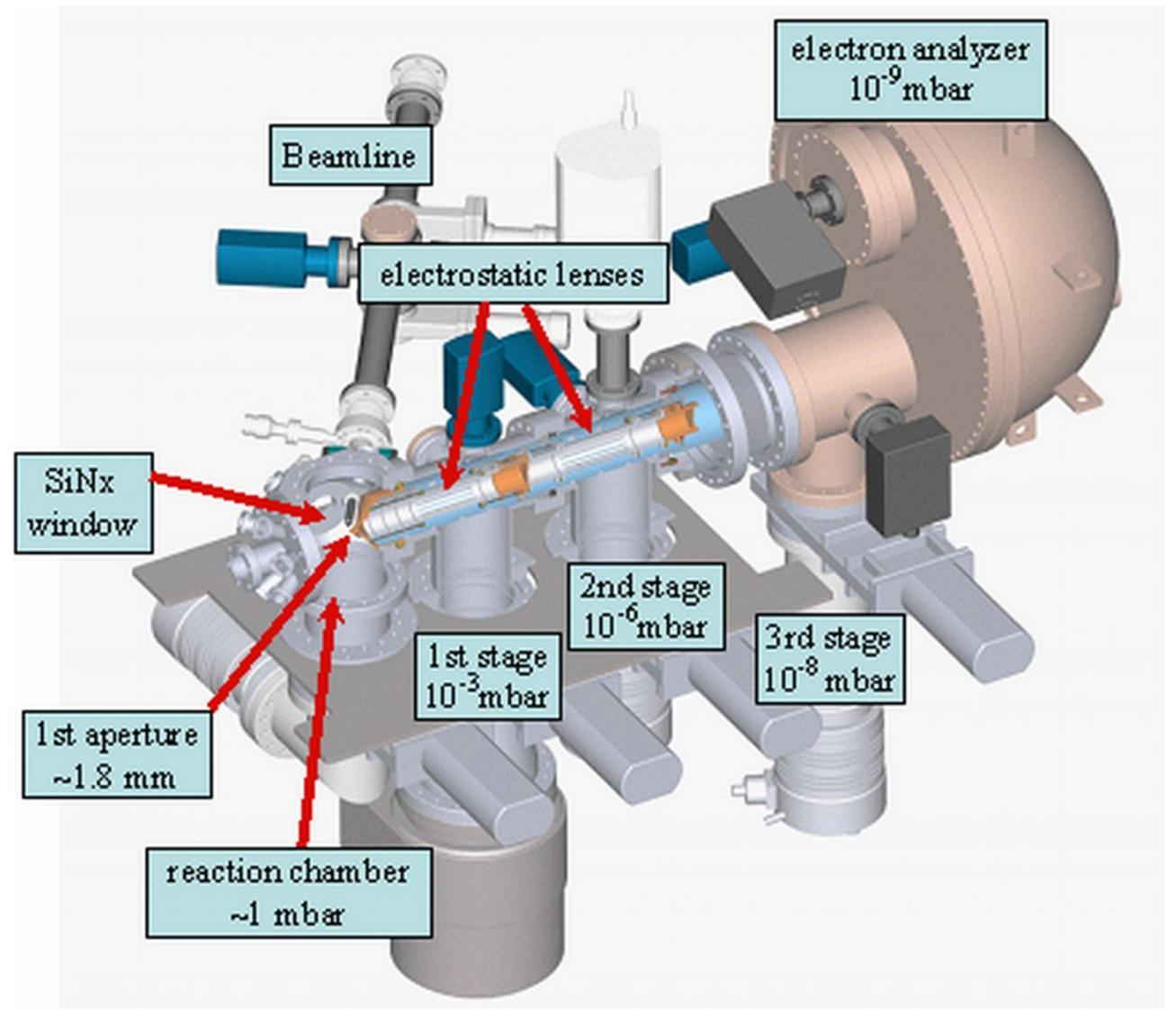

Figure 2.2. Sketch demonstrating the main components of NAP-XPS set-up.

A sketch of the near ambient pressure XPS (NAP-XPS) set-up is shown in Figure 2.2. The stainless steel NAP-XPS chamber consists of four main parts: a) load-lock chamber (not shown in Figure 2.2), b) reaction chamber, c) differential pumping stage, d) electron analyzer.

The load-lock chamber is designed to insert samples and to clean sample surfaces by sputtering. The reaction chamber has a small volume, which is separated from the beamline by a $\mathrm{SiN}_{\mathrm{x}}$ membrane to avoid venting the beamline during in-situ measurements at mbar pressures. The gases are dosed to the reaction chamber through a stainless steel tube; the flows are monitored by five mass-flow controllers. The pressure control stage allows constant pressure to be maintained inside the chamber, independently of gas flow. The reaction chamber is equipped with a differentially pumped electron-impact mass spectrometer ('PRISMA', Pfeiffer 
Vacuum GmbH., Asslar) and a four channel micro gas chromatograph (CP-4900, Varian Inc., Palo Alto) to monitor the gas feed and the formed products.

a.

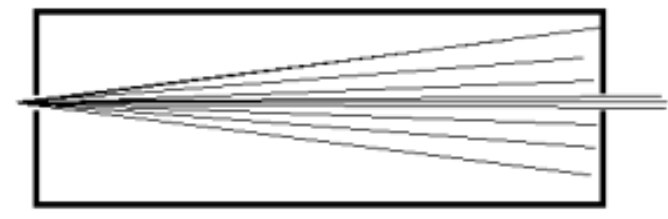

b.

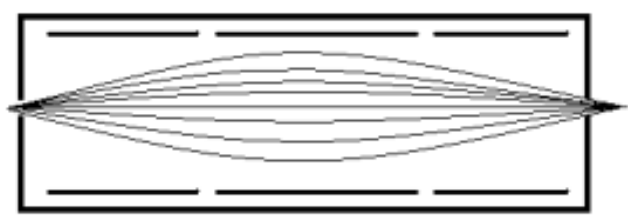

Fugure 2.3. Electron trajectories inside a differentially pumped aperture system a) without electrostatic lenses, b) with electrostatic focusing lenses included. Electrons are assumed to enter from the left.

The differential pumping part is separated from the main chamber by a nozzle with a $1 \mathrm{~mm}$ diameter aperture, and consists of four pumping stages. Across the four pumping stages the pressure decreases gradually from 1 mbar (in the reaction chamber) to $10^{-9}$ mbar (in the electron analyzer). The signal loss is minimized by positioning the sample within ca. $1 \mathrm{~mm}$ of the differentially pumped aperture system, thereby minimizing the path length of the photoelectron in the gas. Simultaneously, the differentially pumped aperture system serves as an electrostatic lens system that decreases significantly electron loss and thus increases the efficiency of electron collection (compare to Figure 2.3a and 2.3b).

\subsection{X-ray photoelectron spectroscopy.}

X-ray photoelectron spectroscopy (XPS, also known as electron spectroscopy for chemical analysis or ESCA) is a well-known surface science technique and has it origin in the work of Robinson and Rawlison [58] and de Broglie [59] a century ago. It provides information about elemental composition (species of atoms on surfaces, concentration of surface atoms, vertical distribution), molecular state of adsorbates and oxidation states of surface species. The detection limit of the method ranges from 0.1 to 0.5 atom percent, i.e. $1-5 \cdot 10^{12}$ atoms $/ \mathrm{cm}^{2}$, it depends on photon energy, 
photon flux, element cross section, analyzer pass energy, aperture settings, dwell time and set-up geometry.

Emission of electrons from the sample is preceded by the absorption of a photon of energy $h v$ according to:

$$
\Psi_{t o t}^{i}(N), \mathrm{E}_{t o t}^{i}(N) \stackrel{h v}{\rightarrow} \Psi_{t o t}^{f}(N, K), \mathrm{E}_{t o t}^{f}(N, K) .
$$

Here $\Psi_{t o t}^{i}(N)$ is the initial-state $N$-electron wave function corresponding to a total energy $\mathrm{E}_{\text {tot }}^{i}(N)$ and $\Psi_{\text {tot }}^{f}(N, K)$ is the $K$ th final-state $N$-electron wave function (including the photoelectron) corresponding to a total energy $\mathrm{E}_{\text {tot }}^{f}(N, K)$. The relevant energy conservation equation is

$$
\mathrm{E}_{\text {tot }}^{i}(N)+h v=\mathrm{E}_{\text {tot }}^{f}(N, K) .
$$

In practice the following assumption is used: the photoelectron is sufficiently weakly coupled to the $(N-1)$-electron ion [60] so as to permit separating the final state of the excitation process to yield:

$$
\Psi_{\text {tot }}^{i}(N), \mathrm{E}_{\text {tot }}^{i}(N) \stackrel{h v}{\rightarrow} \Psi_{\text {tot }}^{f}(N-1, K), \mathrm{E}_{\text {tot }}^{f}(N-1, K)+\varphi^{f}(1) s^{f}(1), E_{\text {kin }}
$$

in which $\Psi_{\text {tot }}^{f}(N-1, K)$ and $\mathrm{E}_{\text {tot }}^{f}(N-1, K)$ refer to the $K$ th $(N-1)$-electron ionic state that can be formed, $E_{\text {kin }}$ is the kinetic energy of $K$ th photoelectron, $\varphi^{f}(1)$ is the spatial part of one-electron orbital describing and $s^{f}(1)$ is the spin part of photoelectron orbit. The form of $\varphi^{f}(1)$ depends on kinetic energy. The energy conservation equation takes the following form:

$$
\mathrm{E}_{\text {tot }}^{i}(N)+h v=\mathrm{E}_{\text {tot }}^{f}(N-1, K)+E_{\text {kin }} .
$$

This form is the most useful in XP spectra analysis. By definition, the binding energy (BE) corresponding to leaving the ion in a state, which is described by $\Psi_{t o t}^{f}(N-$ $1, K)$ :

$$
\mathrm{E}_{b}^{V}(N)=\mathrm{E}_{\text {tot }}^{f}(N-1, K)+\mathrm{E}_{\text {tot }}^{i}(N) .
$$

If we neglect changes in kinetic energy due to work function differences between specimen and electron analyzer, the equation (2.4) will transform to:

$$
\mathrm{E}_{b}^{V}(N)=\mathrm{h} v+E_{\text {kin }} .
$$

The chemical environment of the element affects the value of binding energy measured for a given element. Siegbahn and co-workers [61] showed the importance of these chemical shifts for the identification of chemically different species. 
The chemical shifts contain important information about origin of bonding between an atom and its environment. The physical principles underlying the shifts are simple: the energy of an electron is determined by the Coulomb interaction between the photoelectron and the nuclei (attractive potential) and nearby electrons (repulsive potential). A change in chemical environment leads to a spatial rearrangement of the surrounding electrons and results in a different potential created by all charged particles in the system. The identification of a chemical environment by chemical shifts can be done by comparing the measured binding energy with the binding energy of reference compounds containing the same element. This fingerprint technique is commonly used in catalysis.

Special attention should be paid to energy calibration synchrotron radiation as photon source. There are two most common ways to calibrate BE: 1) align peak positions using reference (in conductive material BE of Fermi edge is taken as $0 \mathrm{eV}$ ); 2) use higher orders of radiation, which are reflected from the mirror according Bragg's law. Usually $1^{\text {st }}$ and $2^{\text {nd }}$ orders are used, the difference in kinetic energy of emitted electrons provides "real" (calibrated) photon energy, according following equations:

$$
\begin{gathered}
h v=E_{b}+E_{\text {kin } 1} \\
2 h v=E_{b}+E_{k i n 2} \\
h v=E_{k i n 2}-E_{k i n 1}
\end{gathered}
$$

For quantitative XPS analysis, least-squares fitting of the spectra should be done. The selection of correct line shape is very important as well as proper background subtraction. For metallic components a Doniach-Sunjic line shape is the best choice, Voight or a product of a Gaussian with a Lorentzian line shapes for others peaks can be used to obtain the best fit. 


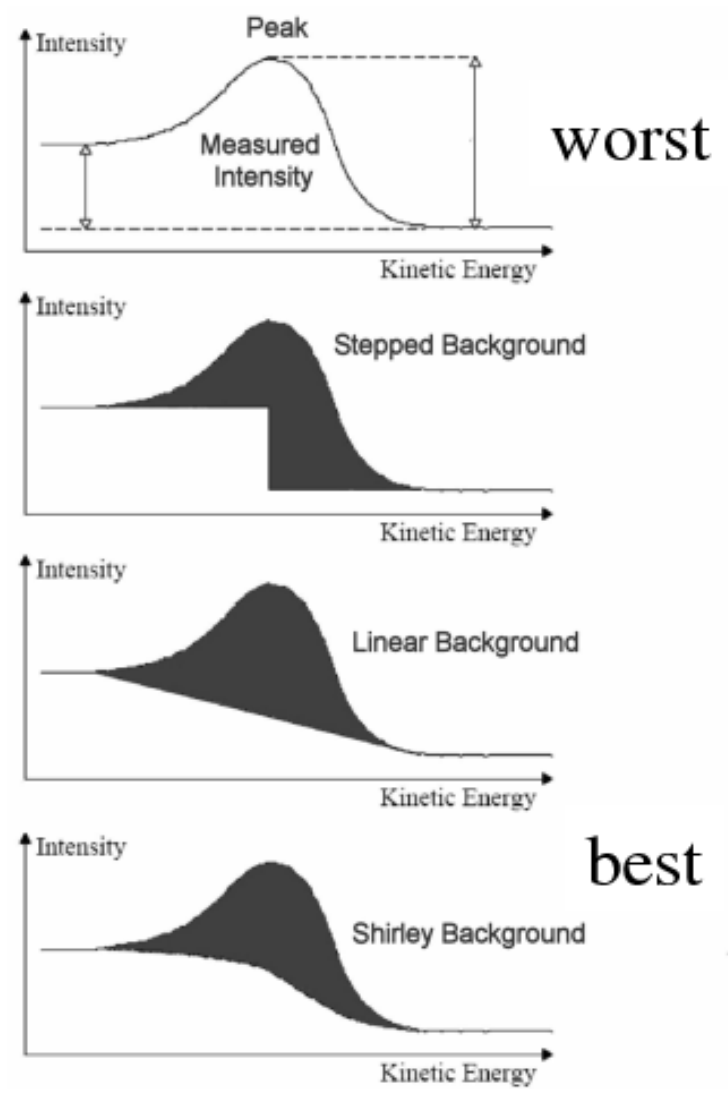

Figure 2.4. Several ways to subtract background.

There are several ways to subtract background as shown in Figure 2.4. The worst case is no background subtraction, stepped and linear backgrounds resent better approximations. The most common method of Shirley [62], where the intensity of background at any given point is proportional to the total integral peak area above the background in the higher kinetic energy peak range is shown at the bottom of Figure 2.4. Another type of background subtraction was introduced by Tougaard [63]. This methodology bases on the integration of the intensity of the background at a given binding energy of the spectral intensities of higher kinetic energies. The linear background suffers from large peak area changes depending on the position of the chosen end points. The Tougaard background is the most accurate one, but the disadvantage of the method is the complications in practical use (required long energy range, minimum peak overlapping). The Shirley background is somewhere in between for accuracy, however its easy application has resulted in its widespread adoption. 
The changes in the XP spectrum may not only caused by different chemical environments, but also X-ray radiation itself can damage the surface. X-ray-induced beam damage during XPS studies requires special attention. The effects of photon beam irradiation on solid surfaces have complex nature, but the main demonstrations are changes in composition (segregation, adsorption-desorption), beam heating (reactions, interdiffusion), changes in physical structure (defects, bond breaking) and charging of insulators. To minimize beam damage a movement of beam spot is necessary time to time.

\subsection{X-ray absorption spectroscopy.}

X-ray absorption spectroscopy (XAS) as a highly informative method of experimental study of molecular and solid-state samples due to the method's elemental selectivity and ability to probe free electronic states, with high energy resolution and high sensitivity to chemical structure.

The process of absorption of X-ray quanta by atoms of polyatomic systems (molecules, complexes, clusters and solids) occurs with the highest probability when the photon energy is close to the binding energy of one of the inner shell electrons of an atom within the system. Two different processes are possible: 1) if $h v \geq E_{i}$, the electron will be emitted from the atom with a kinetic energy $E_{k i n} \geq 0$. In other words, atoms are photoionized followed by a formation of a cation and photoelectron. 2) If $h v<E_{i}$, the electron will remain bounded to a molecule [64].

The first case corresponds to the continuous absorption starting stepwise, when $h v=E_{i}$ (absorption edge). After the absorption edge, a monotonic decrease of the absorption coefficient is observed, which is usually superimposed on the additional structure called the fine structure of X-ray absorption edge (Figure 2.5). The presence of this structure is easily explained by the description of X-ray photon absorption as a two-stage process, consisting of: 1) the act of absorption of a quantum of light by an atom and the appearance of a photoelectron in the inner electron shell; 2) subsequent release of the photoelectron from polyatomic systems. Broad low-intensity oscillations in absorption, which are observed when photoelectron kinetic energy is $>50 \mathrm{eV}$, are called Extended X-ray Absorption Fine Structure (EXAFS). It appears as result of interference of the primary photoelectron 
wave and single scattered photoelectron waves in the potential field of the atom and its neighbors from the nearest coordination spheres.

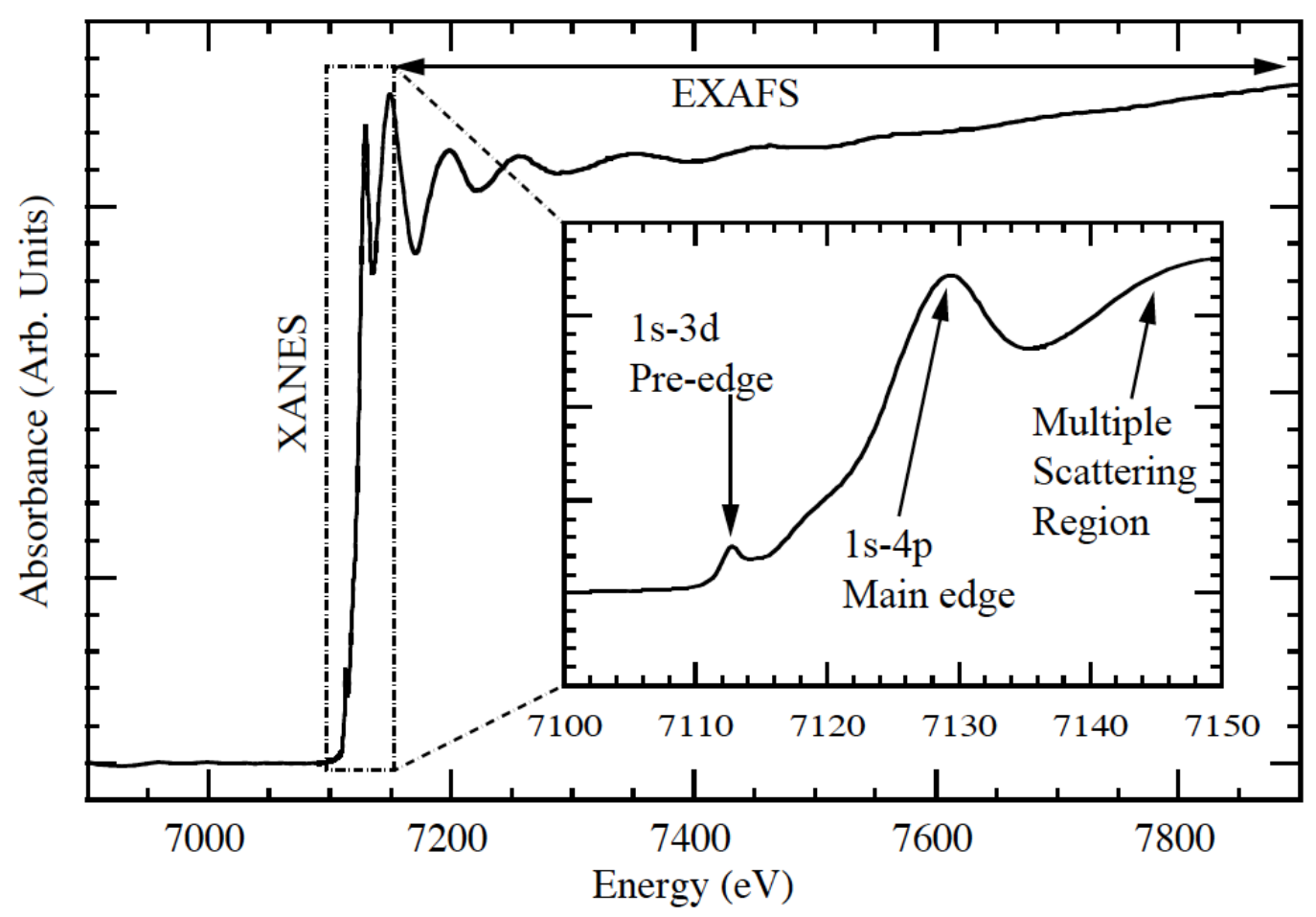

Figure 2.5. XANES and EXAFS at Fe K-edge [65].

In the second case, a series of separate, and often quite narrow, strong absorption lines appear before and after the absorption edge. This Near-Edge X-ray Absorption Fine Structure (NEXAFS) or X-ray Absorption Near-Edge Structure (XANES) is determined by the multiple scattering of low energy photoelectrons $\left(E_{\text {kin }}<30 \mathrm{eV}\right)$ having a wavelength comparable with interatomic distances in the system. Major contribution to the NEXAFS is made by interference of photoelectron waves, which are formed as a result of multiple (resonant) scattering of low-energy photoelectrons atoms by the environment. NEXAFS contains information about the spatial structure of the environment of the absorbing atom and the energy distribution of the free electron states in the system, defining the optical, electrical and other physical and chemical properties of matter.

The traditional approach to the interpretation of NEXAFS spectra of solids is based on the use of data about the electronic structure obtained by the band calculations. In such approach the X-ray absorption process is described as the 
transfer of electrons from the inner (core) shells of an atom to an unoccupied state in the conduction band. A proceeding of the linear absorption coefficient $\tau(E)$ in this case is given by:

$$
\tau(E) \approx \int_{S} \frac{\left|M_{j i} \overrightarrow{(k)}\right|^{2}}{\left|\nabla_{\vec{k}}\right|\left(E_{j i}(\vec{k})\right)} .
$$

Where, $E_{j i}(\vec{k})=E_{i}(\vec{k})-E_{j}(\vec{k})$ is energy of the electron transition from core level to the unoccupied state in the conduction band of the crystal, $M_{j i}(\vec{k})=$ $\int \psi_{j}^{*}(\vec{r}, \vec{k}) \vec{r} \psi_{i}(\vec{r}) d^{3} \vec{r}$ is dipole matrix element of the electron transition between the core level and states in the conduction band, $\vec{k}$ is electron wave vector in the final state. Transitions between levels are allowed, if the matrix element of the dipole transition is nonzero. In this case, the spectral lines are intense. Transitions between levels are called forbidden transitions, if the matrix element is zero. In other words, transitions are allowed, if $\Delta L= \pm 1$ and $\Delta J=0 \pm 1(J=0 \leftrightarrow 0)$, where $L$ is orbital angular momentum quantum number and $J$ is total angular momentum quantum number. Despite the name, the forbidden transitions may occur due to the higher multipole or if third bodies, but these spectral intensities are less.

In equation (10) the integral is taken over the surface $S$ in the space vector $\vec{k}$ in which the energy $E_{j i}(\vec{k})$ is constant (equal to the energy of the absorbed quantum). Since the energy of an electron $E_{i}$ in an inner shell does not depend on the wave vector $\vec{k}$, then $\nabla_{\vec{k}}\left(E_{i j}(\vec{k})\right)=\nabla_{\vec{k}}\left(E_{j}(\vec{k})\right)$. Replacing the value $M_{j i}(\vec{k})$ of some average value at constant constant-energy surface $S$ gives the multiplicative formula for the absorption coefficient:

$$
\tau(E) \approx \overline{\left|M_{\jmath l}(\vec{k})\right|^{2}} N(E) .
$$

Where, $N(E)=\int \frac{d S}{\nabla_{\vec{k}} E_{j}(\vec{k})}$ is the density of the unoccupied electron states in the conduction band of the crystal. The equation (11) allows for a separate discussion of the effect of the density of unoccupied states and the probability of transition to the NEXAFS. A major shortcoming of the band approach is not fully taking into account peculiarities of the electronic structure of solids (the Rydberg series, the discrete bands above the absorption edge, etc.) and the lack of demonstrative relationship between the electronic structure of solids and its components: atoms and molecules. 
Modern molecular orbitals approach takes into account chemical bonding between atoms and molecules. In this approach an electron in a molecule probability can be at each of the atoms of the molecule with certain and near atom it behaves like a normal atomic electron. Molecular orbital $\varphi_{m}$ is represented as a linear combination of atomic orbitals $\chi_{n}$ :

$$
\varphi_{m}=\sum_{n} C_{n m} \chi_{n}
$$

Where, the coefficients $C_{n m}$ are found from the solution of Schrödinger equation by minimizing the total energy of the system. The squares of these coefficients $\left|C_{n m}\right|^{2}$ equal to the probability of finding an electron in the state $\chi_{n}$ near the atom.

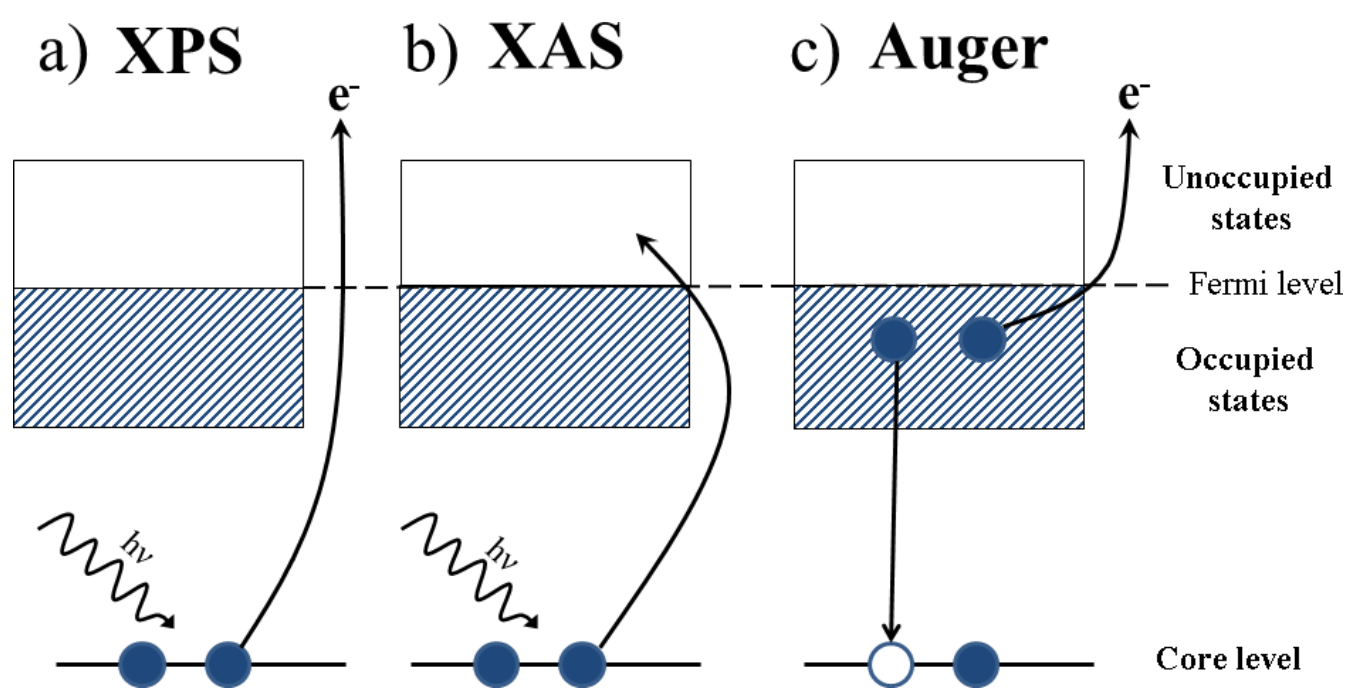

Scheme 2.1. Schematic representation of a) XPS, b) XAS and c) Auger processes.

In Scheme 2.1a simplified XPS process is presented, after photon absorption electron from the core shell is emitted from the sample and then collected by analyzer. In XAS the excited electron stays in a bond states after the photon absorption and provides information about atom's environment (Scheme 2.1b). Unlike previous methods Auger process is a relaxation of a system after excitation. After the filling of the vacancy in the inner core level by an electron from higher level the energy released by the downward transition is given to one of the outer electrons, and this electron is then ejected from the atom with an energy equal to the energy loss of the electron which made the downward transition minus the binding energy of the electron that is ejected from the atom; the kinetic energy of the emitted electron does not depend on excitation photon energy and is unique for each element. 


\subsection{Scanning electron microscopy.}

Scanning electron microscopy (SEM) is a powerful technique to obtain information about the morphology of catalysts. Figure 2.6 shows a schematic of a SEM optical configuration. The instrument must be equipped with a vacuum system. An electron beam is generated from an electron gun. The condenser lens collimates the electron paths are concentrates the electron flux. Then electron beam then passes through a region where its direction can be changed by deflection coils for rastering the beam across the surface of a sample. The objective lens focuses the beam into small spot (ca. 1-5 nm diameter) onto the sample.

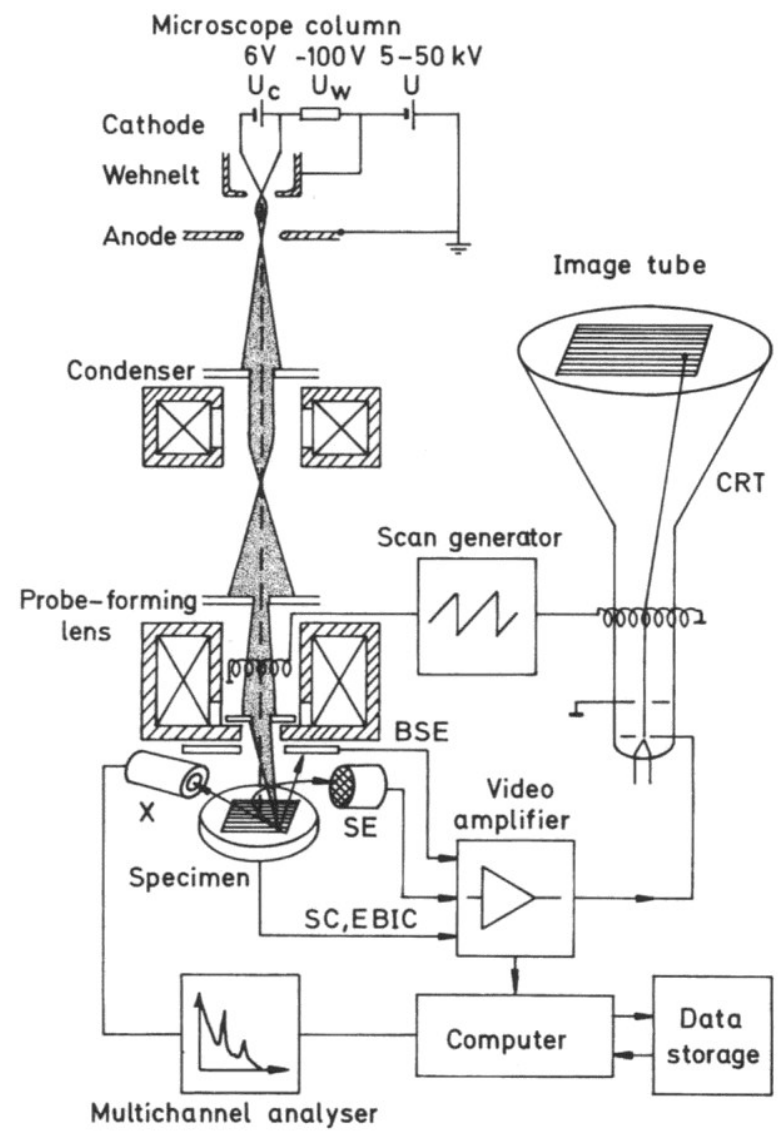

Figure 2.6. Layout of SEM [66].

The interaction between the electron beam and the sample leads to the generation of low-energy secondary electrons, which are collected by the secondary electron detector. The intensity of the electric signal of the detector depends on the nature and the topography (mainly) of the sample in the interaction region. Thus, an 
electron beam scanning the surface of an object may obtain a relief map of the analyzed area.

Environmental Scanning Electron Microscope (E-SEM) allows one to obtaine an image of the specimen in gaseous environments. A scheme of the specimen chamber in E-SEM is shown in Figure 2.7. This instrument makes it possible to find a correlation between in-situ XPS measurements and in-situ morphological changes and dynamics. The maximum pressure in the chamber is $30 \mathrm{~Pa}$

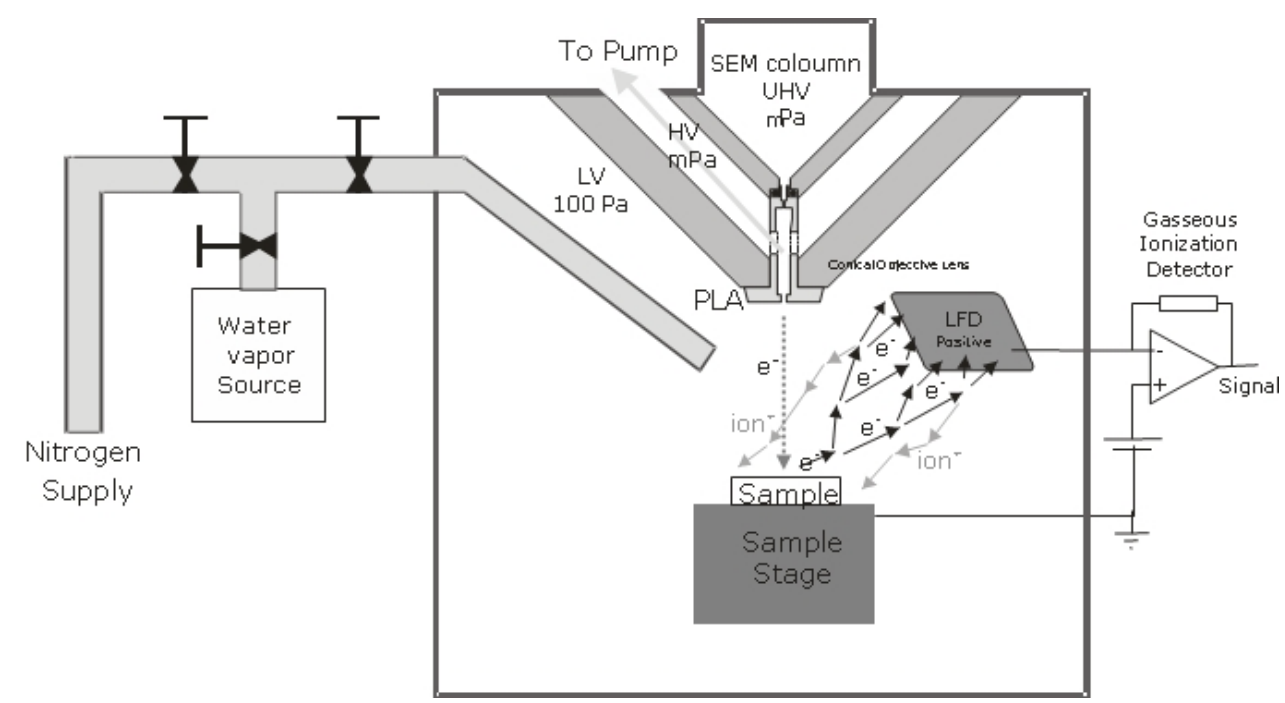

Figure 2.7. The scheme of specimen chamber in E-SEM.

\subsection{Transmission electron microscopy.}

Transmission electron microscopy (TEM) is microscopy technique in which an image of an ultra-thin sample (thickness about 0.1 microns) is formed by the interaction of an electron beam with the specimen. Subsequent magnification happens in the electromagnetic lenses and recording on the fluorescent screen. The first TEM was created by German electronics engineers Max Knoll and Ernst Ruska in 1931. Ernst Ruska was awarded the Noble Prize in Physics for its creation in 1986.

A cross-section and layout of the optical components in a TEM are shown in Figure 2.8. TEM consists of several components: vacuum system, specimen stage, electron source, high voltage source, electromagnetic lenses, apertures and screen. The typical pressure in TEM is $10^{-4} \mathrm{~Pa}$. There are two main reasons: 1) the possibility of creating a considerable potential between the cathode and the ground 
without arcing; 2) increasing the mean free path of the electron gas interaction. The design of the specimen stage includes gateways allowing loading of the sample holder in a vacuum environment of the microscope with minimal increase in pressure. The standard TEM grid size is a $3.05 \mathrm{~mm}$ diameter ring with ultramicrotomy sections. In our TEM measurements we used a lanthanum hexaboride filament as the electron source. The $\mathrm{LaB}_{6}$ filament is heated in order to achieve thermionic emission. The condenser lens system focuses the beam to form a small spot and provides enough magnification (objective lens) to show atomic-scale image.

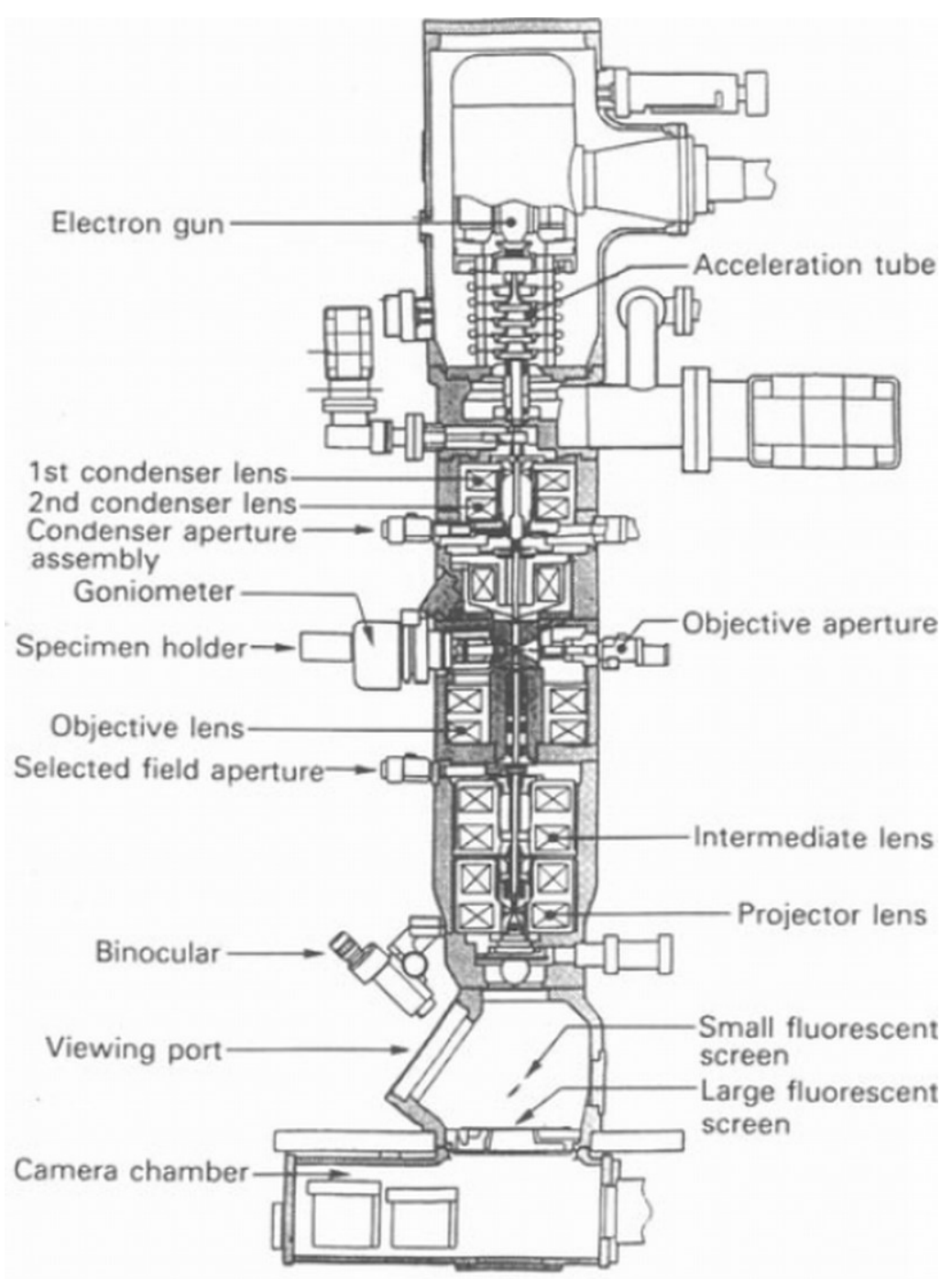

Figure 2.8. Cross-section of TEM [67]. 


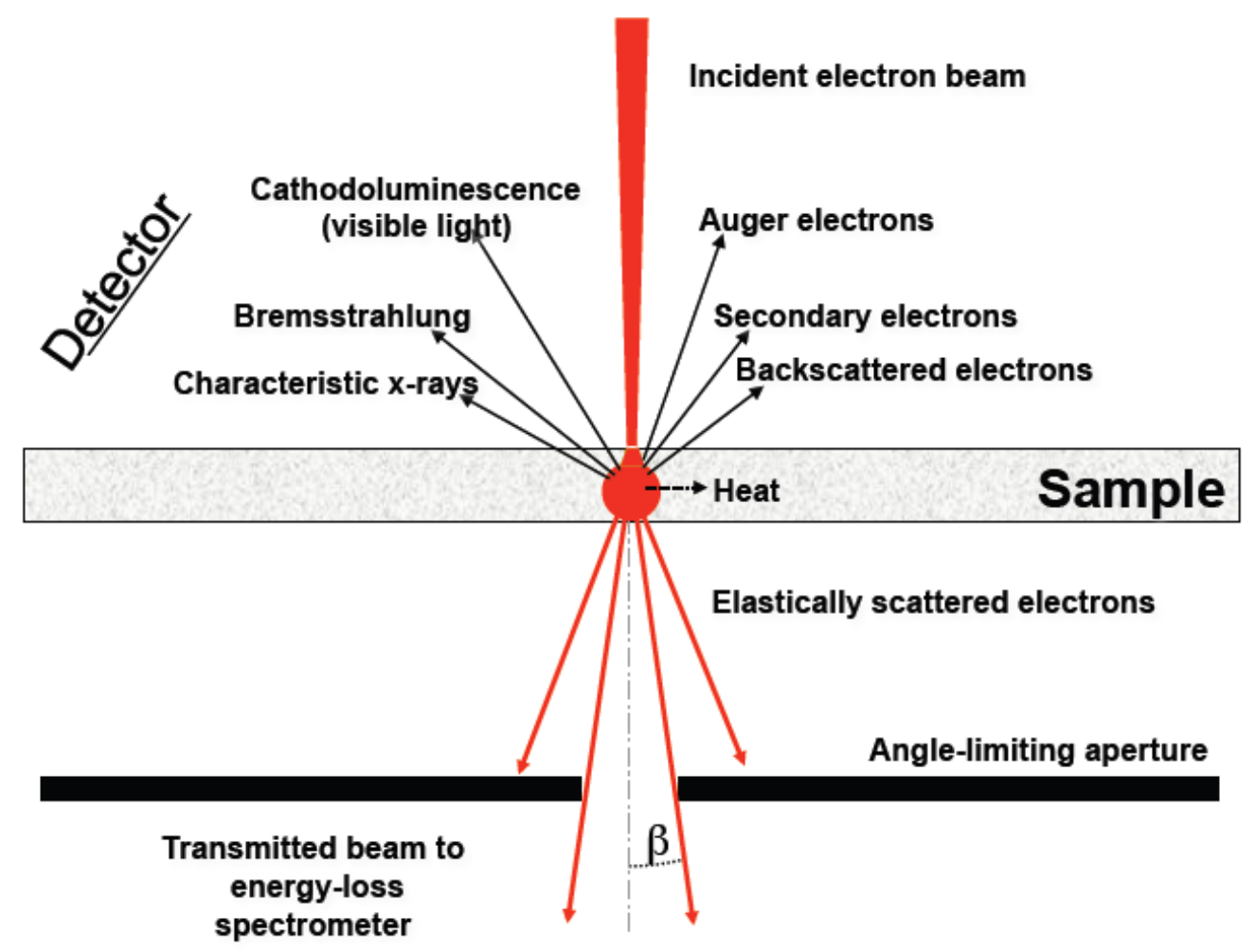

Figure 2.9. Possible signals available in TEM.

A lot of signal can be detected in TEM (Figure 2.9). Commonly TEM collects the following ones:

1) Bright field mode: transmitted electrons that leave the sample at relatively low angles with respect to the optical axis. In this mode, thicker regions or regions with higher atomic numbers appear dark in the measured image.

2) Electron energy loss spectroscopy (EELS): transmitted electrons that have lost energy when passing through the sample.

3) Energy-dispersive X-ray spectroscopy (EDX): X-rays generated from electron excitations in the sample.

It is obvious, that, TEM and SEM have similarities but there are as well some characteristic differences. SEM focuses on the sample's surface, while TEM shows what is beyond the surface. The resolution and magnification of TEM is much better than in SEM, on the other hand SEM provides images with better depth of field in comparison with TEM images. Also TEM requires the specific sample preparation using TEM grid. Both techniques are used for a wide range of scientific applications. 


\subsection{Quadrupole mass spectroscopy.}

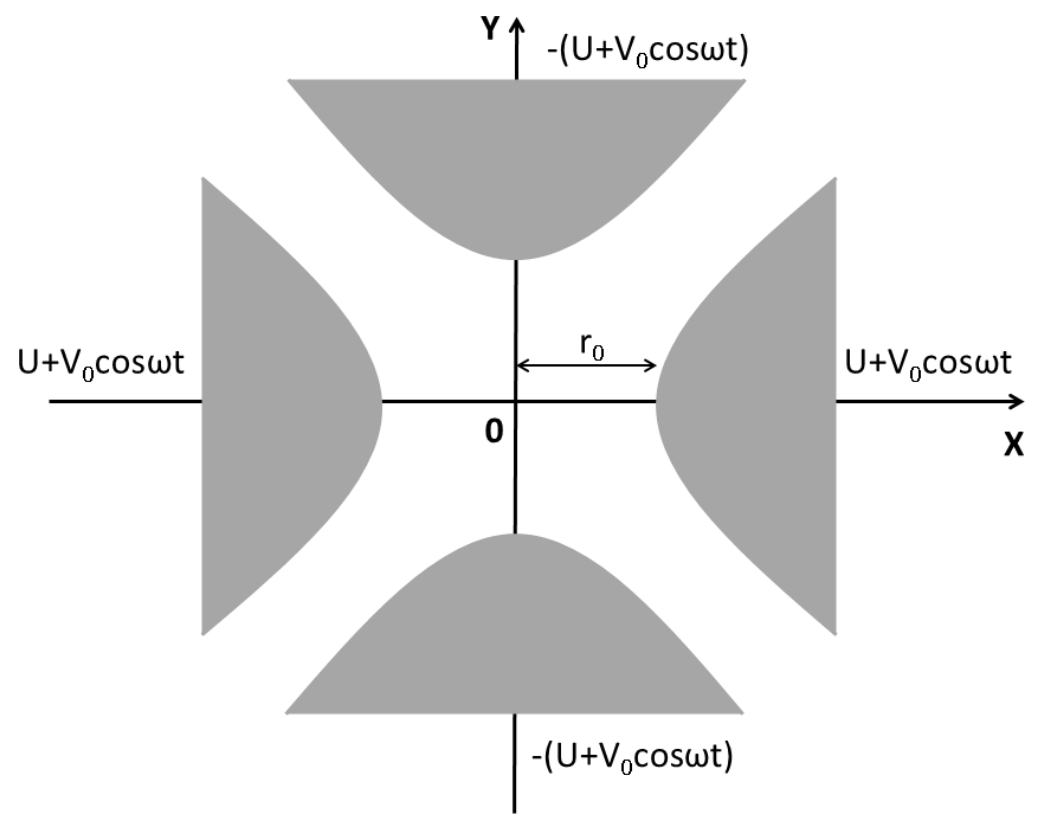

Figure 2.10. End-on view of quadrupole mass spectrometer.

The first mass spectrometer with quadruple (radio frequency electric field) mass separation (QMS) was developed by Paul and co-workers [68]. An end-on view of a QMS is shown on Figure 2.10. Two pairs of rod-shaped electrodes of hyperbolic cross section establish a two-dimension quadrupole field. The voltage applied to the quadrupole array consists of a constant component $U$ and a radio frequency component $V_{0} \cos \omega t$. The motion of an ion injected into the field in the $\mathrm{z}$ direction is described by the following equations

$$
\begin{gathered}
m \ddot{x}+\frac{2 e\left(U+V_{0} \cos \omega t\right) x}{r_{0}^{2}}=0 \\
m \ddot{y}+\frac{2 e\left(U+V_{0} \cos \omega t\right) y}{r_{0}^{2}}=0 \\
m \ddot{z}=0
\end{gathered}
$$

Equations (2.13) and (2.14) for $\mathrm{x}$ and y axes, respectively, can be reduced to Mathieu equation:

$$
\begin{aligned}
& \frac{d^{2} x}{d t^{2}}+(A+2 Q \cos 2 \tau) x=0 \\
& \frac{d^{2} y}{d t^{2}}+(A+2 Q \cos 2 \tau) y=0
\end{aligned}
$$


where $A=\frac{8 e U}{m r_{0}^{2} \omega^{2}}, Q=\frac{8 e V_{0}}{m r_{0}^{2} \omega^{2}}$ and $\tau=\frac{\omega t}{2}$. The solutions of these equations describe ion oscillation in the $\mathrm{x}$ and $\mathrm{y}$ directions, respectively. However, the velocity in the $\mathrm{z}$ direction does not change. The oscillation are stable for certain values of $\mathrm{A}$ and $\mathrm{Q}$, it means that the amplitude are finite at any time. But for other values of A and Q the amplitude increases to infinity (the oscillation are unstable). The range of values of $\mathrm{A}$ and $\mathrm{Q}$ for which the oscillations are stable in $\mathrm{x}$ and $\mathrm{y}$ simultaneously is indicated in Figure 2.11 .

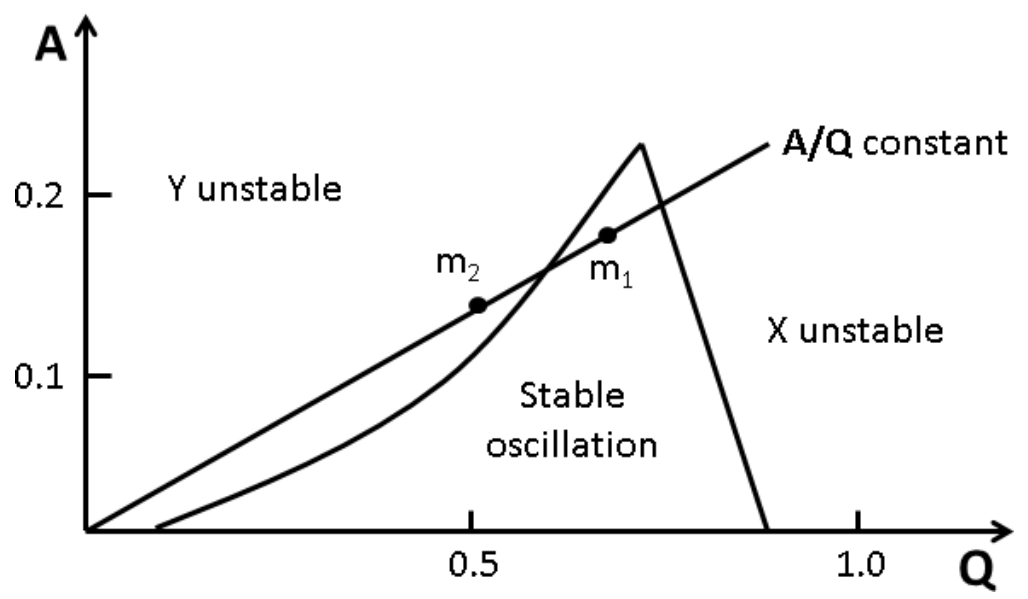

Figure 2.11. Stability diagram for quadrupole mass spectrometer [69].

If the ratio $\mathrm{A} / \mathrm{Q}$ is constant, the points on the straight line passing through the origin of the stability diagram will represent different ionic masses. For the points inside the region of stable oscillation (mass $\mathrm{m}_{1}$ in Figure 2.11), the ions with corresponding masses path through the quadrupole field. For other masses (such as $\mathrm{m}_{2}$ in Figure 2.11), the ions collide with inner parts of the QMS, thus mass separation takes place. To increase the mass resolution, the parameters A and Q are chosen in such way that the representative line passes close to the top of the stability region $(\mathrm{A}=0.237, \mathrm{Q}=0.706)$.

\subsection{Reactor for $\mathrm{CO}$ oxidation at atmospheric pressure.}

The catalytic oxidation of carbon monoxide was investigated at atmospheric pressure in a plug-flow fixed-bed reactor. The measurements were carried out in a set-up consisting of a gas dosing section, a reactor tube inside a copper block oven, and an on-line gas analyzer unit. The gas dosing section includes lines for $\mathrm{He}, \mathrm{H}_{2}$, 
$\mathrm{O}_{2}$, and $\mathrm{CO}$ and a calibration gas $\left(1 \% \mathrm{CO}, 1 \% \mathrm{O}_{2}, 1 \% \mathrm{CO}_{2}\right.$ in $\left.\mathrm{He}\right)$. Each line consists of a filter, a mass flow controller (El-Flow, Bronkhorst), a check valve, and a shutoff valve. The gases are mixed via custom-designed switching valves (Valco, Vici). The reactor itself is a U-tube reactor with an inner diameter of $5 \mathrm{~mm}$ made of glass lined steel (Glass Lined Tubing, SGE). It is connected to a four-way valve (Valco, Vici) using as bypass. The reactor is heated by a custom-made copper block oven, providing an isothermal $( \pm 1 \mathrm{~K})$ zone of $4 \mathrm{~cm}$ at temperatures up to $400{ }^{\circ} \mathrm{C}$. The sample temperature is monitored by an internal thermocouple of type K. Analytics are performed by an on-line detector consisting of IR detectors for $\mathrm{CO}, \mathrm{CO}_{2}$ and $\mathrm{H}_{2} \mathrm{O}$ and a paramagnetic sensor for $\mathrm{O}_{2}$ (X-Stream, Rosemount).

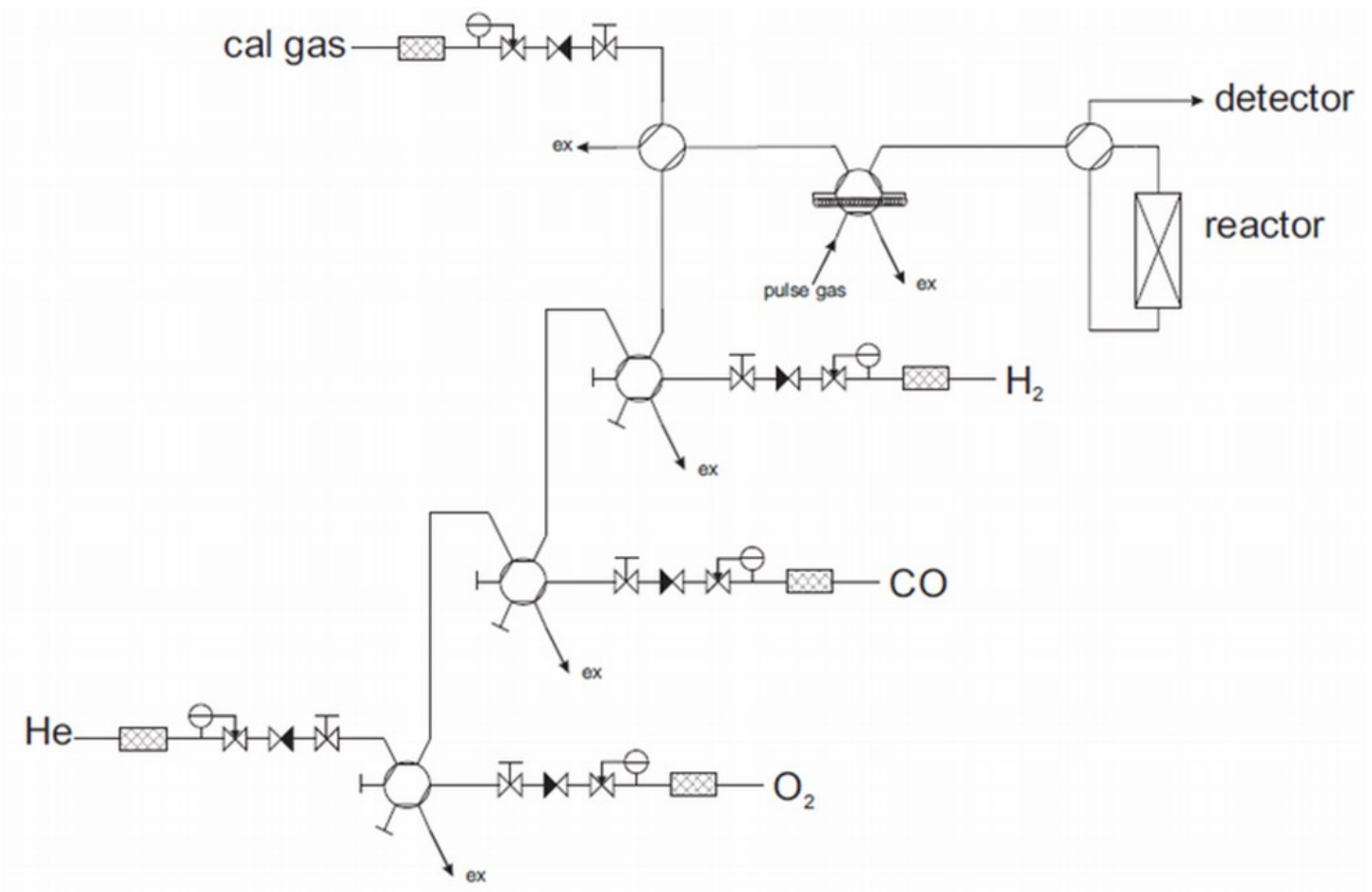

Scheme 2.2. Scheme of reactor for $\mathrm{CO}$ oxidation at atmospheric pressure.

\subsection{XPS measurement performance.}

The XPS measurements were performed at the ISISS beamline at BESSY II/HZB (Berlin, Germany). All measurements were carried out in a stainless steel NAP-XPS chamber described in detail in Chapter 2.2. The powder samples were pressed into a pellet of $8 \mathrm{~mm}$ diameter. The Au samples on transition metal oxides were pressed together with a copper mesh into a pellet. The copper mesh was used to 
prevent sample charging during photoemission. The samples were mounted on a sapphire sample holder between a stainless steel back-plate and a lid with $6 \mathrm{~mm}$ hole, shown in the Figure 2.12. The samples were heated from behind by an infrared laser and the temperature was measured by a type- $K$ thermocouple positioned at the sample's surface. The overall spectral resolution was $0.3 \mathrm{eV}$ in $\mathrm{O} 1 \mathrm{~s}$ and $\mathrm{C} 1 \mathrm{~s}$ and 0.2 $\mathrm{eV}$ in $\mathrm{Au} 4 \mathrm{f}$ regions. The spectral intensity was normalized by the incident photon flux, which was measured using Au reference foil. The binding energies (BE) were calibrated using the Fermi edge, the $A u 4 f_{7 / 2}$ and $C 1 s$ second-order peaks. The accuracy of BE calibration was estimated around $0.05 \mathrm{eV}$.

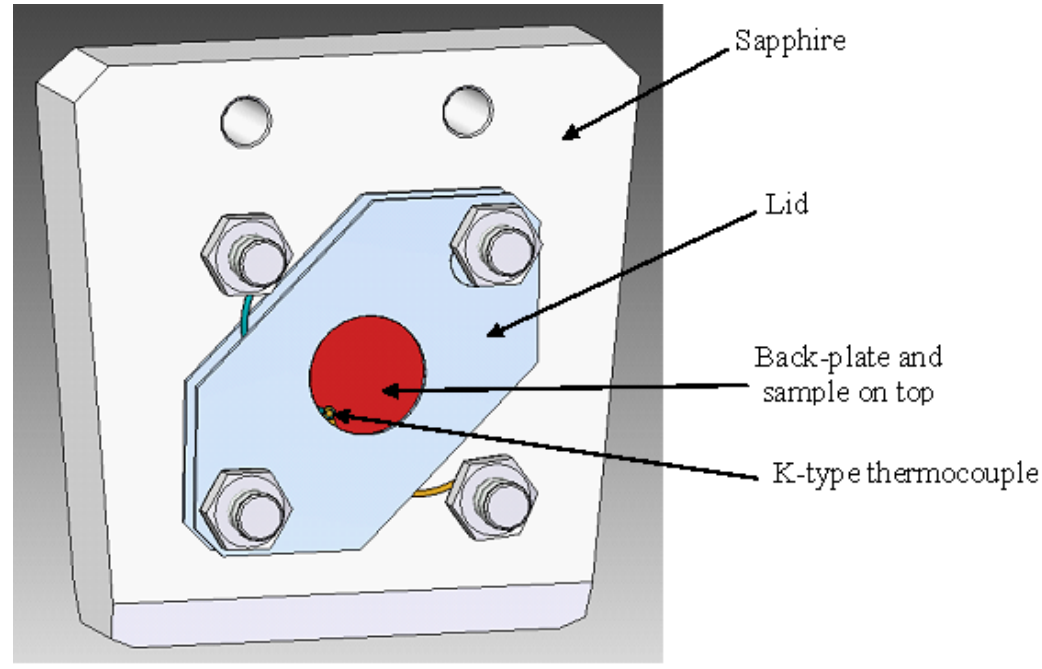

Figure 2.12. Sapphire sample holder with a stainless steel back-plate and a lid with 8 mm hole.

The gold foil was cleaned by standard surface science procedures, with $\mathrm{Ar}^{+}$ sputtering $\left(2 \cdot 10^{-4} \mathrm{mbar}, 1.5 \mathrm{kV}\right)$ for $30 \mathrm{~min}$ at room temperature and subsequent annealing to $400^{\circ} \mathrm{C}$ in vacuum. Cycles of cleaning were repeated until carbon was no longer detected by $\mathrm{C} 1 \mathrm{~s}$ XPS.

$\mathrm{O}_{3}$ was produced using a commercial ozone generator TC-1KC. Oxygen was passed at a rate of $1 \mathrm{~L} / \mathrm{min}$ through Teflon tubing to the ozone generator. The effluent gas from the generator contained a mixture of approximately $1 \%$ ozone and 99\% un-reacted oxygen. The $\mathrm{O}_{3} / \mathrm{O}_{2}$ mix was dosed through Teflon tubing into the experimental cell using a leak valve while the sample kept at $100^{\circ} \mathrm{C}$. The total pressure in the experimental cell was 0.3 mbar. 
All XP spectra were collected in normal photoemission mode. For quantitative XPS analysis, least-squares fitting of the spectra were performed using CasaXPS software (www.casaxps.com). A Doniach-Sunjic line shape for $\mathrm{Au} 4 \mathrm{f}_{7 / 2}$ and a product (multiplication) of a Gaussian with a Lorentzian line shape for $\mathrm{O} 1 \mathrm{~s}$ with Shirley-type background were used to obtain the best fit.

We recorded $\mathrm{Au} 4 \mathrm{f}_{7 / 2}$ and $\mathrm{O}$ 1s spectra at four different kinetic energies: 175 $\mathrm{eV}, 350 \mathrm{eV}, 600 \mathrm{eV}$ and $1000 \mathrm{eV}$, using a special combination of exit slit width of the monochromator and pass energy of the electron analyzer, which keeps the total resolution almost the same over the relevant interval of kinetic energies. These kinetic energies correspond to inelastic mean free paths (IMFP) of $0.49 \mathrm{~nm}, 0.67 \mathrm{~nm}$, $0.91 \mathrm{~nm}$ and $1.29 \mathrm{~nm}$ (assuming predominantly gold in the near-surface region) [70]. 


\section{Results.}

\subsection{Extended Au surface.}

\subsubsection{Clean and oxidized Au foil.}

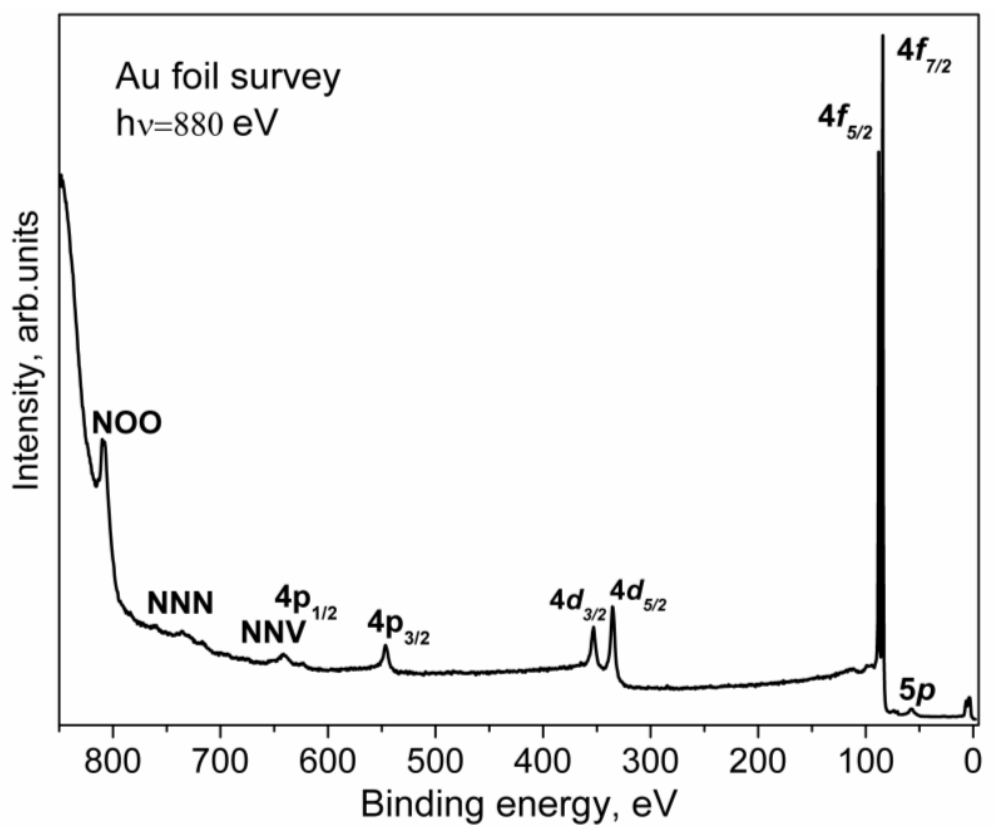

Figure 3.1. Survey photoelectron spectrum of clean Au foil.

The first step to study the interaction of $\mathrm{O}_{3}$ with $\mathrm{Au}$ is to obtain a clean $\mathrm{Au}$ surface. The fresh Au foil was cleaned by repeating cycles of $\mathrm{Ar}^{+}$sputtering and thermal annealing until no additional elements other than Au were visible in a broadenergy survey XP spectrum (Figure 3.1). The corresponding Au $4 f_{7 / 2}$ spectrum of the clean $\mathrm{Au}$ foil (Figure 3.2A(i)) shows the expected metallic peak at a binding energy (BE) of $83.92 \mathrm{eV}$ [71-73] together with an additional component shifted by $0.32 \mathrm{eV}$ towards lower BE, assigned as the surface core-level shift according to the literature [74,75]. The surface-sensitive $\mathrm{O} 1 \mathrm{~s}$ spectrum (using $150 \mathrm{eV}$ kinetic energy photoelectrons) shows only a small peak but no sign of adsorbed oxygen or oxygenated contaminants. (Figure 3.2B(i)). 

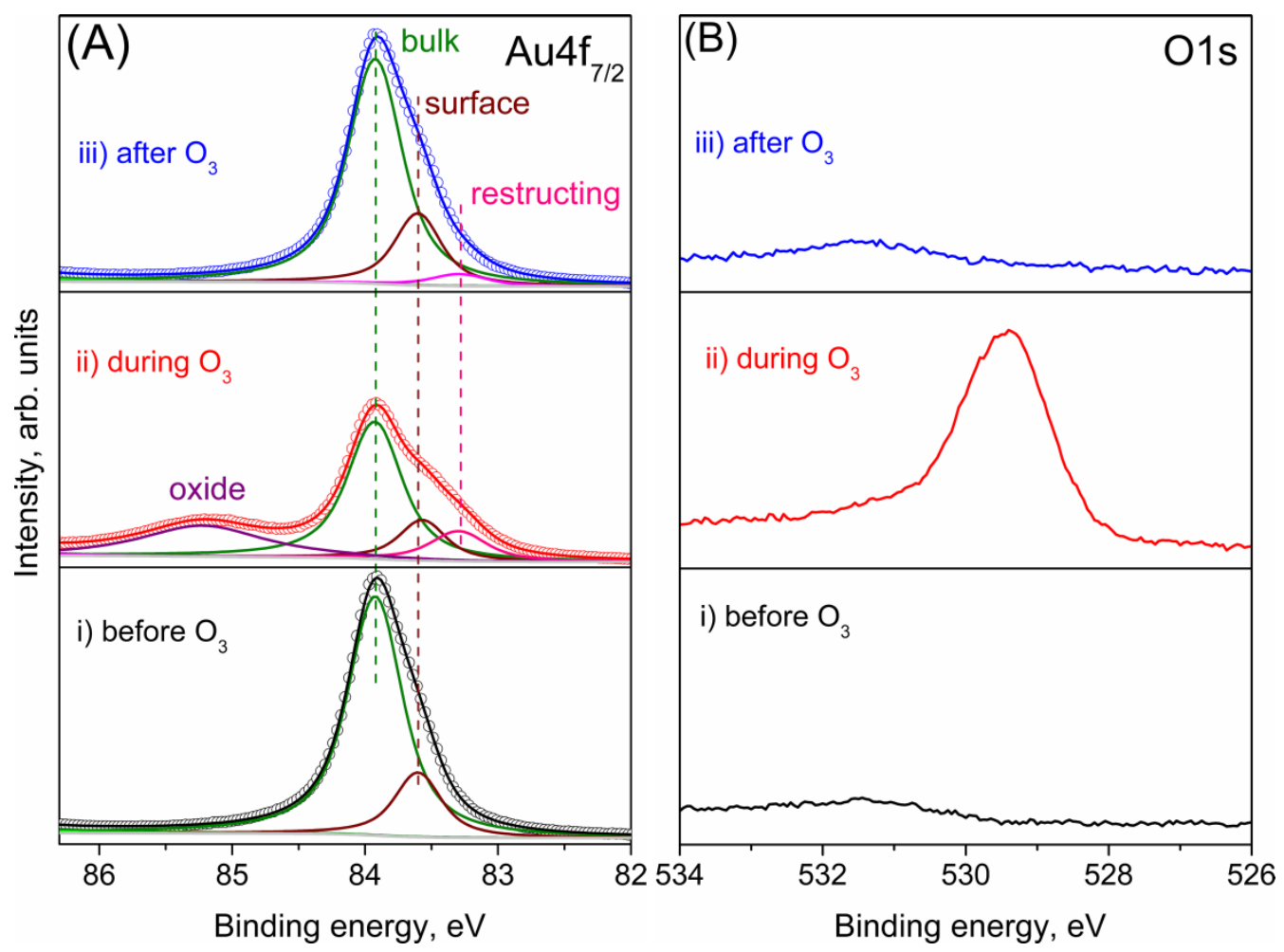

Figure 3.2. Fitting of NAP (a) $\mathrm{Au} 4 \mathrm{f}_{7 / 2}$ and (b) $\mathrm{O} 1 \mathrm{~s}$ photoelectron spectra (using 150 $\mathrm{eV}$ kinetic energy photoelectrons) from gold foil at $100^{\circ} \mathrm{C}$ (i) before (ii) during and (iii) after $\mathrm{O}_{3}$ treatment at 0.3 mbar.

When we introduce the $\mathrm{O}_{2} / \mathrm{O}_{3}$ mixture to the chamber, the $\mathrm{O}$ 1s spectrum immediately changes, developing an intense peak at $529.4 \mathrm{eV}$ (Figure 3.2B(ii)). The atomic element ratio is $\mathrm{O}: \mathrm{Au}=0.84 \pm 0.05$ within a depth of $0.49 \mathrm{~nm}$. Since no contaminants, within the detection limits of XPS, appear on the Au surface during oxidation, this peak can be assigned as oxygen bonded to gold. The corresponding $\mathrm{Au}$ 4f spectrum during $\mathrm{O}_{3}$ exposure (Figure 3.2A(ii)) shows new features in comparison with the clean $\mathrm{Au}$ surface. A well-defined peak appears at $85.22 \mathrm{eV}$, which is assigned to cationic Au species $[73,76]$, together with an additional feature at low BE $(83.29 \mathrm{eV})$. All fitting parameters are given in Table 3.1. This additional component is assigned to the presence of low-coordinated atoms that appear on the $\mathrm{Au}$ surface as result of surface restructuring during oxidation [77] (Figure 3.2). This assignment is further discussed below. 
Table 3.1. Fitting parameters of $\mathrm{Au} 4 \mathrm{f}$ spectrum of $\mathrm{Au}$ foil.

\begin{tabular}{|c|c|c|c|c|c|c|c|c|}
\hline & \multicolumn{2}{|c|}{ bulk } & \multicolumn{2}{c|}{ surface } & \multicolumn{2}{c|}{ restructuring } & \multicolumn{2}{c|}{ oxide } \\
\hline & $\begin{array}{c}\mathrm{BE} \\
(\mathrm{eV})\end{array}$ & $\begin{array}{c}\text { FWHM } \\
(\mathrm{eV})\end{array}$ & $\begin{array}{c}\text { BE } \\
(\mathrm{eV})\end{array}$ & $\begin{array}{c}\text { FWHM } \\
(\mathrm{eV})\end{array}$ & $\begin{array}{c}\text { BE } \\
(\mathrm{eV})\end{array}$ & $\begin{array}{c}\text { FWHM } \\
(\mathrm{eV})\end{array}$ & $\begin{array}{c}\text { BE } \\
(\mathrm{eV})\end{array}$ & $\begin{array}{c}\text { FWHM } \\
(\mathrm{eV})\end{array}$ \\
\hline Before $\mathrm{O}_{3}$ & 83.92 & 0.486 & 83.60 & 0.415 & - & - & - & - \\
\hline During $\mathrm{O}_{3}$ & 83.92 & 0.486 & 83.59 & 0.415 & 83.29 & 0.499 & 85.22 & 1.105 \\
\hline${\text { After } \mathrm{O}_{3}}$ & 83.92 & 0.486 & 83.60 & 0.415 & 83.29 & 0.500 & - & - \\
\hline
\end{tabular}

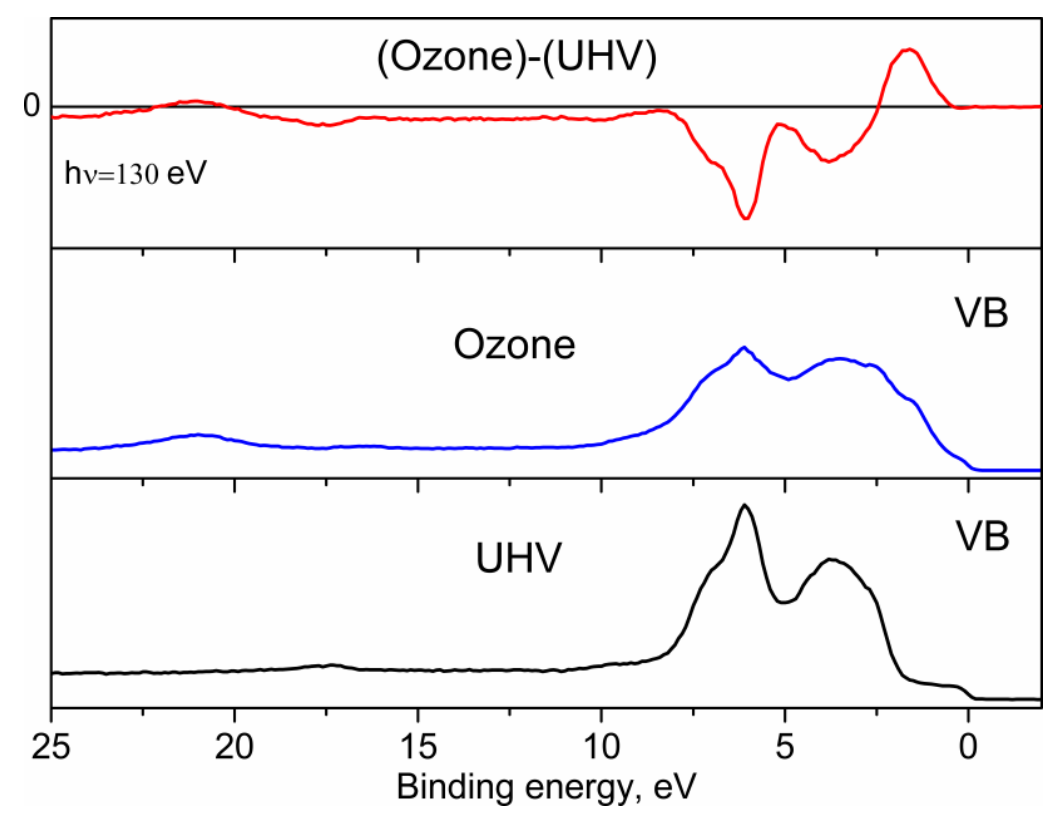

Figure 3.3. Valence band spectra in UHV (bottom), in ozone at 0.3 mbar (middle) and difference spectrum between ozone and UHV environments (top) measured at hv $=130 \mathrm{eV}$. The spectra were normalized to the Fermi edge jump.

The valence band (VB) spectrum of clean gold foil (Figure 3.3) is in good agreement with results obtained previously [78,79], with slight differences in shape due to the polycrystalline surface and lower total resolution. The spectrum corresponds to the density of occupied $d$-states of Au. Corresponding bands are interpreted elsewhere [80]. Changes in VB spectra are observed after ozone treatment. A difference VB spectrum between oxidized and clean foil shows a decrease in density of occupied $\mathrm{Au} d$-states and the appearance of a new structure $(\mathrm{BE} \sim 3 \mathrm{eV}$ ) which corresponds to $\mathrm{O} p$-states. This observation confirms that $\mathrm{Au}$ oxide is formed, because chemical bonding is accompanied by charge transfer. 
Both the cationic Au component and the $\mathrm{O}$ 1s peak disappear when the $\mathrm{O}_{2} / \mathrm{O}_{3}$ mixture is removed and the chamber reaches high vacuum (HV) conditions, as shown in the top spectra of Figures 3.3A and 3.3B. Even the higher chemical potential of 0.3 mbar of $\mathrm{O}_{2}$ at $100^{\circ} \mathrm{C}$ instead of $\mathrm{HV}$ does not prevent the decomposition of the surface oxide. Under $\mathrm{O}_{3}$, the $\mathrm{Au}$ oxide is stable from room temperature up to $250^{\circ} \mathrm{C}$. At higher temperatures the cationic $\mathrm{Au}$ component vanishes even in the presence of $\mathrm{O}_{3}$ as shown in Figure 3.4A. However, as the sample is cooled from $400^{\circ} \mathrm{C}$ to room temperature, the oxide forms on the surface again at temperatures below $300^{\circ} \mathrm{C}$ (see Figure 3.4B).
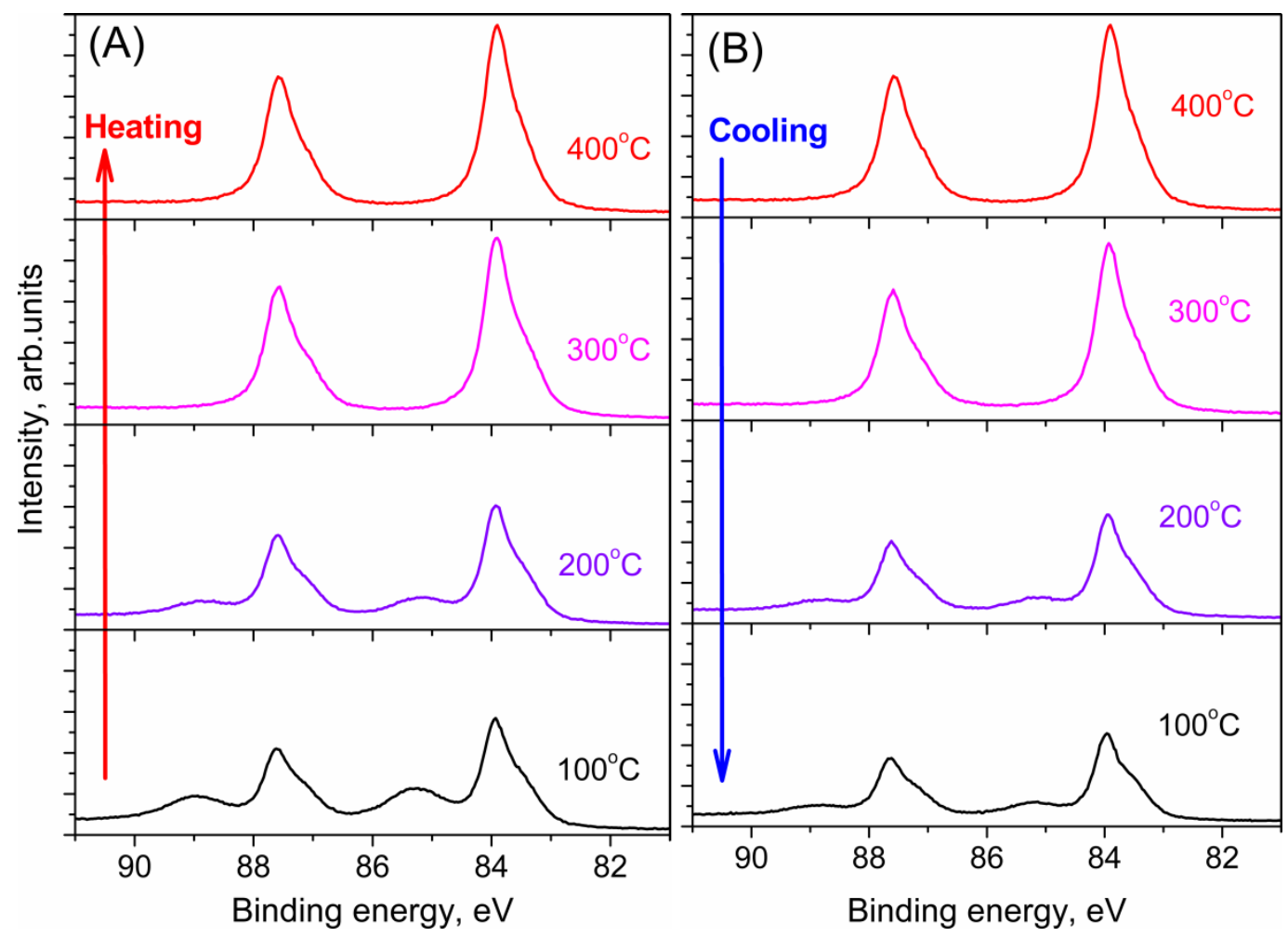

Figure 3.4. $\mathrm{Au} 4 \mathrm{f}$ photoelectron spectra $(\mathrm{h} v=270 \mathrm{eV})$ from gold foil during heating (A) and cooling (B) at various temperatures measured at 0.3 mbar and $\mathrm{CO} / \mathrm{O}_{2}+\mathrm{O}_{3}=1 / 80$. 


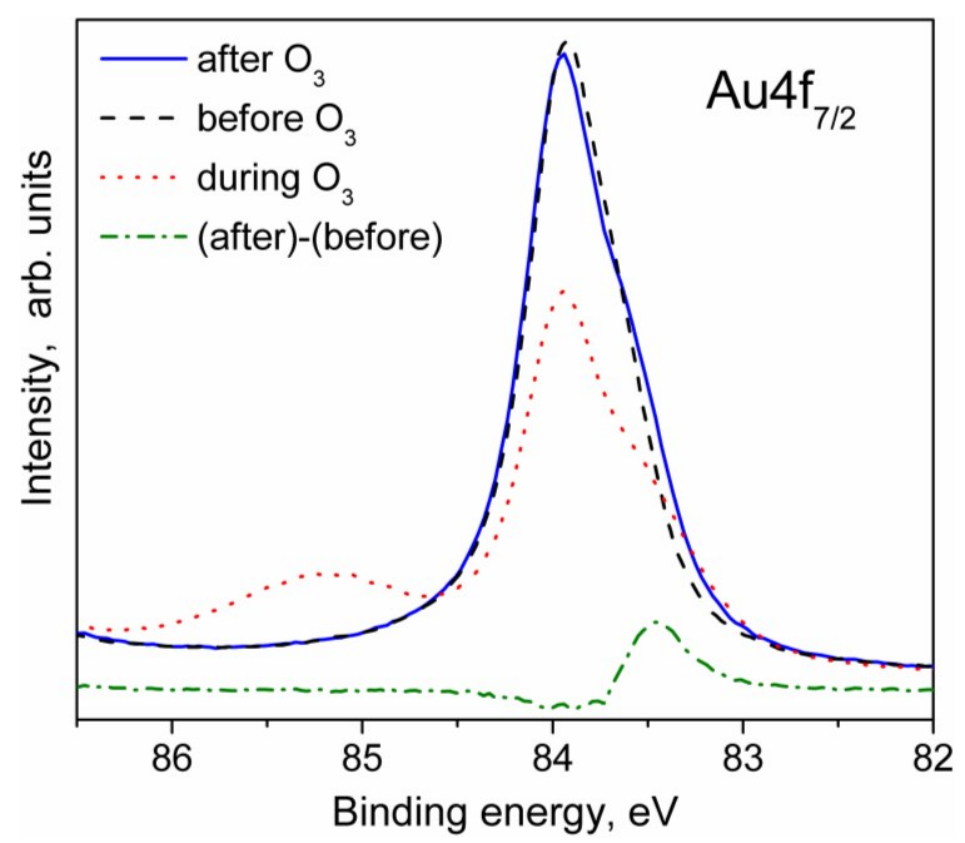

Figure 3.5. NAP-XP $\mathrm{Au} 4 \mathrm{f}_{7 / 2}$ spectra (using $150 \mathrm{eV}$ kinetic energy photoelectrons) of a gold foil at $100^{\circ} \mathrm{C}$ before (black dash line), during (red dot line), after (blue solid) $\mathrm{O}_{3}$ treatment at 0.3 mbar and difference spectrum between $\mathrm{Au} 4 \mathrm{f}_{7 / 2}$ after and before $\mathrm{O}_{3}$ treatment.

Interestingly, although the oxide phase totally vanishes after $\mathrm{O}_{3}$ is removed; the $\mathrm{Au} 4 \mathrm{f}$ spectral shape is not exactly the same as before $\mathrm{O}_{3}$ treatment. The $\mathrm{Au} 4 \mathrm{f}_{7 / 2}$ peak is slightly broader (FWHM changes from $0.59 \mathrm{eV}$ before $\mathrm{O}_{3}$ to $0.64 \mathrm{eV}$ after) with a more pronounced tail to low BE (Figure 3.5). Difference spectrum before and after ozone oxidation (Figure 3.5) clearly shows the existence of an additional component at $83.29 \mathrm{eV}$ assigned to restructuring. At $100^{\circ} \mathrm{C}$, the initial spectrum is recovered only after $4.5 \mathrm{~h}$ (Figure 3.6), but at $350^{\circ} \mathrm{C}$ the additional low BE features disappears after $10 \mathrm{~min}$. The persistence of the additional low-BE component even after the decomposition of the oxide phase and its removal by thermal annealing reinforces the assignment as an additional surface core-level shift related to restructuring. 


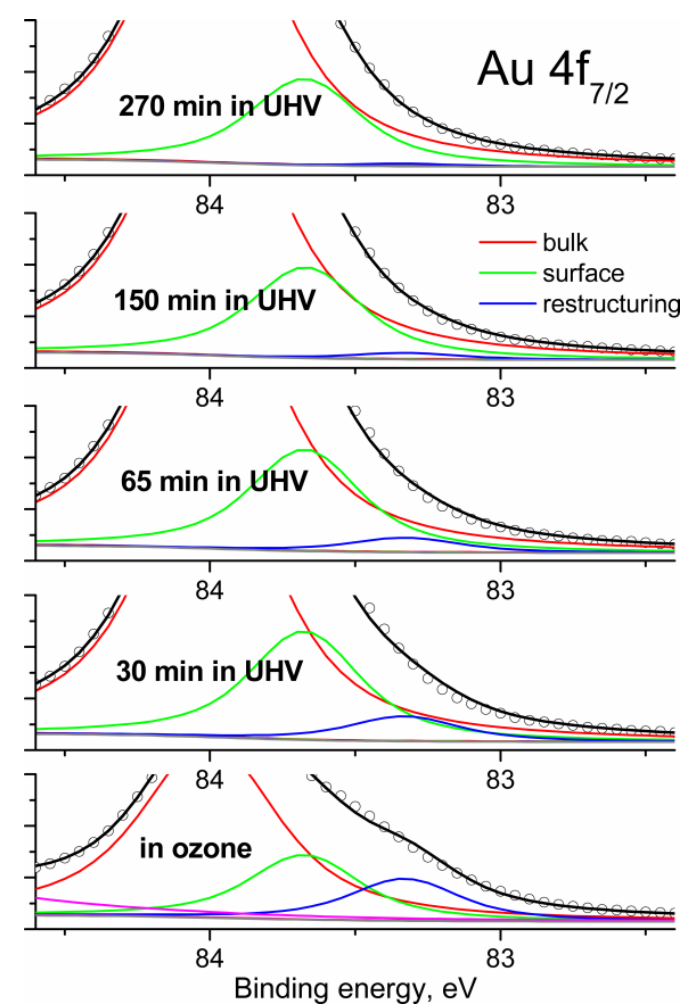

Figure 3.6. $\mathrm{Au} 4 \mathrm{f}_{7 / 2}$ photoelectron spectra $(\mathrm{hv}=270 \mathrm{eV})$ of a gold foil at $100^{\circ} \mathrm{C}$ in UHV after ozone treatment.

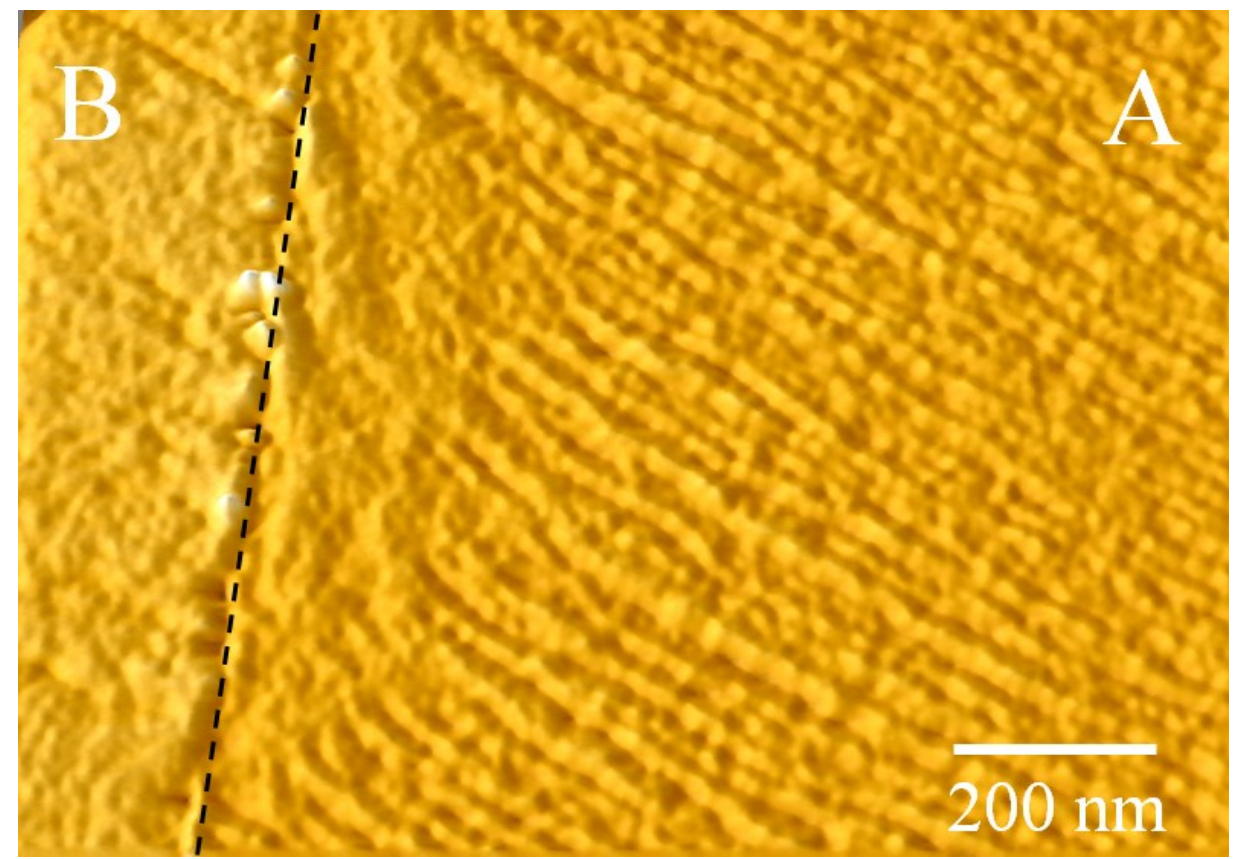

Figure 3.7. Ex-situ SEM image of a Au foil after $\mathrm{O}_{3}(0.3 \mathrm{mbar})$ treatment at $100^{\circ} \mathrm{C}$ showing ridges only in areas that were exposed to $\mathrm{O}_{3}$ (region A). On the left side, where the surface was covered by the sample holder lid, no ridges are observed (region B). 
The structural modifications of the $\mathrm{Au}$ foil after $\mathrm{O}_{3}$ exposure, as suggested by the XPS results, were further confirmed by ex-situ SEM characterization. Figure 3.7 shows an image of a particular region of the Au surface that was partially covered by the sample holder lid. The nearly vertical line marks the position where the edge of the steel lid was pressed against the $\mathrm{Au}$ foil. The region of the sample that was exposed to $\mathrm{O}_{3}$ (region $\mathrm{A}$ in Figure 3.7) shows pronounced contrast variations that are consistent with the presence of ridges on the Au surface. Conversely, the region that was shadowed by the lid shows a rather uniform contrast suggesting a less-structured surface on this length scale (region B in Figure 3.7).

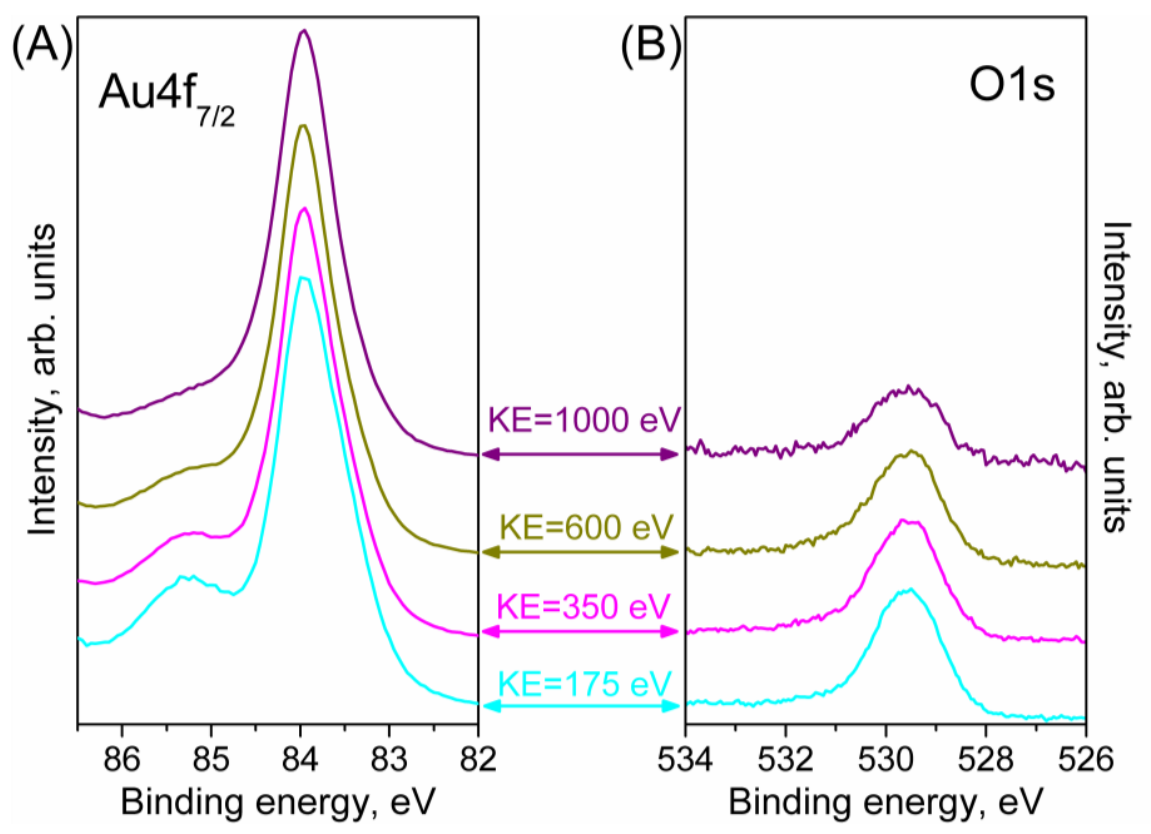

Figure 3.8. NAP-XPS depth profile (a) $\mathrm{Au} 4 \mathrm{f}_{7 / 2}$ and (b) $\mathrm{O} 1 \mathrm{~s}$ as obtained from a gold foil during $\mathrm{O}_{3}(0.3 \mathrm{mbar})$ treatment at $100^{\circ} \mathrm{C}$ for increasing kinetic energies of photoelectrons, i.e. decreasing surface sensitivity. Spectra were measured at $175 \mathrm{eV}$ (cyan line), $350 \mathrm{eV}$ (magenta line), $600 \mathrm{eV}$ (dark yellow line) and $1000 \mathrm{eV}$ (purple line) kinetic energy of photoelectrons.

We exploited the energy tunability of synchrotron radiation to measure a depth profile of the sample. By generating photoelectrons of different kinetics energies, the sample could be probed at various depths. Figure 3.8 shows $\mathrm{Au} 4 \mathrm{f}$ and $\mathrm{O}$ 1s spectra measured using kinetic energies of 175, 350, 600 and $1000 \mathrm{eV}$. The $\mathrm{O} 1 \mathrm{~s}$ spectra intensity is normalized to the area of the corresponding metallic component $\mathrm{Au}^{0}$ in order to emphasize the variations in the total amount of oxygen. It can be clearly 
seen that the cationic $\mathrm{Au}$ feature and the $\mathrm{O}$ 1s peak are consistently less-pronounced for higher-KE photoelectrons, which originate from deeper layers of the $\mathrm{Au}$ foil. Moreover, the main peak at $83.95 \mathrm{eV}$ in the $\mathrm{Au} 4 \mathrm{f}$ is more symmetric at higher kinetic energies, which confirms the assignment of the low-BE components to surface related features. These measurements suggest that only the near-surface region of the $\mathrm{Au}$ foil is oxidized under $\mathrm{O}_{3}$ at mbar pressures; however, quantification of the depth-dependent measurements is required for a better assessment of the thickness of the oxide phase.

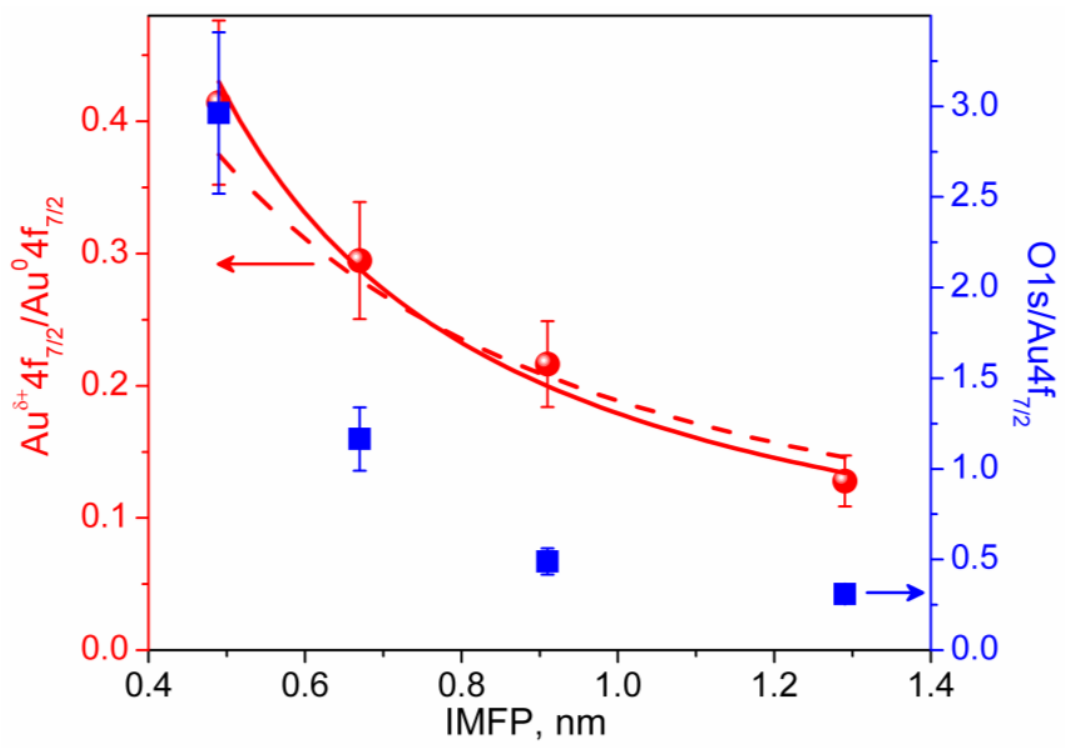

Figure 3.9. The area ratios between cationic $A u 4 f_{7 / 2}$ and $A u^{0} 4 f_{7 / 2}$ (red dots), $\mathrm{O} 1 \mathrm{~s}$ and $\mathrm{Au}^{0} 4 \mathrm{f}_{7 / 2}$ (blue squares) XPS peak as function of inelastic mean free path (IMPF) of Au. Fitting results, assuming an oxide over-layer completely (solid line) and 60\% (dash-dot line) covering the Au surface.

The mean escape depth for each measurement at different kinetic energies can be approximated using known values of the inelastic mean free path ${ }^{*}$ (IMFP) for Au [70], because there are no data about IMFP for $\mathrm{AuO}_{\mathrm{x}}$ in the literature. Depth profiles are constructed from the integrated XPS areas. Figure 3.9 shows the integrated peak areas of the $\mathrm{O} 1 \mathrm{~s}$ and cationic $\mathrm{Au}$ divided by the $\mathrm{Au}^{0}$ area as function of the average escape depth. The normalization by $\mathrm{Au}^{0}$ is necessary to remove the influence of elastic scattering in the gas phase that is also energy dependent. The thickness of the

* The IMFP is defined as the distance a photoelectron beam can travel inside the solid before its intensity decays to $1 / e$ of its initial value. 
oxide phase can be estimated by quantification of the depth profile using a simplified structural model consisting of a uniform oxide layer of thickness $t$ over a semiinfinite substrate $[60,81]$. Using known atomic densities and assuming the same IMFP for the metal and oxide, the unknown thickness $t$ can be obtained by fitting the experimental data.

For calculation we use the equation for semi-infinitive specimen, with uniform over-layer of thickness $t_{A}$ [81]. Suffixes $\mathrm{S}$ (support, $\mathrm{Au}^{0}$ ) and A (active over-layer, cationic $\mathrm{Au}$ ) are used to specify the nature of the atomic species. Over-layer/substrate ratio:

$$
\frac{N_{A}}{N_{S}}=\frac{F_{A} \rho_{A} \sigma_{A} \lambda_{A a}}{F_{S} \rho_{S} \sigma_{S} \lambda_{S a}} \times\left[1-\exp \left(-t_{A} / \lambda_{A a} \cos \theta\right)\right] \exp \left(t_{A} / \lambda_{S a} \cos \theta\right),
$$

where $F$, dependent on the emitted electron energy, includes several instrumental parameters; $\rho$, the atomic density; $\sigma$, the differential cross-section; $\lambda$, IMPF; where $\theta$ is the emission direction angle with respect to the surface normal. Equation 3.1 applies to several situations, including growth on metal [60].

In our calculation we use the following parameters: $F_{A u^{0}}=F_{A u^{\delta+}} ; \lambda_{A u^{0}}=$ $\lambda_{A u^{\delta+}} ; \sigma_{A u^{0}}=\sigma_{A u^{\delta+}} ; \rho_{A u^{0}}=5.9 * 10^{22}$ atom $/ \mathrm{mol} ; \rho_{A u^{\delta+}}=3.09 * 10^{22}$ atom $/ \mathrm{mol}$; $\theta=0^{\circ}$. By assuming the oxide over-layer completely covers the Au surface, a good fit was obtained (solid line in Figure 3.9) and gave a value of $t=0.29 \pm 0.02 \mathrm{~nm}$. However, similar models with incomplete coverage of the surface by the oxide phase (patches) also result in reasonable fittings within the experimental errors, resulting in larger values for the thickness. In the extreme case of $60 \%$ coverage (dash-dot line in the Figure 3.9), the derived over-layer thickness increases to $0.58 \mathrm{~nm}$ (lower coverages do not result in reasonable fittings). Comparing these values to the shortest Au-O distance of $0.201 \mathrm{~nm}$ in the $\mathrm{Au}_{2} \mathrm{O}_{3}$ structure (most stable bulk Au-oxide) or the smaller axis of its unit cell of $0.404 \mathrm{~nm}$ [82], it is reasonable to conclude the formation of a surface oxide phase during the oxidation of a $\mathrm{Au}$ surface with $\mathrm{O}_{3}$ at mbar pressures.

The area ratio in both depth profile curves in Figure 3.9 decays exponentially with escape depth; however, the oxygen curve (blue squares) decays much faster than the cationic Au when probing deeper into the sample. This observation suggests the presence of an additional adsorbed oxygen over-layer that totally or partially covers the surface oxide layer/patches. 


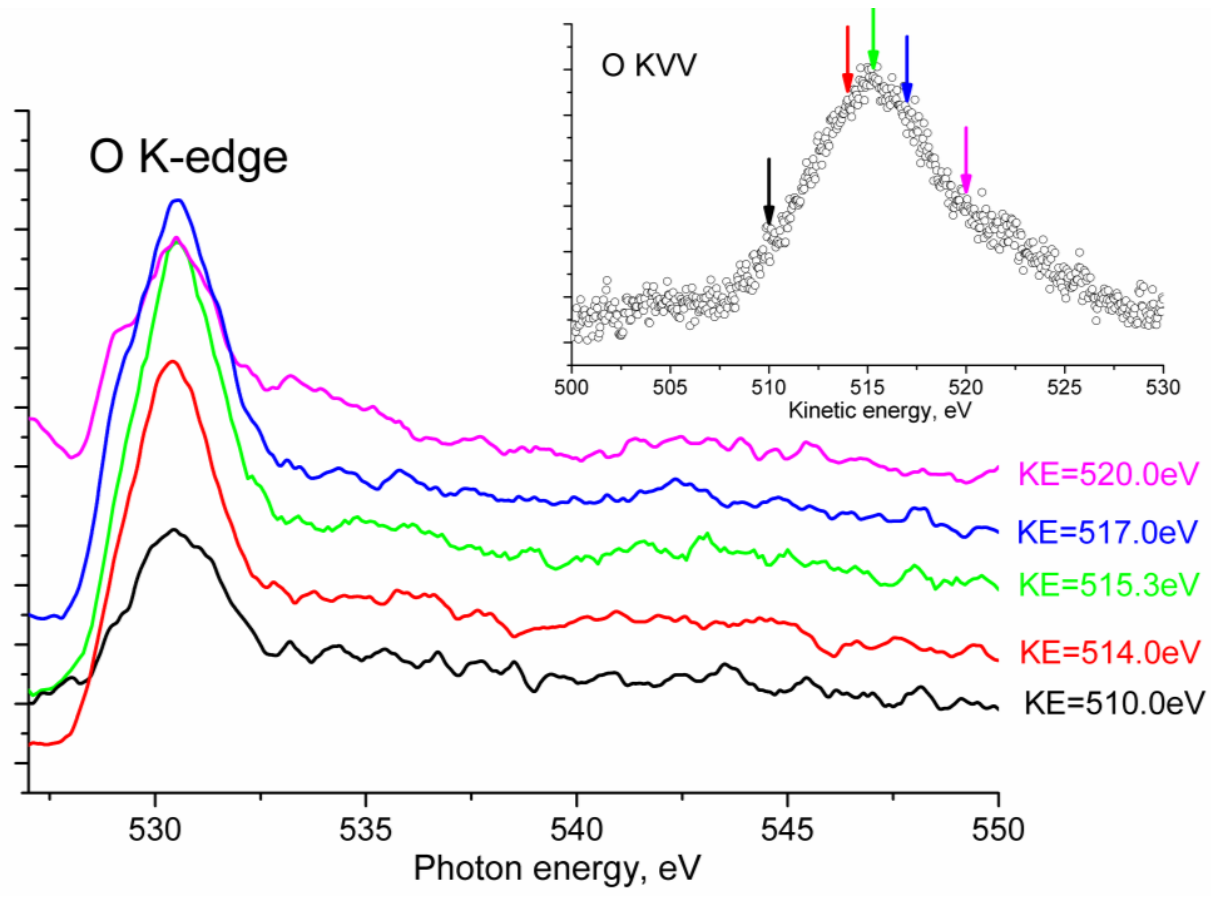

Figure 3.10. $\mathrm{O} K$-edge absorption spectra measured in Auger yield mode in $\mathrm{O}_{3}+\mathrm{O}_{2}$ at 0.3 mbar and $100{ }^{\circ} \mathrm{C}$.

To reveal different oxygen species on the surface $\mathrm{O} K$-edge absorption spectra were measured (Figure 3.10). Auger yield mode was chosen as the most surface sensitive mode. Unfortunately all spectra look similar and the signal from the oxygen gas phase dominates [83].

The limiting step in the oxidation of $\mathrm{Au}$ seems to be the production of atomic oxygen [25]. Since the dissociation probability of $\mathrm{O}_{2}$ is very small on $\mathrm{Au}$ surfaces [84], atomic oxygen must be supplied by other methods. Recent studies have clearly shown that $\mathrm{Au}$ can be readily oxidized when exposed to strong oxidative environments, such as $\mathrm{O}_{2}$-plasma and UV/ozone [72,85]. The formation of Au oxide has been reported, not only for nanoparticles [86,87], but also for extended $\mathrm{Au}$ surfaces, such as single-crystals [86] and polycrystalline thin films [73,76,89]. In our case, the ozone treatment at $100{ }^{\circ} \mathrm{C}$ resulted in the formation of a surface oxide phase with a thickness of 1-2 atomic layers, instead of the 3-4 $\mathrm{nm}$ thick plasma-oxidized thin films reported by others $[73,76,90]$.

This $\mathrm{Au}$ surface oxide is unstable under UHV conditions and in an $\mathrm{O}_{2}$ atmosphere at $100^{\circ} \mathrm{C}$, leaving a clean $\mathrm{Au}$ surface when $\mathrm{O}_{3}$ is removed (Figure 3.3(iii)), in agreement with a previous study [73]. However, under constant $\mathrm{O}_{3}$ 
exposure, the surface oxide is stable up to $250{ }^{\circ} \mathrm{C}$. In contrast, based on resistivity measurements, Tsai et al. [76] reported a decomposition half-life time of approximately $10 \mathrm{~min}$ for $4 \mathrm{~nm}$ Au-oxide films $\left(\mathrm{Au}_{2} \mathrm{O}_{3}\right)$ at $100{ }^{\circ} \mathrm{C}$ in air. The stability of the surface oxide under an $\mathrm{O}_{3}$-containing atmosphere suggests that the surface oxide is in dynamic equilibrium with the gas environment. The constant supply of atomic oxygen, provided in this case by $\mathrm{O}_{3}$ dissociation, counteracts the spontaneous decomposition and the surface oxide that prevails at higher temperatures. The surface-limited oxidation, observed in our conditions, might be related to this competition between oxidation and reduction/decomposition, and would kinetically limit the oxide growth. This model system under dynamic equilibrium is more representative of a practical catalytic system than static phases under UHV. In the real catalyst, atomic $\mathrm{O}$ might be supplied by the oxide support or by direct dissociation of $\mathrm{O}_{2}$ at the kinks or steps of nanoparticles. It is worth mentioning that we did not observe any $\mathrm{X}$-ray-induced oxidation of $\mathrm{Au}$, as has been previously reported by P. Jiang et al. [91], most likely due to the lower photon flux density in our case that limits beam-induced chemistry. The broad $\mathrm{O} 1 \mathrm{~s}$ and cationic $\mathrm{Au}$ peaks suggest that the surface oxide is most likely not a single, long-range, ordered phase, but might consist of multiple oxygen species. For example, in the Ag$\mathrm{O}$ system, the co-existence of different oxygen species has been predicted by theory [92] and experimentally verified [93,94]. Similar conclusions - i.e. that several Au$\mathrm{O}$ species can be generated by kinetic control of the oxidation conditions - were drawn by Ming and Friend after reviewing several studies about the oxidation of $\mathrm{Au}$ [25].

One of the most controversial aspects of the mechanism of $\mathrm{CO}$ oxidation on nano-structured $\mathrm{Au}$ catalysts is the source of atomic oxygen. While some authors suggest that a spillover of lattice oxygen from reducible oxide supports is the source of atomic oxygen, others point to the direct dissociation of $\mathrm{O}_{2}$ at low-coordination sites on the surface of Au nanoparticles $[25,87]$. The additional surface core-level shift component, related to the restructuring that is observed during ozone treatment in our XP spectra, (Figure 3.3A(ii)) indicate the formation of low-coordinated atoms on the $\mathrm{Au}$ surface during oxidation. Similar spectral features were previously observed for stepped single-crystal surfaces [77] with a clear correlation between the 
coordination number of atoms at steps and terraces with the measured surface corelevel shift for $\mathrm{Au}(321)$ and $\mathrm{Au}(310)$ crystals. The surface roughening observed by SEM after the $\mathrm{O}_{3}$ treatment (Figure 3.7) indicates extensive surface restructuring during oxidation, and might have generated the low-coordinated atoms that we had inferred from the XPS analysis. Surface restructuring induced the formation of $\mathrm{Au}$ ad-atoms and clusters on a $\mathrm{Au}(111)$ surface was directly observed by STM after atomic oxygen exposure, generated by electron-induced $\mathrm{NO}_{2}$ dissociation [95].

\subsubsection{CO oxidation on Au foil.}

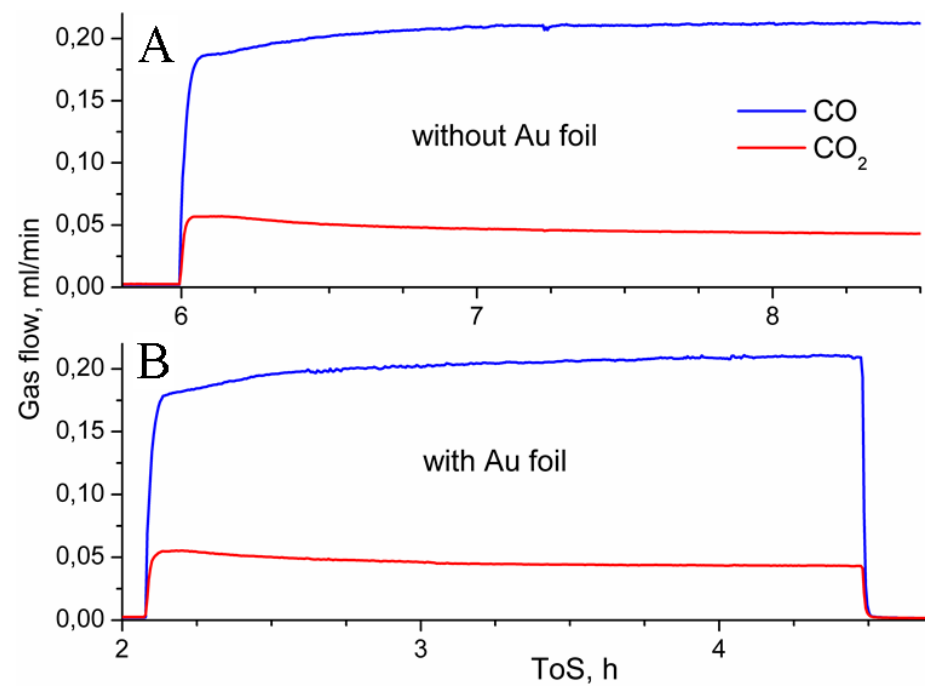

Figure 3.11. The change of the reaction mixture $\left(\mathrm{CO} / \mathrm{O}_{2}+\mathrm{O}_{3}=1 / 20\right)$ with time a) without $\mathrm{Au}$ foil and b) using $\mathrm{Au}$ foil as catalyst at $0.3 \mathrm{mbar}$ and $100{ }^{\circ} \mathrm{C}$.

Catalytic properties of $\mathrm{Au}$ foil were tested in $\mathrm{CO}$ oxidation reaction. The gas mixture ratio was $\mathrm{CO} / \mathrm{O}_{2}+\mathrm{O}_{3}=1 / 20$, temperature was $100{ }^{\circ} \mathrm{C}$ and was kept constant during reaction. $\mathrm{CO}$ was introduced to the NAP-XPS chamber when $\mathrm{O}_{2}+\mathrm{O}_{3}$ flow was already provided.

Figure 3.11A shows changes of the reaction mixture with time measured on $\mathrm{Au}$ foil. When CO comes in the chamber the corresponding signal increases in QMS. Simultaneously with $\mathrm{CO}$ yield the signal of $\mathrm{CO}_{2}$ increases and remains constant for two hours, it decreases to zero just when CO flow is stopped.

Obvious changes happen with $\mathrm{Au} 4 \mathrm{f}$ photoelectron spectra in reaction mixture (Figure 3.12A). The cationic Au component disappears when the $\mathrm{CO} / \mathrm{O}_{2}+\mathrm{O}_{3}$ mixture 
is introduced; even presence of $\mathrm{O}_{3}$ in gas mixture is not enough to reoxidized $\mathrm{Au}$ foil. At the same time metallic component at $84 \mathrm{eV}$ recovers and is the same as in UHV after oxidation (Figure 3.2). After $6 \mathrm{~min}$ in reaction mixture $\mathrm{O} 1 \mathrm{~s}$ spectrum (Figure 3.12B) shows only residual amount of oxygen, thus $\mathrm{CO}$ reduces oxidized foil in presence of $\mathrm{O}_{2}+\mathrm{O}_{3}$ mixture, which may lead to initial increase of $\mathrm{CO}_{2}$ production.
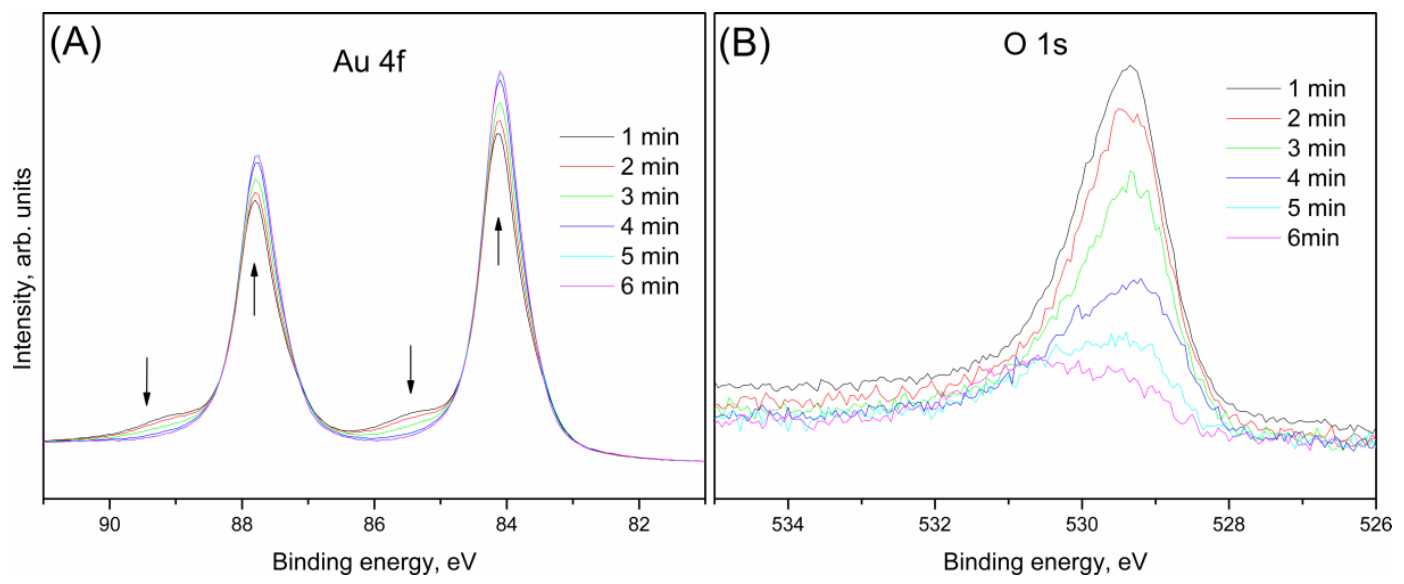

Figure 3.12. Evolution of $\mathrm{Au} 4 \mathrm{f}(\mathrm{A})$ and $\mathrm{O}$ 1s (B) photoelectron spectra (using 700 $\mathrm{eV}$ kinetic energy photoelectrons) from gold foil at $0.3 \mathrm{mbar}$ and $100^{\circ} \mathrm{C}$ in reaction mixture $\left(\mathrm{CO} / \mathrm{O}_{2}+\mathrm{O}_{3}=1 / 20\right)$ with time.

When the same reaction was repeated without Au sample in the chamber (blank reaction) the profile of the gas mixture did not change (Figure 3.11B). The intensity of the signals of $\mathrm{CO}$ and $\mathrm{CO}_{2}$ is independent of presence of $\mathrm{Au}$ foil in the chamber, several reasons can cause to this result: 1) reaction yield is below detection limit of the equipment; 2) background reaction dominates; 3 ) no $\mathrm{CO}$ oxidation on gold foil.

\subsubsection{Clean and oxidized Au powder.}

Since $\mathrm{Au}$ foil does not show any activity in $\mathrm{CO}$ oxidation at low temperature, we decide to use Au powder to increase surface area of catalyst, which allows making sure that the $\mathrm{CO}_{2}$ yield is not below detection limit of the equipment. $\mathrm{Au}$ powder ( $<45 \mu, 99.95 \%$ purity) was pressed to a pellet before mounting on a sapphire sample holder between a stainless steel back-plate and a lid and was loaded to the NAP-XPS chamber subsequently. The experimental parameters used were the same as for Au foil (see Chapter 3.1.1). 


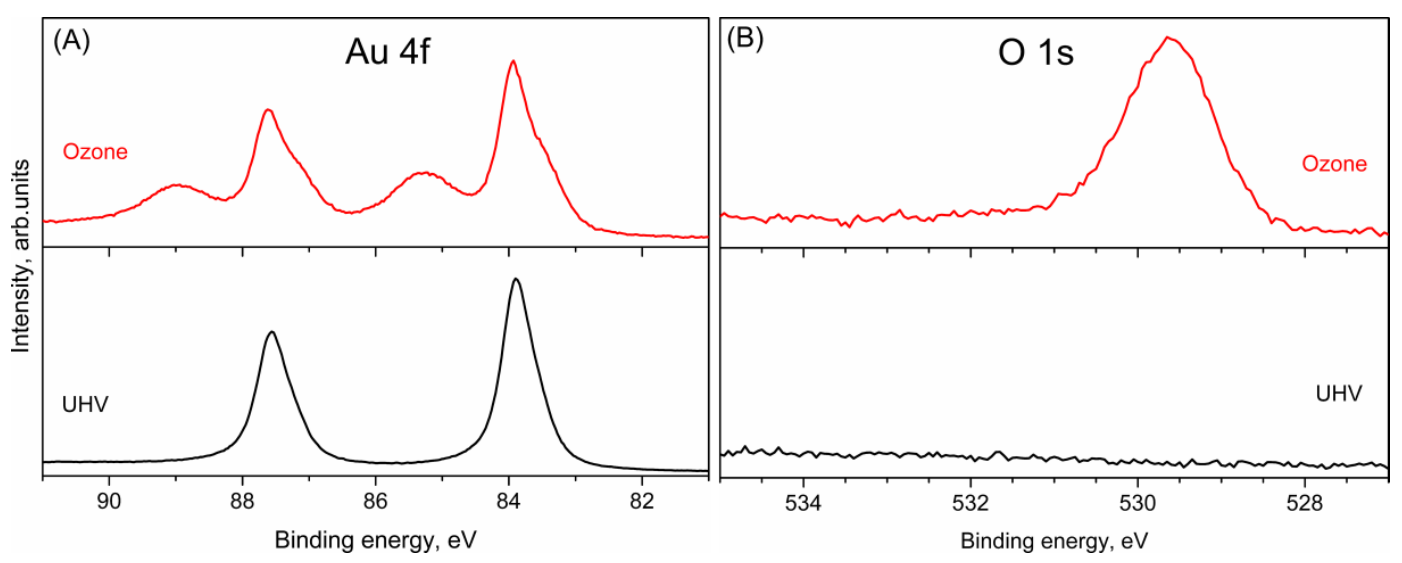

Figure 3.13. $\mathrm{Au} 4 \mathrm{f}(\mathrm{A})$ and $\mathrm{O} 1 \mathrm{~s}(\mathrm{~B})$ photoelectron spectra (using $150 \mathrm{eV}$ kinetic energy photoelectrons) of a gold powder at $100^{\circ} \mathrm{C}$ in UHV (bottom) and ozone $(0.3$ mbar) (top).

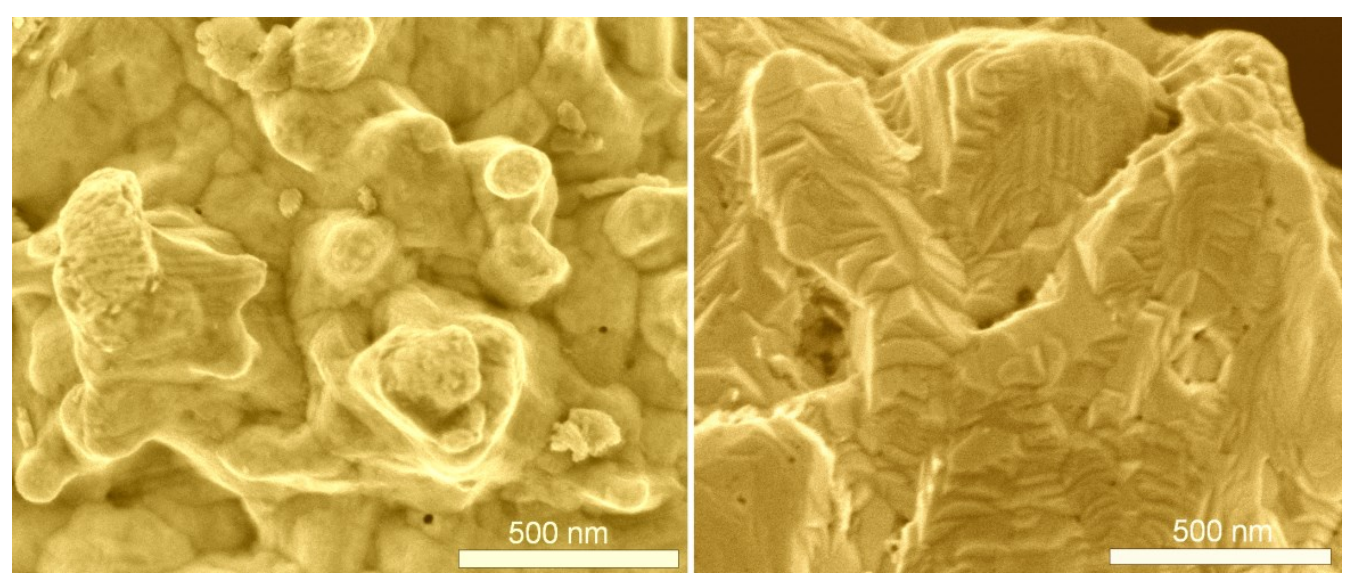

Figure 3.14. $\mathrm{SEM}$ image before (left) and after (right) $\mathrm{O}_{3}(0.3 \mathrm{mbar})$ treatment at $100^{\circ} \mathrm{C}$ showing restructuring of the gold powder surface.

The gold powder was cleaned by $\mathrm{Ar}^{+}$sputtering to remove possible contamination from the surface. Au 4f spectrum of clean powder (Figure 3.13(A)) replicates the shape of the spectrum of clean gold foil (Figure 3.2(A)). O 1s spectrum does not show any sign of oxygen species (Figure 3.13(B)) when measured in UHV.

Both spectra change immediately in ozone environment (Figure 3.13(top)). A well-defined broad peak of cationic Au species [73,76] appears at $85.2 \mathrm{eV}$ in $\mathrm{Au} 4 \mathrm{f}$, which is assigned to ionic Au species. The metallic peak (BE 83.95) [71-73] is more asymmetric to low binding energy region, which corresponds to surface core level shift $[74,75]$. Also high intensity peak arises at $529.4 \mathrm{eV}$ in $\mathrm{O} 1 \mathrm{~s}$ spectrum. Therefore 
the behavior of oxidized $\mathrm{Au}$ powder is similar to $\mathrm{Au}$ foil and all results obtained for $\mathrm{Au}$ foil can be extrapolated to Au powder.

After $\mathrm{O}_{3}$ exposure the restructurings of the Au powder can be observed in exsitu SEM image (Figure 3.14). The shape of particles before $\mathrm{O}_{3}$ treatment is roundish, while kinks and edges are visible after $\mathrm{O}_{3}$ exposure. Thus we have a lot of low-coordinated atoms on the surface after oxidation.

\subsubsection{CO oxidation on Au powder.}

Catalytic properties of $\mathrm{Au}$ powder were tested in $\mathrm{CO}$ oxidation reaction using the similar condition as for Au foil in NAP-XPS chamber.

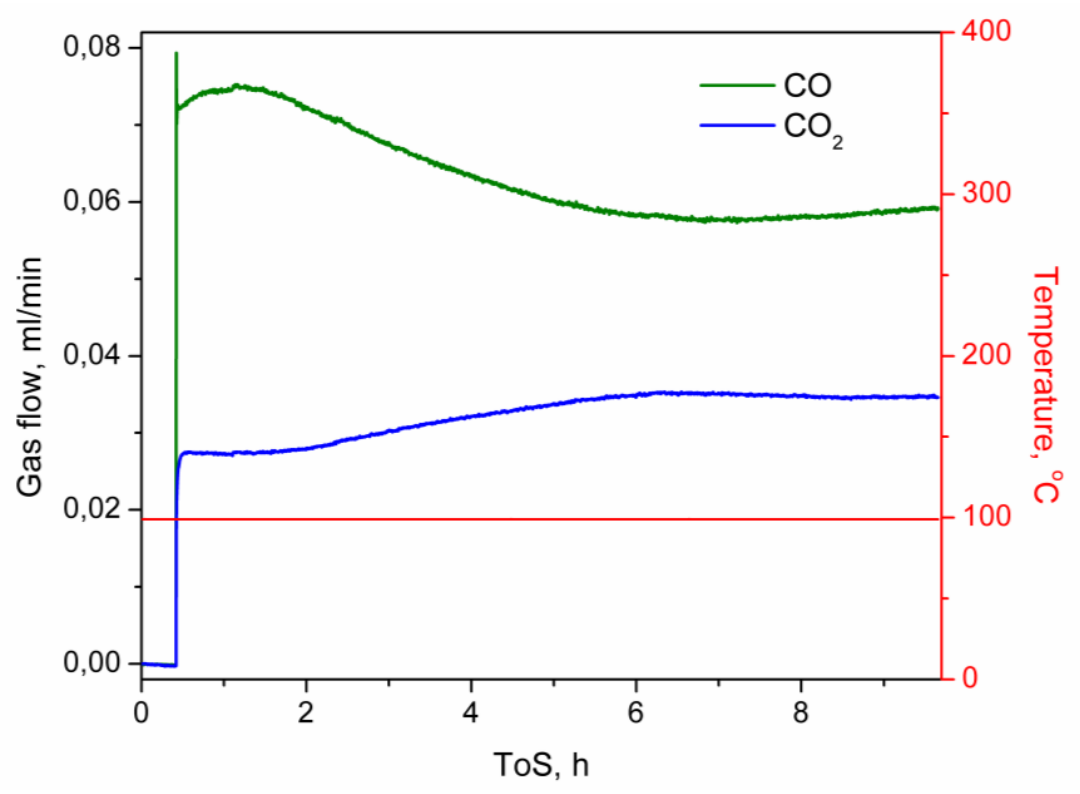

Figure 3.15. The changes of the reaction mixture $\left(\mathrm{CO} / \mathrm{O}_{2}+\mathrm{O}_{3}=1 / 80\right)$ with time using Au powder as catalyst at $0.3 \mathrm{mbar}$ and $100^{\circ} \mathrm{C}$.

Figure 3.15 shows changes of the reaction mixture with time using Au powder as catalyst. In the beginning the QMS signals of $\mathrm{CO}$ and $\mathrm{CO}_{2}$ increase when $\mathrm{CO}$ was introduced in the chamber. After 1 hour approximately $\mathrm{CO}_{2}$ signal grows slowly and reach plateau after 6 hours, $\mathrm{CO}$ signals shows opposite trend at the same time. This behavior clearly shows presence of reaction in the chamber.

During $\mathrm{CO}$ oxidation $\mathrm{Au} 4 \mathrm{f}_{7 / 2}$ and $\mathrm{O} 1 \mathrm{~s}$ photoelectron spectra were measured to monitor changes of Au surface (Figure 3.16). We see that after 5 minute exposition in reaction mixture (Figure 3.16 bottom) the Au surface is still oxidized as evidence 
by the presence of cationic $\mathrm{Au}$ species at $85.2 \mathrm{eV}$ in $\mathrm{Au} 4 \mathrm{f}$ spectrum and broad peak in $\mathrm{O} 1 \mathrm{~s}$. Further exposition shows decreasing of cationic Au component and after 6.5 hours it is totally vanished, that coincide in time with changes of $\mathrm{CO}_{2}$ flow in QMS. However oxygen species are still visible in $\mathrm{O}$ 1s spectrum (Figure 3.16 top) after oxide decomposition, the shape of the peak is more asymmetric and it is shifted to low binding energy region.

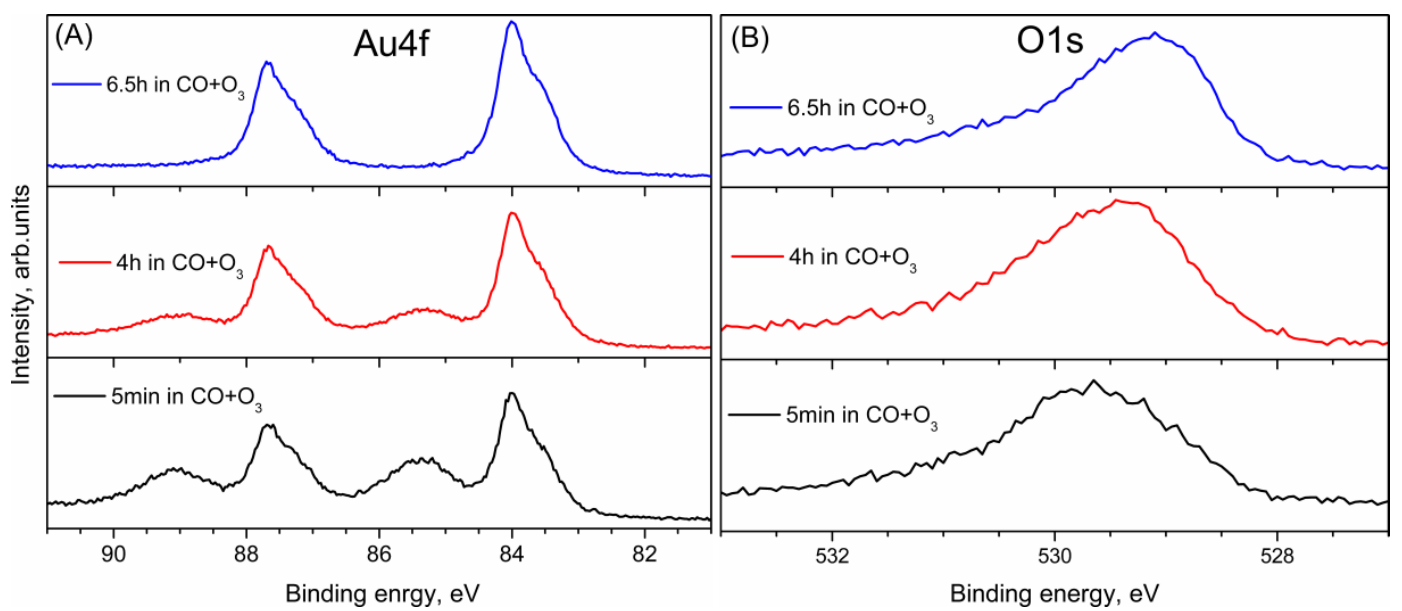

Figure 3.16. In-situ Au 4f (left) and O 1s (right) photoelectron spectra (using $150 \mathrm{eV}$ kinetic energy photoelectrons) of gold powder at $100^{\circ} \mathrm{C}$ during $\mathrm{CO}$ oxidation at 0.3 mbar.

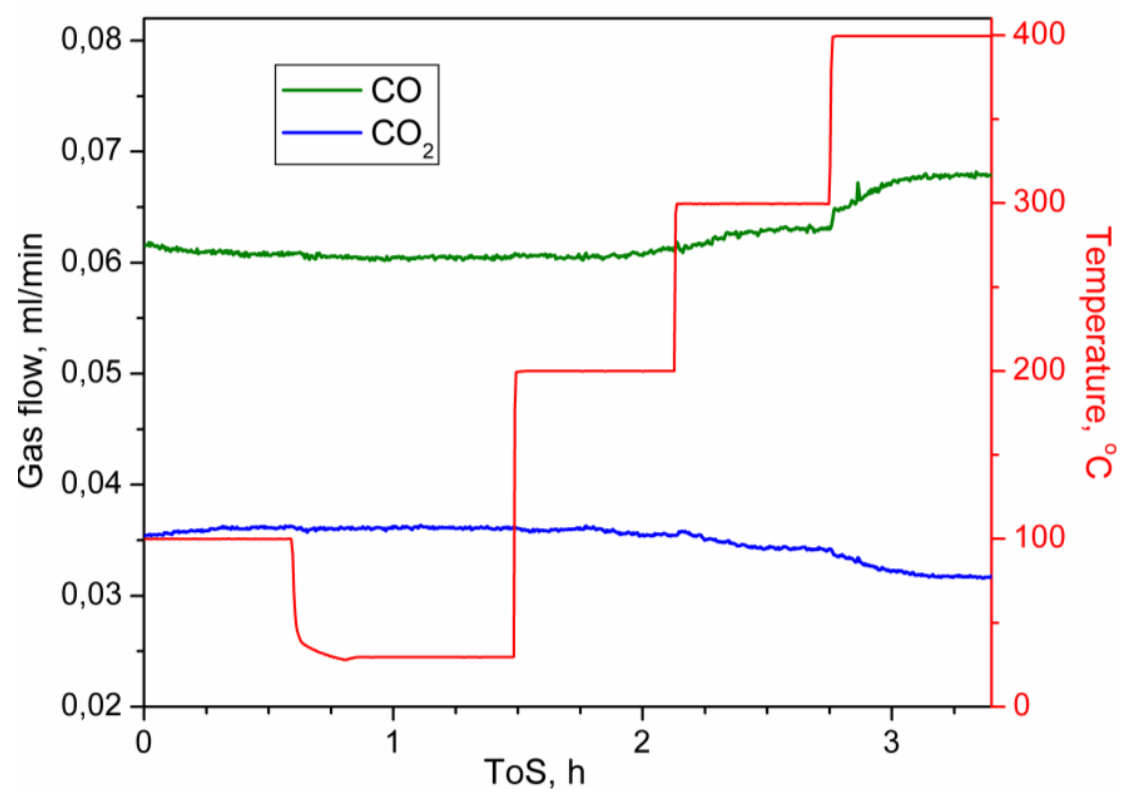

Figure 3.17. CO oxidation on Au powder at 0.3 mbar and different temperature. 


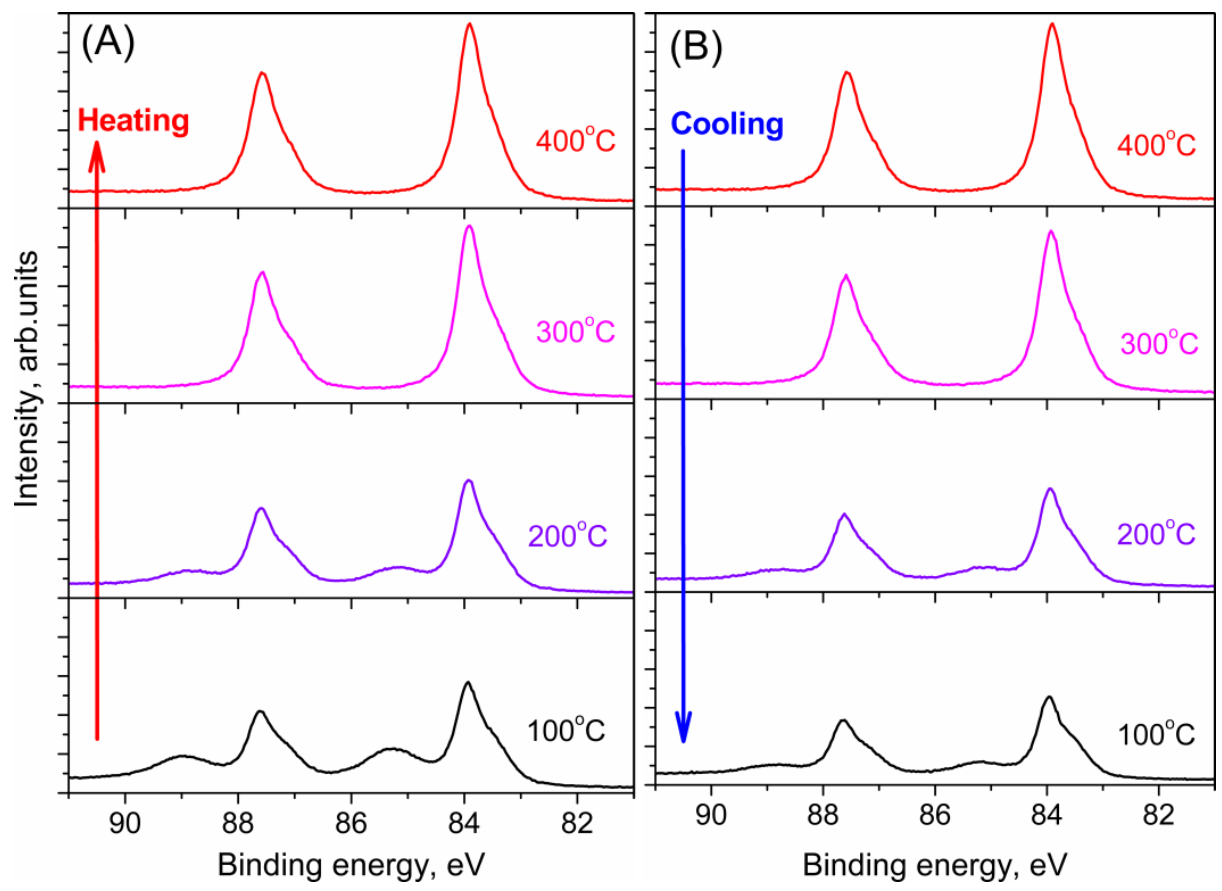

Figure 3.18. Au $4 \mathrm{f}$ photoelectron spectra $(\mathrm{h} v=270 \mathrm{eV})$ from gold powder during heating (A) and cooling (B) at various temperatures measured at 0.3 mbar and $\mathrm{CO} / \mathrm{O}_{2}+\mathrm{O}_{3}=1 / 80$.

To study $\mathrm{CO}$ oxidation on $\mathrm{Au}$ powder in detail the reaction temperature was varied (Figure 3.17). From room temperature to $200{ }^{\circ} \mathrm{C}$, variations of $\mathrm{CO}_{2}$ flow are tiny. At $300^{\circ} \mathrm{C}$ the conversion of $\mathrm{CO}$ to $\mathrm{CO}_{2}$ decreases, further temperature increasing leads to reduction of $\mathrm{CO}_{2}$ rate. The changes happen only when the temperature is tuned and then the flows are kept stable. Therefore performance of CO oxidation depends on temperature, it decreases with temperature. XP spectra of $\mathrm{Au}$ powder (Figure 3.18) show similar behavior to Au foil (Figure 3.4) during heating and cooling.

Since CO oxidation at different temperature does not shed light on active sites of $\mathrm{Au}$, it was decided to vary the gas mixture. In Figure $3.19 \mathrm{CO}$ oxidation $\left(\mathrm{CO} / \mathrm{O}_{2}+\mathrm{O}_{3}=1 / 80\right)$ on Au powder with and without $\mathrm{O}_{3}$ in gas mixture is shown.

High conversion of $\mathrm{CO}$ is observed in $\mathrm{O}_{3}$ containing atmosphere. After 1.5 hours the ozone generator was switched off, that did not change pressure in the chamber. Evacuating $\mathrm{O}_{3}$ from the gas mixture leads to slow decreasing of $\mathrm{CO}_{2}$ yield and $\mathrm{CO}_{2}$ signal does not reach minimum after 1 hour. The explanation can be the following: the residual $\mathrm{O}_{3}$ in the Teflon tube still comes in the chamber even after the 
generator is switched off. When ozone generator was switched on again-occurring at a ToS of 2.7 hours in Figure $3.19-\mathrm{CO}_{2}$ signal reaches initial value immediately. This experiment shows that $\mathrm{O}_{3}$ reacts with $\mathrm{CO}$ very well. The temperature dependence in the Figure 3.17 becomes clear, because $\mathrm{O}_{3}$ is not stable compound at high temperature [96]. The less $\mathrm{O}_{3}$ concentration in the mixture, the less $\mathrm{CO}$ conversion.

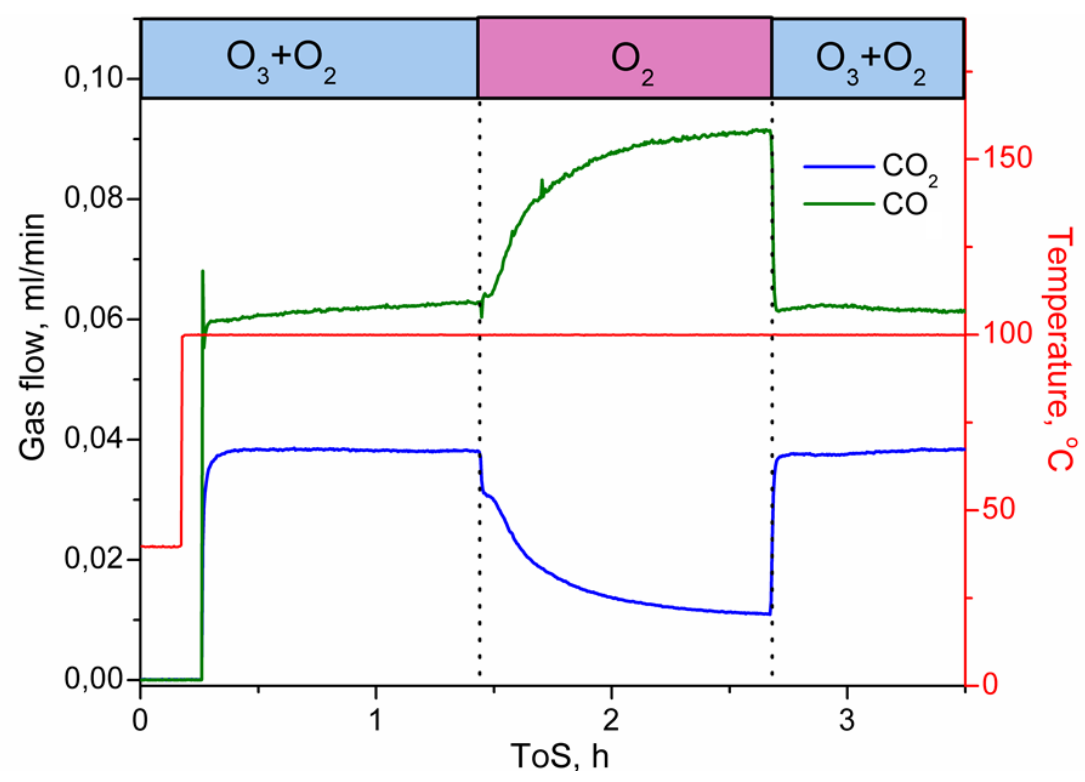

Figure 3.19. $\mathrm{CO}$ oxidation $\left(\mathrm{CO} / \mathrm{O}_{2}+\mathrm{O}_{3}=1 / 80\right)$ on $\mathrm{Au}$ powder with and without $\mathrm{O}_{3}$ at 0.3 mbar and $100{ }^{\circ} \mathrm{C}$.

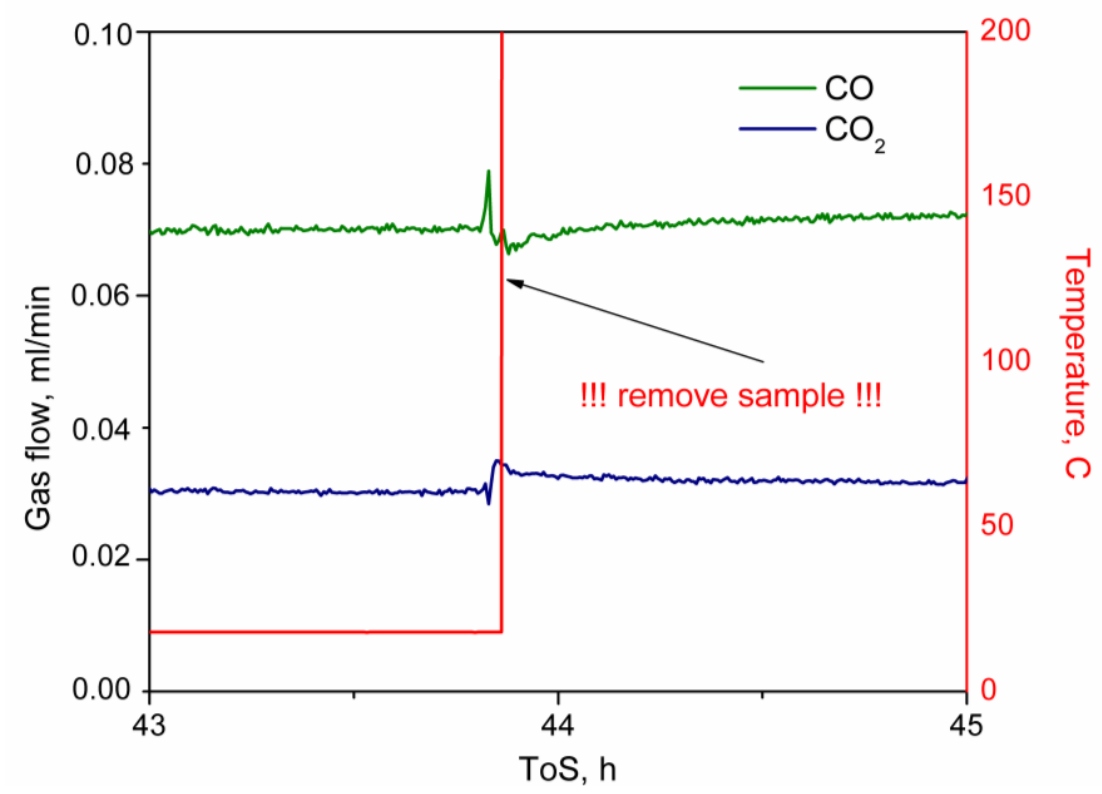

Figure 3.20. Gas mixture changes while removing Au powder out of the chamber. 
The role of $\mathrm{Au}$ powder in $\mathrm{CO}$ oxidation is still unclear; therefore the simple test was done. The sample containing Au powder was removed from the chamber without stopping the reaction (Figure 3.20). No difference in the gas yield, so we conclude that background reaction dominates and the role of Au powder is negligible.

\subsubsection{Conclusions.}

The obtained spectroscopy and microscopy results can be interpreted by the restructuring of the Au surface as reported by others, suggesting the presence of lowcoordinated atoms on the surface of the Au foil after ozone treatment. However, it should be stressed that the presence of such proposed active sites for molecular oxygen dissociation does not prevent the disappearance of the Au-oxide when $\mathrm{O}_{3}$ is removed at $100^{\circ} \mathrm{C}$. Although, the low-coordinated atoms may have an enhanced interaction strength with surrounding molecules, and still might play a role in $\mathrm{O}_{2}$ adsorption at room temperature, our results do not show that they enhance $\mathrm{O}_{2}$ dissociation. This observation suggests that low-coordinated Au sites alone might not dissociate molecular oxygen as efficiently at room temperature [32,95] or the number of active sites was not sufficient to compensate for the thermal decomposition of the oxide, unlike the case of $\mathrm{O}_{3}$ dissociation.

From the results presented we suggest the following picture of the system goldozone under a constant chemical potential of $\mathrm{O}_{3}$. The surface consists of an overlayer of oxygen being chemisorbed on a surface oxide by a thickness of $0.29 \mathrm{~nm}$. This layer may be presented as a tri-layer oxygen-gold-oxygen with a region of oxygen atoms diffusing in deeper layers with decreasing probability. The formation of the surface oxide mobilized gold atoms leading to a significant restructuring of the surface and the frequent formation of coordinatively undersaturated species, which leads to shape changes in the $\mathrm{Au} 4 \mathrm{f}$ spectra. These species may be responsible for holding the atomic oxygen at the surface. Whereas the restructuring remains upon lowering the chemical potential of oxygen to vacuum levels, the absorbed oxygen species and also the surface oxide vanish even at $100^{\circ} \mathrm{C}$ indicating that the heat of adsorption and heat of formation respectively are small even in the presence of the 
massive restructuring. This sheds light on the energetic consequences of the formation of coordinatively undersaturated gold species.

We prefer such a picture of a laterally homogeneous multi-layer architecture over the alternative of laterally inhomogeneous patches of different surface oxide species as the SEM image does not reveal indications for extensive lateral inhomogeneity. 


\subsection{Au nanoparticles on oxygen-free support.}

\subsubsection{Au/HOPG.}

It was shown in the previous chapters, that extended Au surfaces are inactive in $\mathrm{CO}$ oxidation reaction, even after oxidation. But physical and catalytic properties of Au change with size reduction to nanometer. In the last decade, Au NPs, particularly below $5 \mathrm{~nm}$ in size, attracted attention for unique catalytic properties [97-99]. Since real catalysts are very complex system a lot of factors, such as size, support, method of synthesis, etc., may influence their performance. Therefore, systematic studies of these parameters are necessary. In the present thesis Au on oxygen-free support were chosen as model catalyst with no Au-support interaction to study the catalytic properties of nanosized Au.

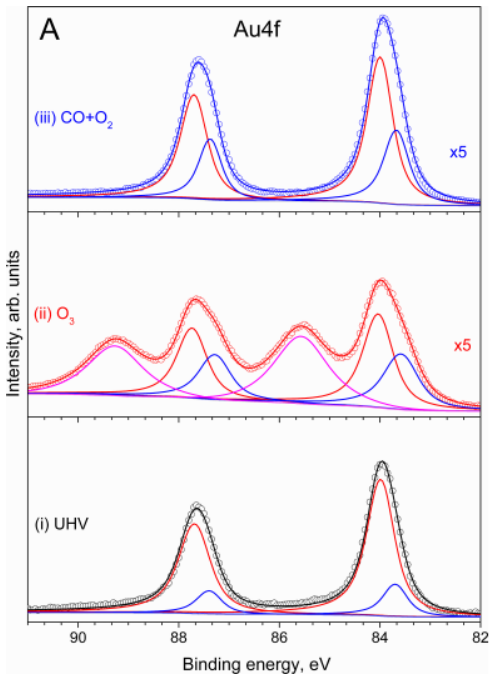

Figure 3.21. NAP (a) Au 4f, (b) O 1s and (c) C 1s XP spectra of Au/HOPG (i) in $\mathrm{UHV}$ at RT, (ii) under $\mathrm{O}_{3}$ at 0.3 mbar, $100{ }^{\circ} \mathrm{C}$ and (iii) under $\mathrm{CO}$ and $\mathrm{O}_{2}$ $\left(\mathrm{CO}: \mathrm{O}_{2}=1: 75\right)$ atmosphere at $0.3 \mathrm{mbar}, \mathrm{RT}$.

Model Au/HOPG (highly oriented pyrolytic graphite) catalysts were prepared inside a preparation chamber attached to a photoelectron spectrometer (Novosibirsk, Russia) which was built by SPECS (Germany). The analyzer chamber was equipped with a hemispherical analyzer PHOIBOS-150-MCD-9, an ellipsoidal monochromator FOCUS 500 and an X-ray source XR $50 \mathrm{M}$ with double Al/Ag 
anode. The three-step preparation procedure, previously used to prepare $\mathrm{Ag} / \mathrm{HOPG}$ model catalysts, as described in detail elsewhere [100], was used to prepare $\mathrm{Au} / \mathrm{HOPG}$ model catalysts. This procedure consists of an initial stage of defect formation on the HOPG surface by soft $\mathrm{Ar}^{+}$sputtering followed by $\mathrm{Au}$ deposition and surface annealing at $\mathrm{T}=300{ }^{\circ} \mathrm{C}$ in UHV (for $\mathrm{Au}$ NPs stabilization). The $\mathrm{Au}$ nanoparticle size was varied by changing the amount of deposited gold, which was controlled by monitoring the ratio of $\mathrm{Au} 4 \mathrm{f}$ to $\mathrm{C} 1 \mathrm{~s}$ XPS peak areas.

The first step to study the Au catalyst is to characterize the freshly prepared samples. Photoelectrons with $150 \mathrm{eV}$ kinetic energy were used to collect surface sensitive $\mathrm{Au} 4 \mathrm{f}, \mathrm{O} 1 \mathrm{~s}$ and $\mathrm{C} 1 \mathrm{~s}$ spectra in $\mathrm{UHV}$ and $\mathrm{CO}+\mathrm{O}_{2}$, and photons with $720 \mathrm{eV}$ energy were used to collect $\mathrm{Au} 4 \mathrm{f}, \mathrm{O} 1 \mathrm{~s}$ and $\mathrm{C}$ 1s spectra during $\mathrm{O}_{3}$ treatment (Figure 3.21). Au $4 \mathrm{f}$ spectrum of the fresh Au/HOPG in UHV at RT (Figure 3.21A(i)) shows one sharp peak at a binding energy (BE) of $83.95 \mathrm{eV}$, assigned to bulk $\mathrm{Au}$ in the metallic state, according to the literature [71-73]. The component shifted to low BE by the $0.3 \mathrm{eV}$ is assigned to low-coordinated $\mathrm{Au}$ atoms [74,75,77]. The corresponding $\mathrm{O}$ 1s spectrum shows the presence of oxygen on the surface (Figure $3.21 \mathrm{~B}(\mathrm{i}))$. The asymmetry of $\mathrm{O} 1 \mathrm{~s}$ peak indicates that there are more than just one oxygen specie and the position of its maximum (BE 532.6 eV) suggests the presence of $\mathrm{C}-\mathrm{O}, \mathrm{C}=\mathrm{O}$ and/or $\mathrm{C}-\mathrm{OH}$ bonds $[101,102]$. C 1s spectrum (Figure 3.21C(i)) shows well-known graphite peak at BE of $284.3 \mathrm{eV}$ [103].

When the $\mathrm{O}_{2} / \mathrm{O}_{3}$ mixture was introduced into the chamber and the sample was heated to $100{ }^{\circ} \mathrm{C}$, the $\mathrm{Au} 4 \mathrm{f}$ spectrum changed (Figure 3.21A(ii)). A well-defined peak appears at $85.6 \mathrm{eV}$, which is assigned to an ionic Au species [73,76]; however, with lower $\mathrm{BE}$ than that of $\mathrm{Au}_{2} \mathrm{O}_{3}(\mathrm{BE} 85.9 \mathrm{eV})$ [89,104]. Under $\mathrm{O}_{3}$ the numbers of low coordinated $\mathrm{Au}$ atom increasing, this is evidenced by an increase and broadening in low BE peak at $83.5 \mathrm{eV}$. According to Weststrate et al. [77] the less neighbors the lower $\mathrm{BE}$, in other words an oxidation restructures $\mathrm{Au}$ surface and forms lowcoordinated $\mathrm{Au}$ atoms (for example edges, kinks, etc.) on the surface. The surface sensitive $\mathrm{O}$ 1s spectrum (Figure $3.21 \mathrm{~B}(\mathrm{ii})$ ) is broader in comparison with one measured in UHV. The $\mathrm{O} 1 \mathrm{~s}$ spectrum in $\mathrm{O}_{3}$ atmosphere consists of at least two components: the high $\mathrm{BE}$ species are associated with carbon-oxygen species or $\mathrm{OH}$ groups (BE $532.6 \mathrm{eV}$ ) while the low $\mathrm{BE}$ component corresponds to oxygen on $\mathrm{Au}$ 
(BE 530.1 eV) [73,85]. A decrease in the intensity of $\mathrm{C} 1 \mathrm{~s}$ spectrum (Figure $3.21 \mathrm{C}(\mathrm{ii}))$ is due to decrease of inelastic mean free path of photoelectron in oxygen compared to UHV.

Table 3.2. Surface composition of $\mathrm{Au} / \mathrm{HOPG}$ at different conditions.

\begin{tabular}{|c|c|c|c|c|}
\hline & $\mathbf{A u}^{\mathbf{0}}, \mathbf{\%}$ & $\mathbf{A u}^{\mathbf{3 +}}, \mathbf{\%}$ & $\mathbf{O}, \mathbf{\%}$ & $\mathbf{C ,} \mathbf{\%}$ \\
\hline $\mathrm{UHV}$ & 16.5 & - & 5.0 & 78.5 \\
\hline $\mathrm{O}_{3}$ & 7.4 & 4.6 & 9.5 & 75.5 \\
\hline $\mathrm{CO}+\mathrm{O}_{2}$ & 8.0 & - & 10.3 & 81.7 \\
\hline
\end{tabular}

As was shown in Chapter 3.1, all signs of gold oxide vanish when $\mathrm{O}_{3}$ is evacuated from the chamber. Even an $\mathrm{O}_{2}$-rich gas mixture $\left(\mathrm{CO} / \mathrm{O}_{2}=1: 75\right)$ does not prevent the decomposition of the oxide (Figure 3.21(iii)). In contrast to the changes found for extended $\mathrm{Au}$ surfaces exposed to ozone [105], the $\mathrm{Au} 4 \mathrm{f}$ spectral shape of $\mathrm{Au}$ NPs remains unchanged after $\mathrm{O}_{3}$ treatment (Figure 3.21A(iii)). The low BE components of the $\mathrm{Au} 4 \mathrm{f}$ spectra does not change much, only small intensity decrease, which can be due to sintering or/and carbon accumulation (Figure 3.21C(iii)). Consistently, the peak shape of the $\mathrm{O} 1 \mathrm{~s}$ spectrum returns to nearly the same shape as when measured in UHV, but with a slightly broader width due to the formation of new carbon-oxygen species. Note that only oxygen bonding to the carbon remains on the surface.
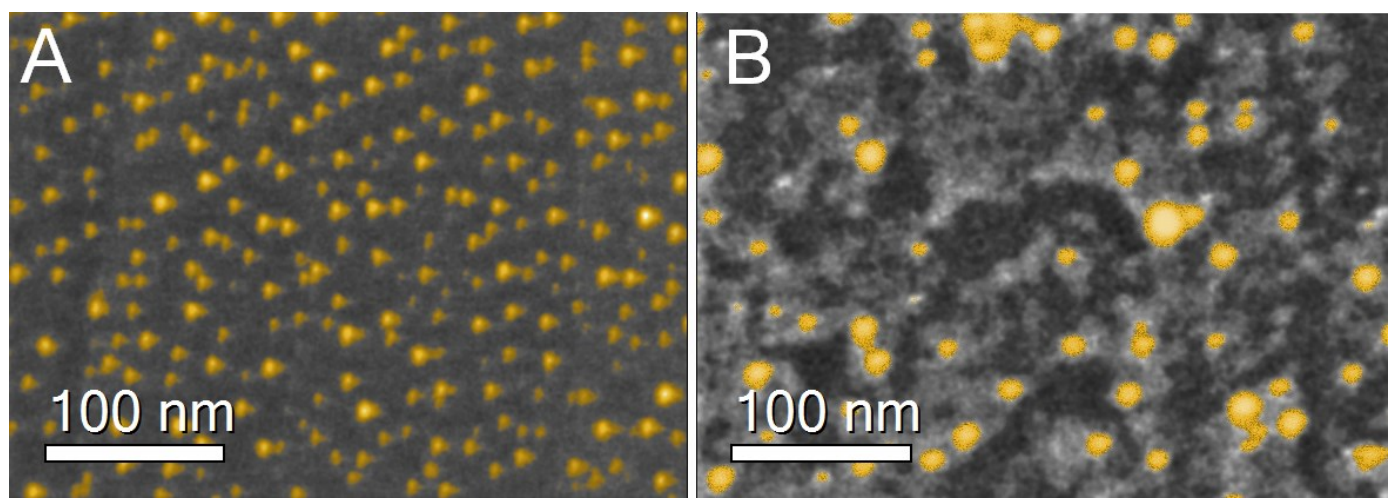

Figure 3.22. SEM image of $\mathrm{Au} / \mathrm{HOPG}$ a) before and b) after $\mathrm{O}_{3}$ treatment at $250{ }^{\circ} \mathrm{C}$ and $\mathrm{CO}$ oxidation at 0.3 mbar. Images were colorized in order to highlight the differences between the two samples. 
The quantitative analysis of surface composition is presented in Table 3.2. The dominant element on the surface obviously is carbon at all conditions. The amount of $\mathrm{Au}$ on the untreated sample is $16.5 \%$. $\mathrm{O}_{3}$ treatment leads to oxidation of ca. $30 \%$ of $\mathrm{Au}$ and significant increasing of oxygen concentration. Decreasing of $\mathrm{Au}$ concentration during and after $\mathrm{O}_{3}$ treatment points out, that the sintering takes place.

The structural evolution of Au NPs during CO oxidation may help to shed light on the origin of $\mathrm{Au}$ activation. An SEM image of the untreated $\mathrm{Au} / \mathrm{HOPG}$ is presented in Figure 3.22A. The image shows Au NPs with a narrow size distribution of 6-8 nm. After $\mathrm{O}_{3}$ treatment and $\mathrm{CO}$ oxidation, the Au NPs are not homogenously distributed anymore, as shown in Figure 3.22B. The mean parrticle size is higher $(\sim 10 \mathrm{~nm})$ than the fresh sample and some agglomerated particles are visible, which is in good agreement with quantification of the surface composition made by XPS. Burning of graphite at the interface with the Au NPs is accompanied by the migration of metallic particles on the HOPG surface (the tracks are darker in Figure 3.22B). This may occur because the aggressive oxidation by $\mathrm{O}_{3}$ leads to high mobility of $\mathrm{Au}$ NPs due to destruction (burning and oxidation) of carbon surface [106].

To estimate catalytic performance Au/HOPG sample was placed in the NAPXPS chamber without any pretreatment. Then the reaction mixture $\left(\mathrm{CO}: \mathrm{O}_{2}=1: 75\right)$ was introduced to the chamber (Figure 3.23A). Small fluctuations of CO flow are due to fluctuations of the MFC at very low flow. Initially, the $\mathrm{CO}_{2}$ yield exhibits a small increase for a short time: we attribute this activity to a reaction between $\mathrm{CO}$ and residual $\mathrm{O}$ on the HOPG surface. For long time on stream, Au/HOPG does not show any significant activity under the described conditions, therefore we reason that size reduction is not sufficient to activate $\mathrm{Au}$.

We tried to slightly oxidize $\mathrm{Au}$ before the reaction, using an $\mathrm{O}_{3}$ treatment. QMS data is presented in Figure 3.23B, in which Au NPs that were pre-treated with $\mathrm{O}_{3}$ are exposed to a constant flow of a 1:75 mixture of $\mathrm{CO}$ and $\mathrm{O}_{2}$. The activity of the oxidized sample is much higher than that of the sample not pre-treated with $\mathrm{O}_{3}$, but a strong deactivation takes place, and after approximately 2 hours the $\mathrm{CO}_{2}$ yield is negligible. Thus the aglomeration does not influence the activity of Au/HOPG, suggesting that other reasons apart of the structural changes are responsible of the 
activation of $\mathrm{Au}$ for $\mathrm{CO}$ oxidation. We assume that the increase of the $\mathrm{CO}_{2}$ yield after the $\mathrm{O}_{3}$ treatment is caused by the stoichiometric reaction between the remaining surface oxygen and $\mathrm{CO}$.
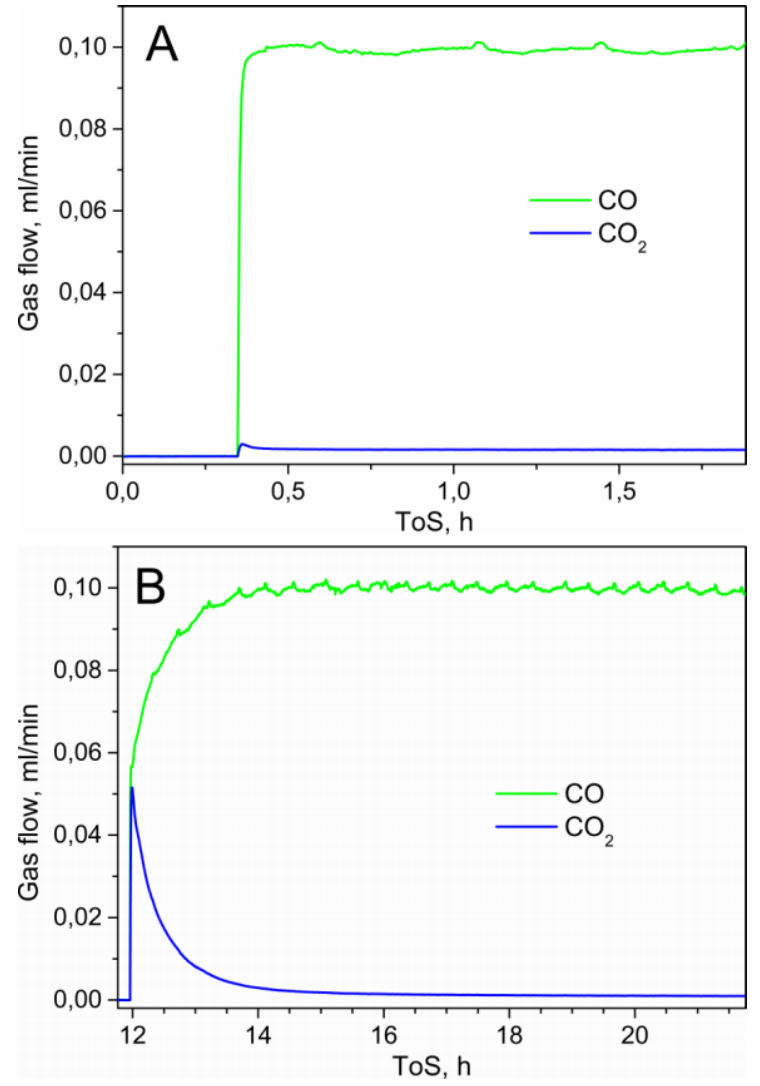

Figure 3.23. QMS data $\left(\mathrm{CO}: \mathrm{O}_{2}=1: 75\right)$ of $\mathrm{Au} / \mathrm{HOPG}$ a) before and $\left.\mathrm{b}\right)$ after $\mathrm{O}_{3}$ treatment at 0.3 mbar and RT.

\subsubsection{Au/N-CNTs and Au/O-CNTs.}

Multi-walled carbon nanotubes were supplied by Applied Science 1td. $20 \mathrm{~g}$ CNTs were treated with $1 \mathrm{~L}$ of concentrated $\mathrm{HNO}_{3}$ under reflux for $4 \mathrm{~h}$. Then the nanotubes were filtrated and washed with distilled water until the filtrate showed a neutral $\mathrm{pH}$. Subsequently, the sample was dried at $110{ }^{\circ} \mathrm{C}$ for $3 \mathrm{~d}$ in air. $\mathrm{N}$ functionalized carbon nanotubes $(\mathrm{N}-\mathrm{CNTs})$ were obtained via a treatment of the previously oxidized nanotubes with $\mathrm{NH}_{3}$ at $700{ }^{\circ} \mathrm{C}$ for $6 \mathrm{~h}$. For this purpose $3 \mathrm{~g}$ of the material were placed in a quartz tube under a flow of $120 \mathrm{ml} / \mathrm{min}$ composed of $10 \%$ $\mathrm{NH}_{3}$ in $\mathrm{Ar}$. 
$5 \mathrm{mg}$ of $\mathrm{NaN}_{3}$ were dissolved in $10 \mathrm{ml}$ of MilliQ water. Then $6 \mathrm{mg}$ of trihydrate chloroauric acid $\left(\mathrm{HAuCl}_{4} \cdot 3 \mathrm{H}_{2} \mathrm{O}\right)$ were added to the solution, which subsequently turned orange. The ratio $\mathrm{NaN}_{3} / \mathrm{HAuCl}_{4} \cdot 3 \mathrm{H}_{2} \mathrm{O}$ was 5:1. $300 \mathrm{mg}$ of N-CNTs were added to the solution in order to allow the adsorption of the Au precursor on the NCNTs with a final Au load of $1 \mathrm{wt} \%$. The addition of the N-CNTs induced gas release and caused the solution to turn colorless, indicating the decomposition and complete adsorption of the precursor. Afterwards, the N-CNT suspension was filtered and the total precursor decomposition was ensured by photo-treatment with an UV/Vis lamp for $30 \mathrm{~min}$.

$10 \mathrm{~g}$ Baytubes C150HP were treated with $500 \mathrm{~mL}$ of 3 molar $\mathrm{HNO}_{3}$ (diluted with water from nitric acid 65\% (Merck)) at room temperature (RT) for $24 \mathrm{~h}$. Then the O-functionalized CNTs (O-CNTs) were thoroughly washed and filtrated with Millipore water until a neutral $\mathrm{pH}$ was obtained. For the synthesis of $\mathrm{Au} / \mathrm{O}-\mathrm{CNTs}, 1$ $\mathrm{g}$ of O-CNTs was impregnated with $6 \mathrm{~mL}$ aqueous solution containing $20.2 \mathrm{mg}$ of $\mathrm{HAuCl}_{4}$. The slurry was then sonicated in an ultrasonic bath for $10 \mathrm{sec}$ and afterwards the solvent was evaporated slowly at RT in air for $48 \mathrm{~h}$. Thereafter, the samples containing the metal precursor were reduced in $20 \% \mathrm{H}_{2} / \mathrm{Ar}$ gas mixture at $250{ }^{\circ} \mathrm{C}$ for $2 \mathrm{~h}$, a final Au load was $1 \mathrm{wt} \%$.

The results obtained for Au NPs on nitrogen- and oxygen-functionalized carbon nanotubes $(\mathrm{Au} / \mathrm{N}-\mathrm{CNTs}$ and $\mathrm{Au} / \mathrm{O}-\mathrm{CNTs})$ are similar to $\mathrm{Au} / \mathrm{HOPG}$. The $\mathrm{Au}$ particle size was $<5 \mathrm{~nm}$. The Au NPs on functionalized CNTs consisted of a few large (ca. $40 \mathrm{~nm}$ diameter) particles, sparsely distributed along the tubes (Figure 3.24), along with a majority of densely dispersed nanoclusters visible only by scanning transmission electron microscopy (STEM) (Figure 3.25 and 3.26). In these images $\mathrm{Au}$ NPs are colorized in order to highlight the difference between CNTs and Au; in case of N-CNTs the Au NPs are atomic distributed, meanwhile Au NPs supported on O-CNTs are 2-3 $\mathrm{nm}$ in diameter. Under the same conditions, the fresh samples were inactive for $\mathrm{CO}$ oxidation as $\mathrm{Au} / \mathrm{HOPG}$, in spite of the significant increase of the catalyst surface area that resulted from the higher support area and Au size reduction. After $\mathrm{O}_{3}$ treatment, $\mathrm{Au} / \mathrm{N}-\mathrm{CNTs}$ and $\mathrm{Au} / \mathrm{O}-\mathrm{CNTs}$ show the same initial activity profile as discussed for $\mathrm{Au} / \mathrm{HOPG}$ and, the same rate of deactivation ( $\sim 2.5$ hours) (Figure 3.27). 


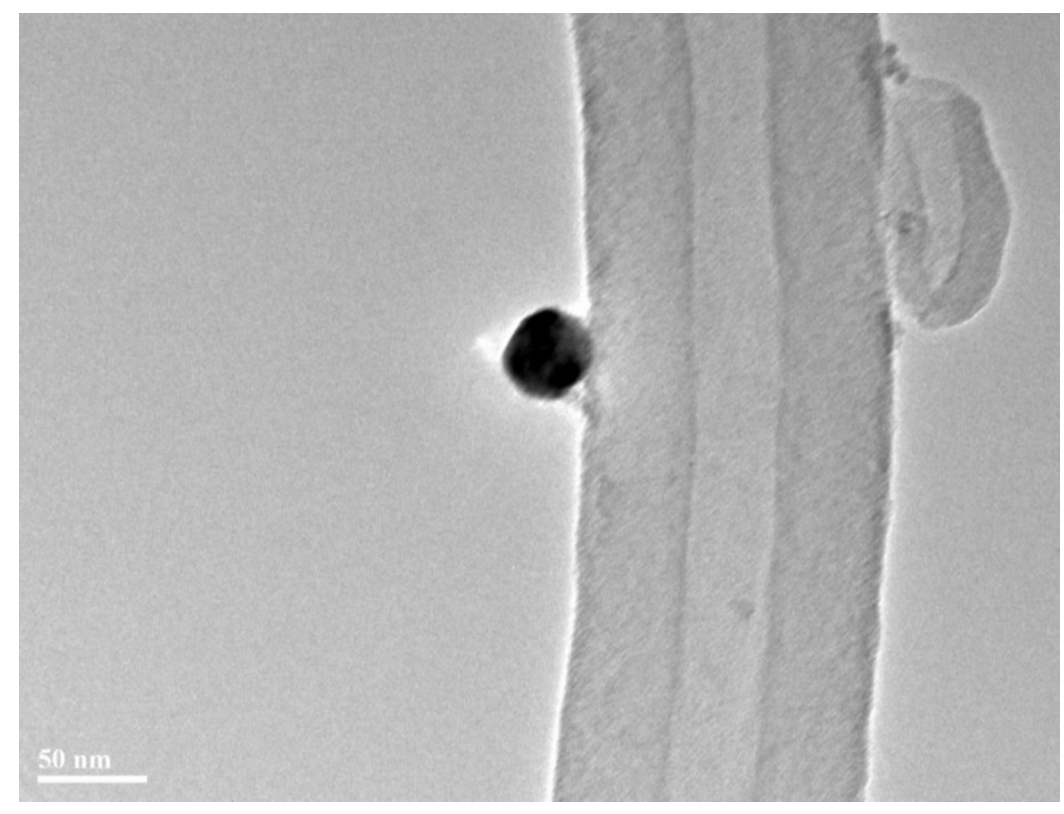

Figure 3.24. TEM image of large Au particle supported on N-CNT.

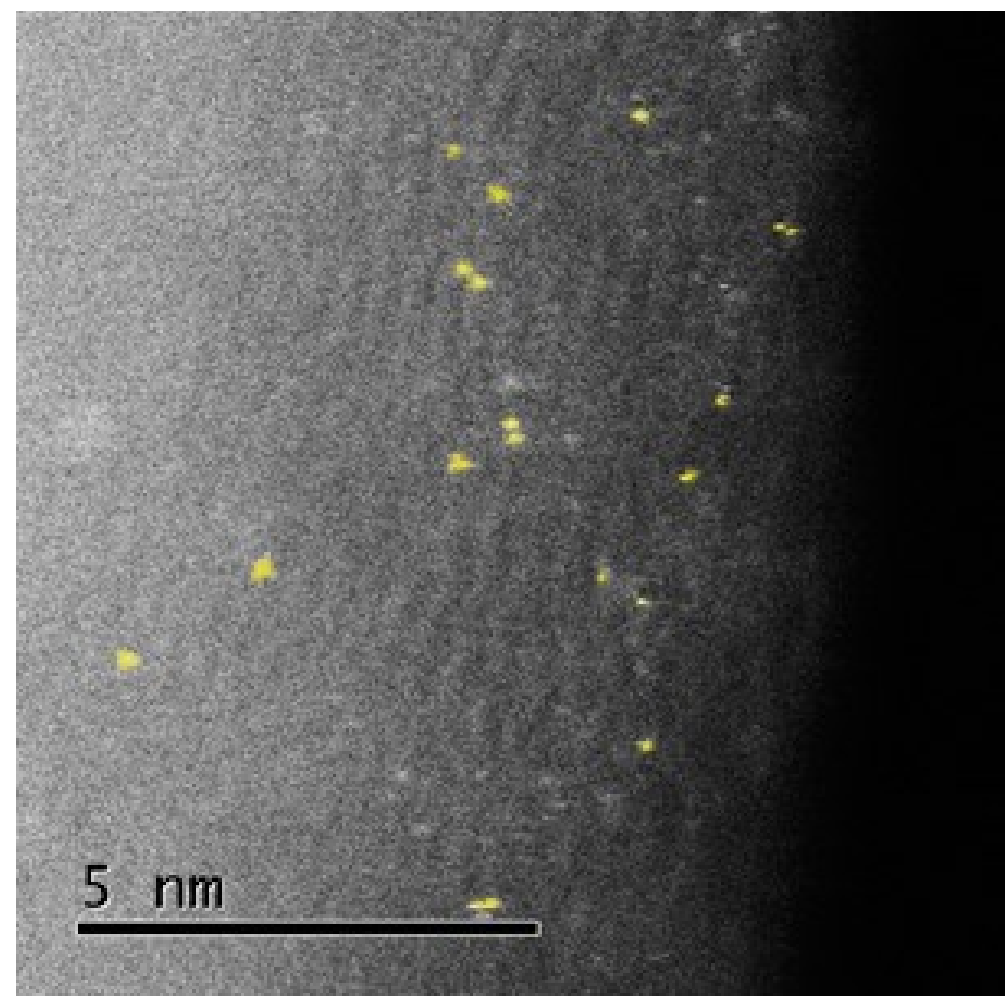

Figure 3.25. STEM image of fresh Au/N-CNTs. 


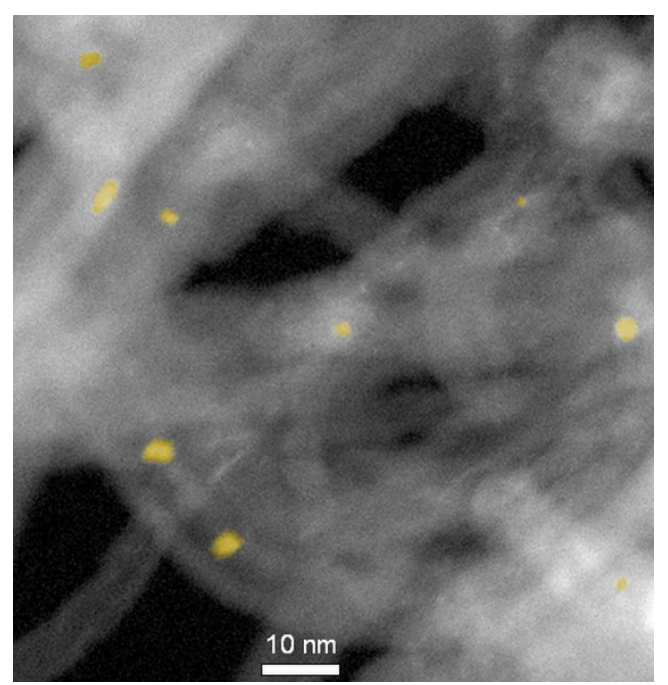

Figure 3.26. STEM images of fresh $\mathrm{Au} / \mathrm{O}-\mathrm{CNTs}$.

In order to exclude any pressure gap effects, Au-based samples were tested at 1 bar in mixture of $\mathrm{CO}$ and $\mathrm{O}_{2}\left(\mathrm{CO}: \mathrm{O}_{2}=2: 1\right)$ (Figure 3.28). At RT no activity was detected, even increasing the temperature to $473 \mathrm{~K}$ does not lead to any $\mathrm{CO}_{2}$ production. Thus, untreated (fresh) Au NPs supported on functionalized carbon nanotubes are totally catalytic inactive at low temperature in $\mathrm{CO}$ oxidation reaction.
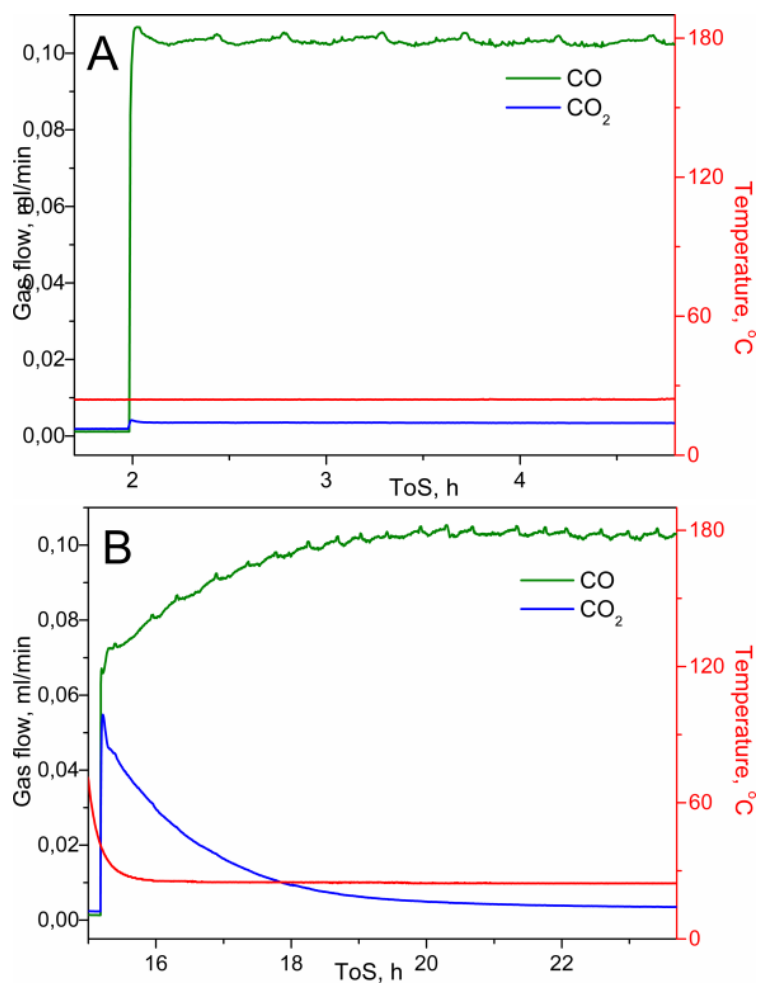

Figure 3.27. QMS data $\left(\mathrm{CO}: \mathrm{O}_{2}=1: 75\right)$ of $\left.\mathrm{Au} / \mathrm{O}-\mathrm{CNTs} \mathrm{A}\right)$ before and $\left.\mathrm{B}\right)$ after $\mathrm{O}_{3}$ treatment at 0.3 mbar and RT. 

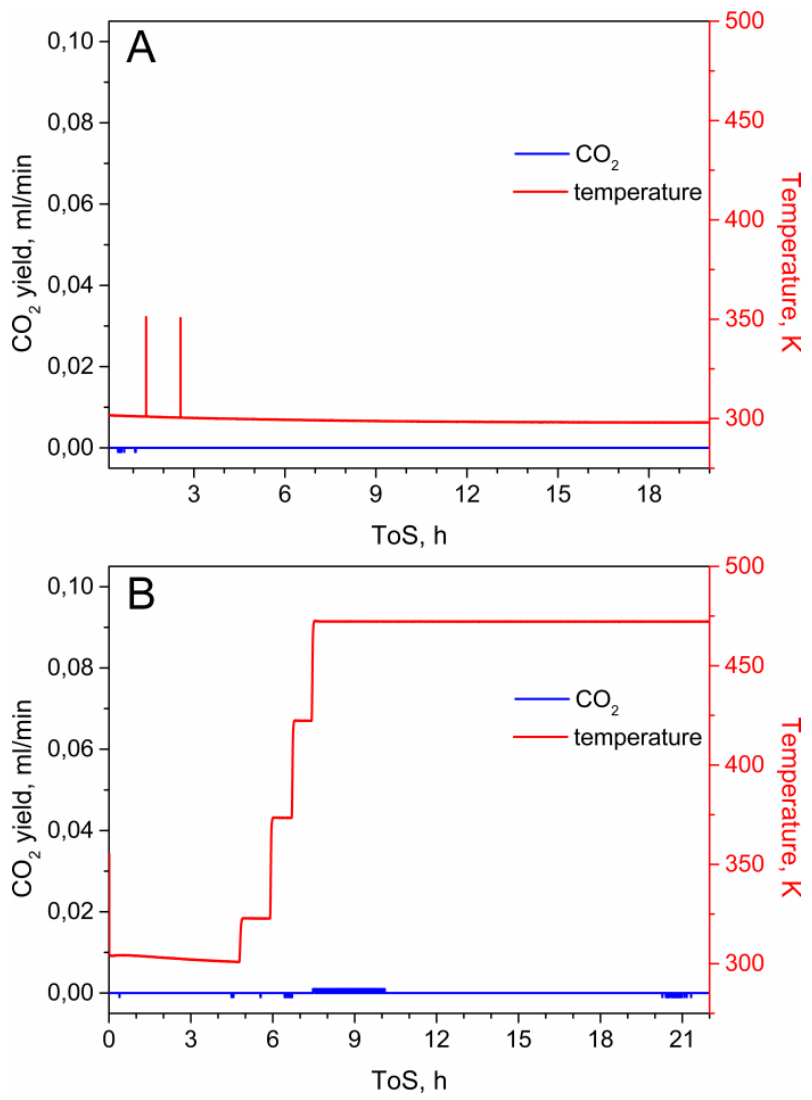

Figure 3.28. QMS data $\left(\mathrm{CO}: \mathrm{O}_{2}=2: 1\right)$ of a) $\mathrm{Au} / \mathrm{N}-\mathrm{CNTs}$ and b) $\mathrm{Au} / \mathrm{O}-\mathrm{CNTs}$ at 1 bar without any pretreatment.

\subsubsection{HOPG}

In order to prove that stoichiometric reaction takes place, 'blank' measurements were done. A pristine HOPG crystal was placed in the sample holder and all treatment procedures were repeated. Untreated HOPG does not catalyze the oxidation of $\mathrm{CO}$ as clearly shown in the Figure 3.29A. However after interaction with $\mathrm{O}_{3}$, HOPG demonstrates an initial high $\mathrm{CO}$ conversion that strongly decreases with time. After $\mathrm{O}_{3}$ treatment $\mathrm{Au} / \mathrm{HOPG}$ produces $1.68 \mathrm{ml}$ of $\mathrm{CO}_{2}$ in $2.4 \mathrm{~h}$ (Figure 3.23), while pure HOPG produces $1.63 \mathrm{ml}$ of $\mathrm{CO}_{2}$ in $2.4 \mathrm{~h}$ (Figure 3.29) after the same pretreatment. The difference is within error bar of the measurements. Since HOPG contains only carbon atoms, the origin of sample's activity can be attributed only to the stoichiometric reaction between chemisorbed oxygen on the HOPG surface and $\mathrm{CO}$ in the gas phase. 

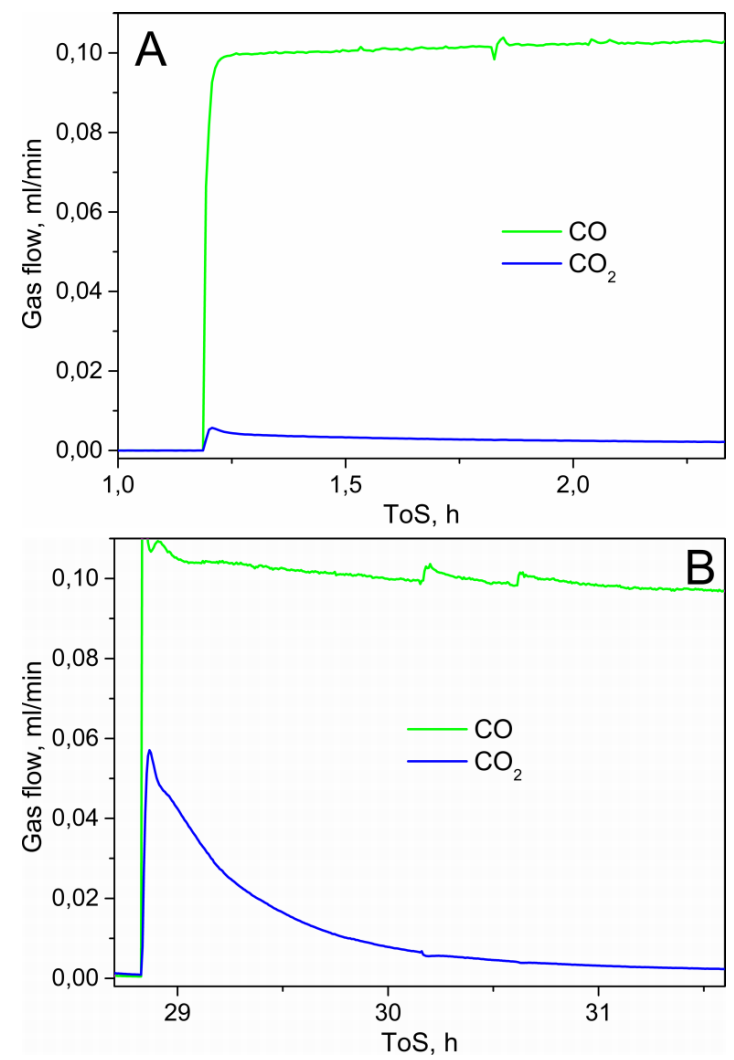

Figure 3.29. QMS data ( $\left.\mathrm{CO}: \mathrm{O}_{2}=1: 75\right)$ of $\left.\mathrm{HOPG} A\right)$ before and $\left.\mathrm{B}\right)$ after $\mathrm{O}_{3}$ treatment at 0.3 mbar and RT.

\subsubsection{Au/Au foil}

To further corroborate the idea that the reactivity is due to a stoichiometric reaction between $\mathrm{CO}$ and $\mathrm{O}$ functional groups on the carbon surface, we investigated $\mathrm{Au}$ nanoparticles supported on oxygen-free $\mathrm{Au}$ foil. The $\mathrm{Au}$ foil was chosen as a support because it is expected to be inactive in $\mathrm{CO}$ oxidation.

After preparation, the surface composition of the $\mathrm{Au} / \mathrm{Au}$ foil is very important. All fitting parameters are given in Tables 3.3 and 3.4. The corresponding $\mathrm{Au} 4 \mathrm{f}$ spectrum (Figure 3.30A(i)) of $\mathrm{Au} / \mathrm{Au}$ foil shows the metallic peak at a $\mathrm{BE}$ of 83.95 $\mathrm{eV}$ with second component shifted to the low BE by $0.3 \mathrm{eV}$. This peak is assigned to the surface core-level shift [74,75], which is ascribed mainly to the lower coordination of surface atoms compared to bulk atoms. The $\mathrm{O}$ 1s spectrum (Figure 3.30B(i)) displays one broad peak at $\mathrm{BE}$ of $532.5 \mathrm{eV}$, which is in the range observed for carbonates and oxygen-containing (hydro)carbons on gold [107]. The presence of 
carbonates and/or oxygen-containing (hydro)carbons on the surface is confirmed by the C 1s spectrum (Figure 3.30C(i)).

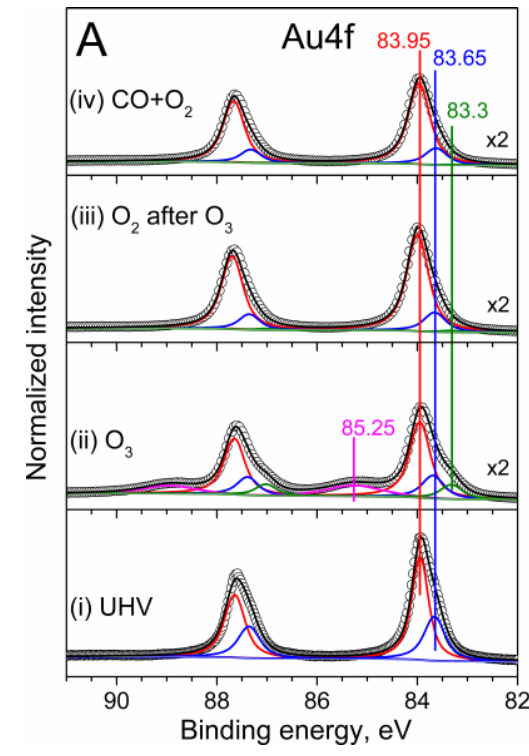

Figure 3.30. NAP (a) Au 4f,
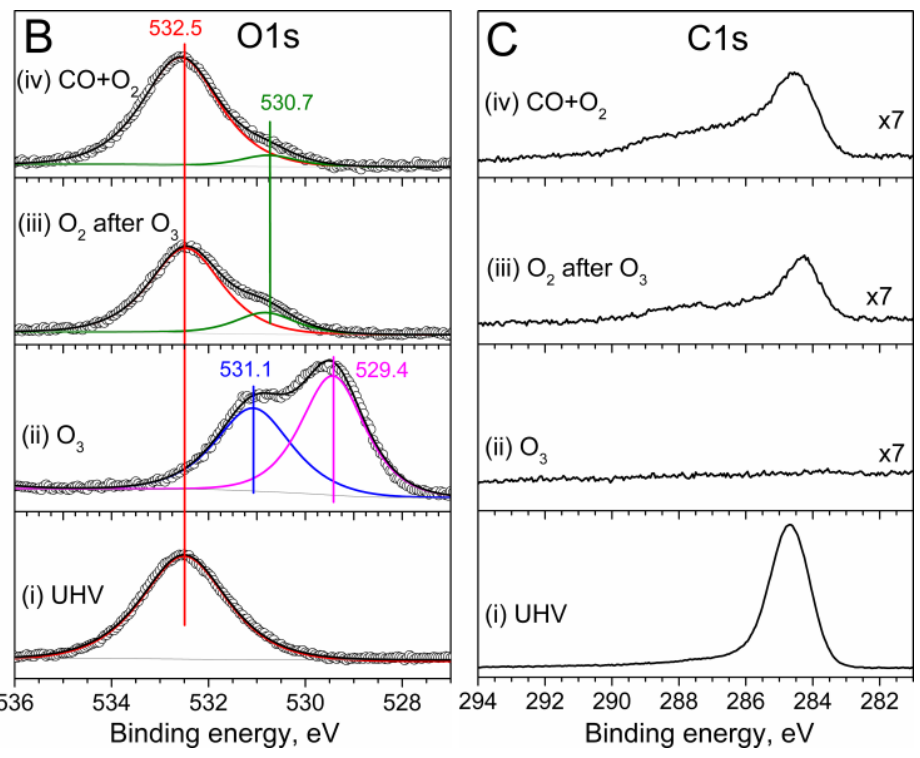

$\mathrm{UHV}$ at RT, (ii) under $\mathrm{O}_{3}$ at $0.3 \mathrm{mbar}, 150{ }^{\circ} \mathrm{C}$, (iii) under $\mathrm{O}_{2}$ after $\mathrm{O}_{3}$ treatment at 0.3 mbar, RT and (iv) under $\mathrm{CO}$ and $\mathrm{O}_{2}$ atmosphere $\left(\mathrm{CO}: \mathrm{O}_{2}=1: 75\right)$ at $0.3 \mathrm{mbar}$, RT.

Table 3.3. Fitting parameters of $\mathrm{Au} 4 \mathrm{f}_{7 / 2}$ spectra of $\mathrm{Au} / \mathrm{Au}$ foil.

\begin{tabular}{|c|c|c|c|c|c|c|c|c|}
\hline \multicolumn{9}{|c|}{$\mathrm{Au} \mathrm{4f_{7/2 }}$} \\
\hline & \multicolumn{2}{|c|}{ bulk } & \multicolumn{2}{c|}{ surface } & \multicolumn{2}{c|}{ restructuring } & \multicolumn{2}{c|}{ oxide } \\
\hline & $\begin{array}{c}\mathrm{BE} \\
(\mathrm{eV})\end{array}$ & $\begin{array}{c}\text { FWHM } \\
(\mathrm{eV})\end{array}$ & $\begin{array}{c}\mathrm{BE} \\
(\mathrm{eV})\end{array}$ & $\begin{array}{c}\text { FWHM } \\
(\mathrm{eV})\end{array}$ & $\begin{array}{c}\mathrm{BE} \\
(\mathrm{eV})\end{array}$ & $\begin{array}{c}\text { FWHM } \\
(\mathrm{eV})\end{array}$ & $\begin{array}{c}\mathrm{BE} \\
(\mathrm{eV})\end{array}$ & $\begin{array}{c}\text { FWHM } \\
(\mathrm{eV})\end{array}$ \\
\hline $\mathrm{UHV}$ & 83.95 & 0.49 & 83.66 & 0.50 & - & - & - & - \\
\hline $\mathrm{O}_{3}$ & 83.95 & 0.49 & 83.69 & 0.52 & 83.32 & 0.52 & 85.25 & 1.30 \\
\hline $\mathrm{O}_{2}$ after $\mathrm{O}_{3}$ & 83.98 & 0.51 & 83.65 & 0.52 & 83.34 & 0.52 & - & - \\
\hline $\mathrm{CO}+\mathrm{O}_{2}$ & 83.96 & 0.51 & 83.65 & 0.52 & 83.32 & 0.52 & - & - \\
\hline
\end{tabular}

To clean the $\mathrm{Au}$ surface from the surface carbon impurities, an $\mathrm{O}_{3}$ treatment at $150{ }^{\circ} \mathrm{C}$ was performed. When we apply the combination of high temperature (150 ${ }^{\circ} \mathrm{C}$ ) and very reactive treatment $\left(\mathrm{O}_{3}\right)$ the carbon is burned of very rapidly, as is clearly visible in the Figure 3.309C(ii). The influence of the $\mathrm{O}_{3}$ to the sample is not limited only to the burning of the carbon, but also the oxidation of the Au surface takes place. The corresponding $\mathrm{Au}$ 4f spectrum (Figure 3.30A(ii)) reveals the 
formation of $\mathrm{Au}$ oxide, the broad peak at $\mathrm{BE}$ of $85.25 \mathrm{eV}$ appears under $\mathrm{O}_{3}$ conditions, which is assigned to an ionic Au species $[73,76]$. Simultaneously, a new feature in comparison with the untreated sample appears in low $\mathrm{BE}$ region $(\mathrm{BE}=83.3$ $\mathrm{eV}$ ), which is assigned to the surface restructuring during oxidation [77,105]. The $\mathrm{O}$ 1s spectrum (Figure 3.30B(ii)) has also undergone changes: the broad peak at 532.5 $\mathrm{eV}$ vanishes due to carbon removal and a double peak in the lower BE region is formed. The component with $\mathrm{BE}$ of $529.4 \mathrm{eV}$ can be assigned to a surface oxide or chemisorbed oxygen on $\mathrm{Au}[85,88,108]$; the other component $(\mathrm{BE}=531.1 \mathrm{eV})$ has to be attributed to $\mathrm{O}$ in water and/or hydroxyl groups [73,85], but also the oxidation of contaminants in concentrations below the detection limits of XPS cannot be excluded [85].

Table 3.4. Fitting parameters of $\mathrm{O} 1 \mathrm{~s}$ spectra of $\mathrm{Au} / \mathrm{Au}$ foil.

\begin{tabular}{|c|c|c|c|c|c|c|}
\hline \multicolumn{7}{|c|}{ O 1s } \\
\hline & \multicolumn{2}{|c|}{ (hydro)carbon } & \multicolumn{2}{c|}{ surface oxide } & \multicolumn{2}{l|}{ Hydroxyl group/comntaminants } \\
\hline & BE & FWHM & BE & FWHM \\
$(\mathrm{eV})$ & $(\mathrm{eV})$ & $(\mathrm{eV})$ & $\begin{array}{c}\mathrm{BE} \\
(\mathrm{eV})\end{array}$ & $\begin{array}{c}\text { FWHM } \\
(\mathrm{eV})\end{array}$ & $(\mathrm{eV})$ \\
\hline $\mathrm{UHV}$ & 532.50 & 2.06 & - & - & - & - \\
\hline $\mathrm{O}_{3}$ & - & - & 529.42 & 1.55 & 531.07 & 1.82 \\
\hline $\mathrm{O}_{2}$ after $\mathrm{O}_{3}$ & 532.37 & 1.75 & - & - & 530.72 & 1.49 \\
\hline $\mathrm{CO}+\mathrm{O}_{2}$ & 532.38 & 1.73 & - & - & 530.66 & 1.53 \\
\hline
\end{tabular}

After $\mathrm{O}_{3}$ cleaning the sample was cooled down to RT and $\mathrm{O}_{3}$ was substituted by $\mathrm{O}_{2}$. The cooling leads to immediate carbon accumulation as shown in the $\mathrm{C} 1 \mathrm{~s}$ spectrum (Figure 3.30C(iii)), because usual backpressure in the reaction chamber is in $10^{-8}$ mbar range instead of $10^{-10}-10^{-12}$ mbar in UHV chambers. The high BE tail of the $\mathrm{C} 1 \mathrm{~s}$ spectrum indicates the formation of $\mathrm{C}-\mathrm{O}$ and $\mathrm{C}=\mathrm{O}$ bonds on the surface during cooling in $\mathrm{O}_{3}$ and further treatment in $\mathrm{O}_{2}$. The $\mathrm{O}$ 1s spectrum in $\mathrm{O}_{2}$ (Figure 3.30B(iii)) confirms the formation of oxygen-containing (hydro)carbons on the $\mathrm{Au}$ surface, corresponding peak at $532.5 \mathrm{eV}$ is well pronounced. But additionally, a small peak at $530.7 \mathrm{eV}$ is arises, and can be assigned to residual oxidized contaminants or to (hydro)carbons adsorbed on the low-coordinated atoms (defects) on the surface. There is no peak $(\mathrm{BE}<530 \mathrm{eV})$ related to the Au oxide(s). Also no 
signs of $\mathrm{Au}$ oxide(s) (BE $85.25 \mathrm{eV}$ ) are in the Au 4f spectrum (Figure 3.30A(iii)), but deconvolution of the spectrum shows that the peak assigned to the surface reconstruction $(\mathrm{BE} 83.3 \mathrm{eV})$ remains. Therefore, $\mathrm{O}_{3}$ evacuation leads to decomposition of oxide(s) and carbon accumulation.

Following $\mathrm{O}_{3}$ treatment, we introduced a reaction mixture $\left(\mathrm{CO} / \mathrm{O}_{2}=1: 75\right)$ into the chamber. The spectra do not change substantially. Further carbon accumulation occurs, as is seen by the increase in intensity of the $\mathrm{C}$ 1s peak (Figure 3.30C(iv)). The shapes of the $\mathrm{O} 1 \mathrm{~s}$ (Figure 3.30B(iv)) and Au 4f (Figure 3.30A(iv)) spectra are similar in general to the ones measured in $\mathrm{O}_{2}$ atmosphere; only the intensity of the peak $(\mathrm{BE}=530.7 \mathrm{eV})$ corresponding to residual oxidized contaminants or to (hydro)carbons adsorbed on the low-coordinated atoms (defects) decreases.

Table 3.5. Surface composition of $\mathrm{Au} / \mathrm{Au}$ foil at different conditions.

\begin{tabular}{|c|c|c|c|c|}
\hline & $\mathbf{A u}^{\mathbf{0}} \mathbf{\%}$ & $\mathbf{A u}^{\mathbf{3 +}}, \mathbf{\%}$ & $\mathbf{O}, \mathbf{\%}$ & $\mathbf{C ,} \%$ \\
\hline $\mathrm{UHV}$ & 24.8 & - & 6.2 & 69.0 \\
\hline $\mathrm{O}_{3}$ & 47.7 & 8.9 & 41.8 & $<1.5$ \\
\hline $\mathrm{O}_{2}$ & 37.3 & - & 23.4 & 39.3 \\
\hline $\mathrm{CO}+\mathrm{O}_{2}$ & 8 & - & 10.3 & 81.7 \\
\hline
\end{tabular}

Quantification of the surface composition of $\mathrm{Au} / \mathrm{Au}$ foil is presented in Table 3.5. The untreated sample is mostly covered by carbon (69.0\%). Nevertheless initial considerable carbon coverage $\mathrm{O}_{3}$ treatment cleans surface from carbon totally. Contemporaneously to carbon burning $\mathrm{Au}$ oxidation takes place during $\mathrm{O}_{3}$ treatment, oxygen concentration on the surface in $\mathrm{O}_{3}$ atmosphere exceeds stoichiometric ratio of $\mathrm{Au}_{2} \mathrm{O}_{3}$, which indicates the presence of an additional adsorbed oxygen overlayer. Changing chemical potential from $\mathrm{O}_{3}$ to $\mathrm{O}_{2}$ leads the decomposition of the surface oxide and immediate carbon accumulation (39.3\%). Following CO oxidation only facilitates further increasing carbon concentration on the surface of $\mathrm{Au} / \mathrm{Au}$ foil.

Microscopy does not reveal big differences between fresh and oxidized samples. SEM images of untreated $\mathrm{Au} / \mathrm{Au}$ foils show a particle size of ca. $10 \mathrm{~nm}$ (Figure 3.31A). In turn, the $\mathrm{Au}$ particle size distribution on $\mathrm{O}_{3}$-treated samples shows some sintering effects and a slightly rougher surface (Figure 3.31B). 
A fresh electrochemically prepared sample $\mathrm{Au} / \mathrm{Au}$ foil was tested under reaction conditions (Figure 3.32A) at 0.3 mbar. The presence of the sample in the set-up does not influence the $\mathrm{CO}$ conversion. The $\mathrm{CO}_{2}$ yield is negligible for the overall measurements. The adsorption of (hydro)carbons (see above XPS part), which cover the surface, prevent access of the gas mixture to the catalyst surface.
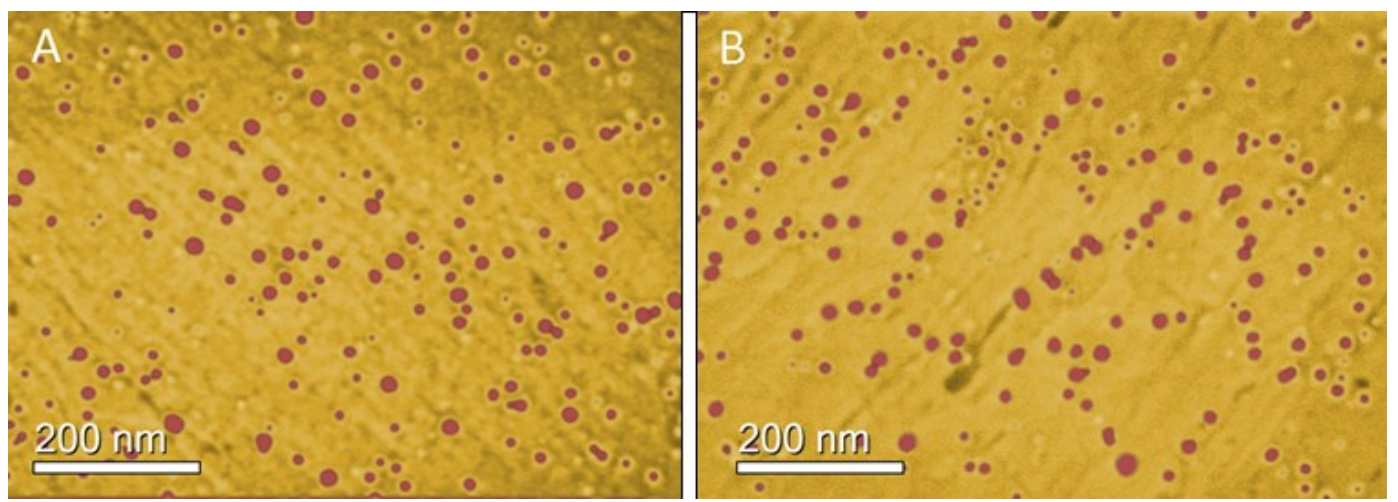

Figure 3.31. SEM images of $\mathrm{Au} / \mathrm{Au}$ foil a) before and b) after $\mathrm{O}_{3}$ treatment at 0.3 mbar. Images were colorized in order to highlight the differences between the two samples.

However, the oxidized Au sample looks more promising, but is not stable for long times (Figure 3.32B). CO consumption and deactivation time ( 2 hours) are similar to those observed on $\mathrm{Au} / \mathrm{HOPG}$. The corresponding $\mathrm{Au} 4 \mathrm{f}, \mathrm{O} 1 \mathrm{~s}$ and $\mathrm{C} 1 \mathrm{~s}$ spectra are shown in Figure 3.33. In the $\mathrm{Au} 4 \mathrm{f}$ spectrum the peak assigned to surface reconstruction $(\mathrm{BE} 83.3 \mathrm{eV}$ ) is almost vanished (green line in Figure 3.33A). The two components of the $\mathrm{O} 1 \mathrm{~s}$ spectra (Figure 3.33B) show opposite behavior: the oxygen-containing (hydro)carbons $(\mathrm{BE}=532.5 \mathrm{eV})$ peak increases, while the intensity of the peak $(\mathrm{BE}=530.7 \mathrm{eV})$ corresponding to residual oxidized contaminants or to (hydro)carbons adsorbed on the low-coordinated atoms (defects) decreases during the reaction. The explanation of such behavior can be that the reaction occurs between oxidized (hydro)carbons $\left(\mathrm{O}_{3}\right.$ functionalized carbon) and $\mathrm{CO}$ molecules. When the oxygen supply is depleted the reaction stops, and poisoning due to carbon accumulation takes place, which is evident from increasing of $\mathrm{C} 1 \mathrm{~s}$ peak (Figure 3.33C). Thus, oxidized $\mathrm{Au} / \mathrm{Au}$ foil itself does not catalyze $\mathrm{CO}$ oxidation at low temperature. 

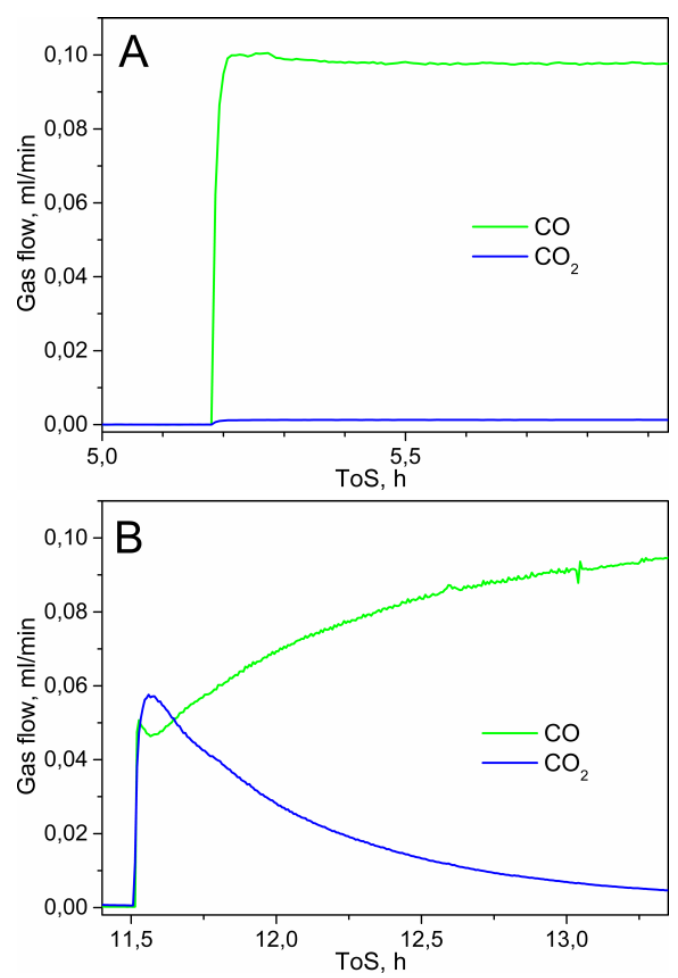

Figure 3.32. QMS data $\left(\mathrm{CO}: \mathrm{O}_{2}=1: 2\right)$ of $\mathrm{Au} / \mathrm{Au}$ foil a) before and $\left.\mathrm{b}\right)$ after $\mathrm{O}_{3}$ treatment at 0.3 mbar and RT.
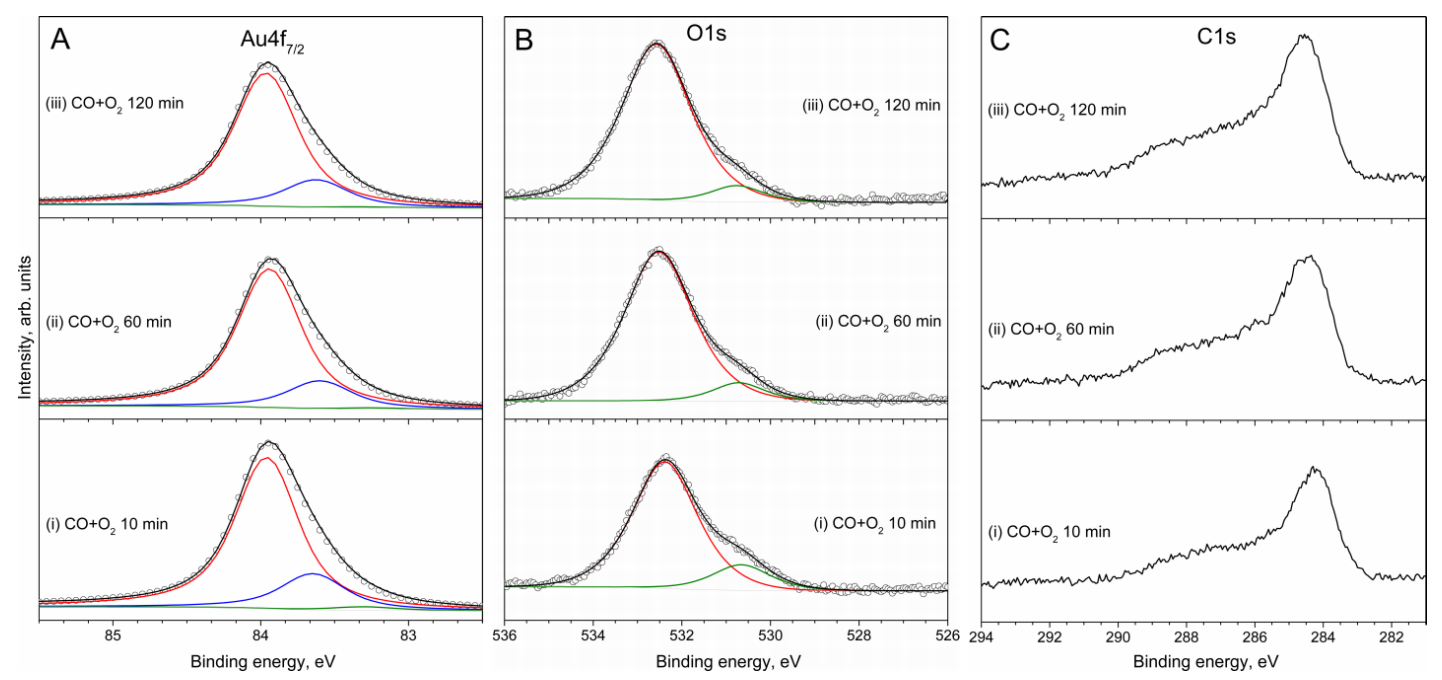

Figure 3.33. NAP (a) $\mathrm{Au} 4 \mathrm{f}_{7 / 2}$, (b) $\mathrm{O} 1 \mathrm{~s}$ and (c) $\mathrm{C} 1 \mathrm{~s}$ XP spectra of $\mathrm{Au} / \mathrm{Au}$ foil under $\mathrm{CO}$ reaction $\left(\mathrm{CO}: \mathrm{O}_{2}=1: 2\right)$ after $\mathrm{O}_{3}$ treatment at 0.3 mbar, RT (i) after $10 \mathrm{~min}$, (ii) 60 min and (iii) $120 \mathrm{~min}$. 


\subsubsection{Conclusions.}

The results presented here indicate that Au NPs supported on oxygen-free substrates are not active catalysts in $\mathrm{CO}$ oxidation, unless an external source of oxygen is provided. This behavior is found to be independent of the method of preparation and the nature of the support. Freshly prepared samples are covered by a carbon overlayer, which probably prevents access of the gas mixture to the active sites of the catalyst. $\mathrm{O}_{3}$ treatment allows cleaning of the surface, but at the same time to functionalize the (hydro)carbon overlayer. Oxygen-functionalized (hydro)carbons may still be present if their removal by $\mathrm{O}_{3}$ treatment was not completed, and can react with $\mathrm{CO}$. The stoichiometric reaction ends rather soon after reaction initiation, and $\mathrm{O}_{2}$ alone cannot re-functionalize the (hydro)carbons.

Under a constant chemical potential of $\mathrm{O}_{3}$, an $\mathrm{Au}$ oxide is formed, but evacuation or substitution of $\mathrm{O}_{3}$ by $\mathrm{O}_{2}$ results in the disappearance of the surface oxide. Therefore, participation of $\mathrm{Au}$ oxide in $\mathrm{CO}$ oxidation can be excluded. Remaining low-coordinated atoms do not have sufficient catalytic properties, and $\mathrm{CO}$ oxidation does not occur on the Au NPs even after oxidation. Our results clearly show that the size reduction andlor the oxidation of $\mathrm{Au}$ is not an effective strategy to activate Au. 


\subsection{Au nanoparticles on oxide support.}

\subsection{1 $\mathrm{Au} / \mathrm{Fe}_{2} \mathrm{O}_{3}-\mathrm{PC}$ (photo-induced decomposition of an $\mathrm{Au}-$ azido-complex to generate zero-valence Au-species)}

In a large 3-necked flask, equipped with a magnetic stirrer and a centered junction of the appropriate size to house the radiation source, $1 \mathrm{~g}$ of solid $\mathrm{Fe}_{2} \mathrm{O}_{3}$ (Hematite, SIGMA-ALDRICH, p.a.) was suspended in a solution of $66 \mathrm{mg} \mathrm{NaN}_{3}$ (SIGMA-ALDRICH) in $2 \mathrm{~L}$ of deionized water (MILLIPORE). The radiation source, a HERAEUS UV-TQ-150 mercury lamp, a water-cooled quartz device, was submerged into the liquid phase. From a stock, $10 \mathrm{~mL}$ of a solution of $\mathrm{HAuCl}_{4}$ were added to the suspension in order to have a total of $10 \mathrm{mg}$ of gold and a 20 -fold molar excess of azide relative to the gold.

The decomposition of the intermediate auro-azido species and deposition of the zero-valence $\mathrm{Au}$ onto the dispersed support particles was stimulated by UV irradiation over $2 \mathrm{~h}$. The suspension was continuously stirred and kept at room temperature.

The solid was separated from the liquid phase by suction-filtration and washed with deionized water. Finally, the sample was dried in a vacuum desiccator over $\mathrm{KOH}$. The absence of color in the filtrate was indicative for near-quantitative capture of the gold by the support. The final Au load was $1 \mathrm{wt} \%$.

In order to have a benchmark for comparison, the first step in this study was to characterize the morphology of freshly prepared catalysts. A TEM image of an untreated $\mathrm{Au} / \mathrm{Fe}_{2} \mathrm{O}_{3}-\mathrm{PC}$ is presented in the Figure 3.34A. The image shows a round $\mathrm{Au} \mathrm{NP}$ of about $25 \mathrm{~nm}$ in diameter. The contact angle between the Au NP and the support $\left(\mathrm{Fe}_{2} \mathrm{O}_{3}\right)$ is high, and no spreading of the support material over the $\mathrm{Au} \mathrm{NP}$ surface. After annealing in $\mathrm{O}_{2}$ and $\mathrm{CO}$ oxidation, $\mathrm{Au}$ NPs do not change significantly, retaining the same mean particle size as before oxidation (Figure 3.34B). The low degree of wetting between gold and the oxide support is also retained, with a contact angle of ca. $130^{\circ}$, which allows one to conclude that the interaction between $\mathrm{Au}$ NPs and $\mathrm{Fe}_{2} \mathrm{O}_{3}$ is not significantly altered during annealing and $\mathrm{CO}$ oxidation. 


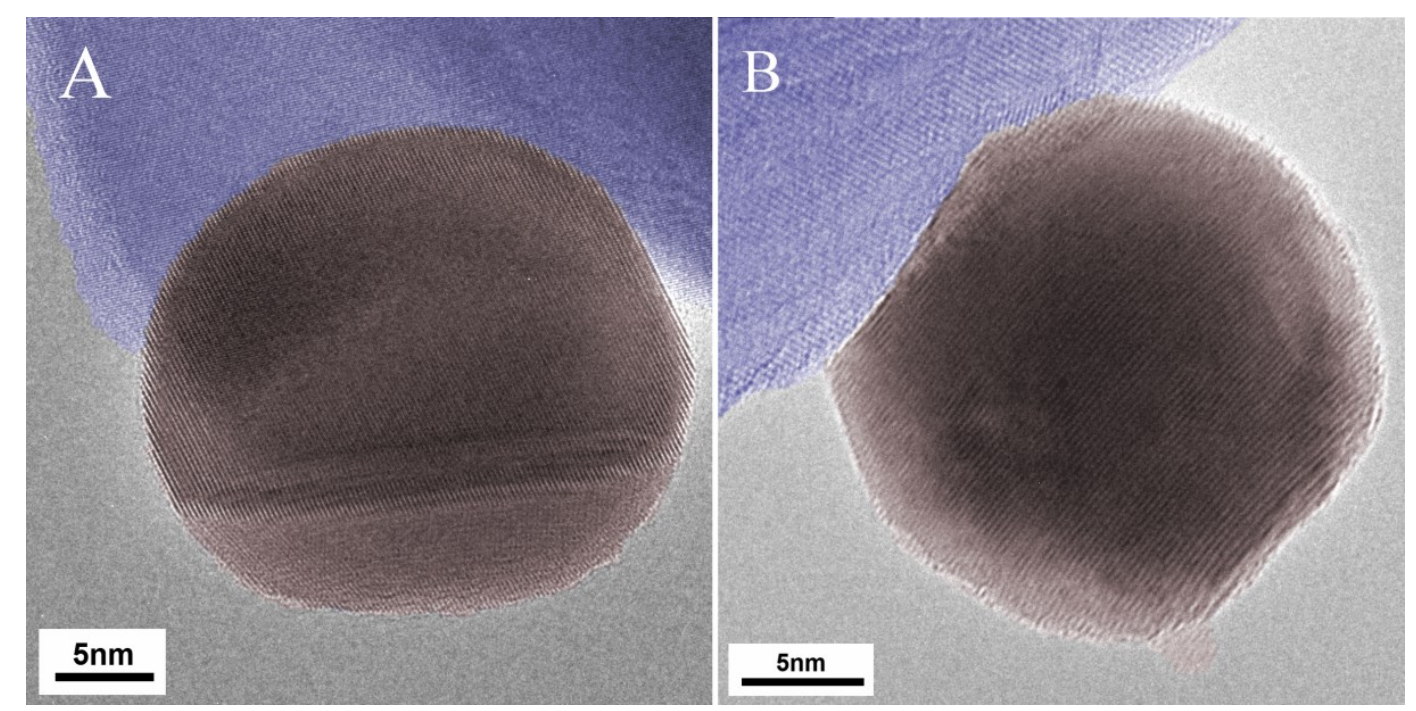

Figure 3.34. TEM images of $\mathrm{Au} / \mathrm{Fe}_{2} \mathrm{O}_{3}-\mathrm{PC}$ (A) before and (B) after annealing in $\mathrm{O}_{2}$ at $300{ }^{\circ} \mathrm{C}$ and $\mathrm{CO}$ oxidation $\left(\mathrm{CO}: \mathrm{O}_{2}=1: 2\right)$ at 0.3 mbar and $300{ }^{\circ} \mathrm{C}$. Images were colorized in order to highlight the differences between the two samples.

NAP-XPS provides information about the electronic structure of $\mathrm{Au}$ under reaction conditions. Due to carbon contamination on the fresh sample, $\mathrm{Au} / \mathrm{Fe}_{2} \mathrm{O}_{3}-\mathrm{PC}$ was annealed in $\mathrm{O}_{2}$ to $300^{\circ} \mathrm{C}$ to remove the majority of the carbon. No significant changes in particle size distribution were found after annealing. Photoelectrons with $160 \mathrm{eV}$ kinetic energy were used to collect the $\mathrm{O} 1 \mathrm{~s}$ and $\mathrm{C} 1 \mathrm{~s}$ spectra (Figure 3.35B and 3.34C). The spectra collected during annealing in $\mathrm{O}_{2}$ are presented in Figure 3.35(i). At the beginning of the annealing process, the $\mathrm{C} 1 \mathrm{~s}$ spectrum (Figure 3.35C(i)) shows one intense broad peak at a binding energy (BE) of $284.5 \mathrm{eV}$, which decreases with temperature. The corresponding $\mathrm{O}$ 1s spectrum (Figure 3.35B(i)) consists of three components (Table 3.6). The lowest binding energy species (BE $529.9 \mathrm{eV})$ is associated with lattice oxygen of ferric oxide $\left(\mathrm{Fe}_{2} \mathrm{O}_{3}\right)$ [109], higher binding energy species are assigned to the copper oxides/hydroxides (BE $531.6 \mathrm{eV}$ ) from the copper mesh [110,111] and oxygen-containing (hydro)carbons (BE 533.7 eV) [107]. 

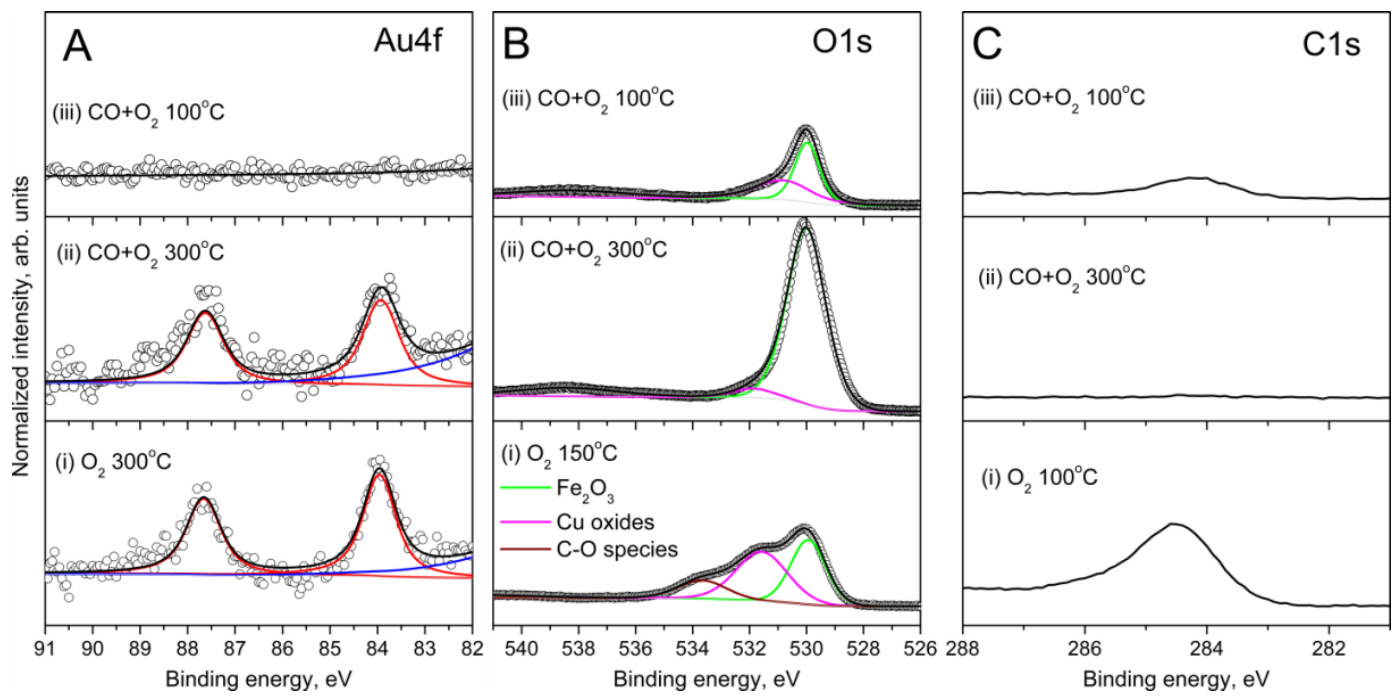

Figure 3.35. (A) $\mathrm{Au} 4 \mathrm{f}$, (B) $\mathrm{O} 1 \mathrm{~s}$ and (C) $\mathrm{C} 1 \mathrm{~s} \mathrm{XP}$ spectra of $\mathrm{Au} / \mathrm{Fe}_{2} \mathrm{O}_{3}-\mathrm{PC}$ at 0.3 mbar (i) in $\mathrm{O}_{2}$ during annealing, (ii) in $\mathrm{CO}+\mathrm{O}_{2}\left(\mathrm{CO}: \mathrm{O}_{2}=1: 2\right)$ at $300{ }^{\circ} \mathrm{C}$ and (iii) in $\mathrm{CO}+\mathrm{O}_{2}\left(\mathrm{CO}: \mathrm{O}_{2}=1: 2\right)$ at $100{ }^{\circ} \mathrm{C}$. Photoelectrons with $160 \mathrm{eV}$ kinetic energy were used to collect the $\mathrm{O} 1 \mathrm{~s}$ and $\mathrm{C} 1 \mathrm{~s}$ spectra, and photoelectrons with $900 \mathrm{eV}$ kinetic energy were used to collect the Au $4 \mathrm{f}$ spectra.

Table 3.6. Fitting parameters of $\mathrm{Au} 4 \mathrm{f}_{7 / 2}$ and $\mathrm{O} 1 \mathrm{~s}$ spectra of $\mathrm{Au} / \mathrm{Fe}_{2} \mathrm{O}_{3}-\mathrm{PC}$.

\begin{tabular}{|c|c|c|c|c|c|c|c|c|}
\hline & \multicolumn{2}{|c|}{$\mathrm{Au} 4 \mathrm{f}_{7 / 2}$} & \multicolumn{5}{c|}{$\mathrm{O} 1 \mathrm{~s}$} \\
\hline & \multicolumn{2}{|c|}{$\mathrm{Au}^{0}$} & \multicolumn{2}{c|}{ (hydro)carbon } & \multicolumn{2}{c|}{$\begin{array}{c}\text { Copper } \\
\text { oxides/hydroxides }\end{array}$} & \multicolumn{2}{c|}{$\mathrm{Fe}_{2} \mathrm{O}_{3}$} \\
\hline & $\begin{array}{c}\mathrm{BE} \\
(\mathrm{eV})\end{array}$ & $\begin{array}{c}\mathrm{FWHM} \\
(\mathrm{eV})\end{array}$ & $\begin{array}{c}\mathrm{BE} \\
(\mathrm{eV})\end{array}$ & $\begin{array}{c}\text { FWHM } \\
(\mathrm{eV})\end{array}$ & $\begin{array}{c}\mathrm{BE} \\
(\mathrm{eV})\end{array}$ & $\begin{array}{r}\text { FWHM } \\
(\mathrm{eV})\end{array}$ & $\begin{array}{c}\mathrm{BE} \\
(\mathrm{eV})\end{array}$ & $\begin{array}{c}\text { FWHM } \\
(\mathrm{eV})\end{array}$ \\
\hline $\mathrm{O}_{2}$ & 83.97 & 0.83 & 533.7 & 2.0 & 531.6 & 2.1 & 529.9 & 1.5 \\
\hline $\begin{array}{c}\mathrm{CO}+\mathrm{O}_{2} \\
300\end{array}$ & 83.97 & 0.89 & - & - & 531.8 & 1.7 & 530.0 & 1.6 \\
\hline $\begin{array}{c}\mathrm{CO}+\mathrm{O}_{2} \\
100{ }^{\circ} \mathrm{C}\end{array}$ & - & - & - & - & 531.6 & 1.6 & 530 & 1.2 \\
\hline
\end{tabular}

In order to penetrate through the carbonaceous layer, photoelectrons with higher kinetic energy $(900 \mathrm{eV})$ were used for measuring the $\mathrm{Au} 4 \mathrm{f}$ spectra (Figure 3.35A). The $\mathrm{Au} 4 \mathrm{f}$ spectrum of $\mathrm{Au} / \mathrm{Fe}_{2} \mathrm{O}_{3}-\mathrm{PC}$ in $\mathrm{O}_{2}$ at $300{ }^{\circ} \mathrm{C}$ (Figure $3.35 \mathrm{~A}(\mathrm{i})$ ) shows only one sharp peak at a $\mathrm{BE}$ of $83.97 \mathrm{eV}$, assigned to bulk $\mathrm{Au}$ in its metal 
state, in accordance with the accepted $\mathrm{Au} 4 \mathrm{f}_{7 / 2}$ binding energy value [71-73]. Note that the contribution from the neighboring $\mathrm{Cu} 3 \mathrm{p}_{1 / 2}$ peak (blue line in Figure 3.35A) (BE $77.6 \mathrm{eV}$ ) [112] has to be taken into account for correct fitting.

After annealing, $\mathrm{O}_{2}$ was substituted by a reaction gas mixture of $\mathrm{CO}$ and $\mathrm{O}_{2}$ in a 1-to-2 ratio, keeping the temperature of $\mathrm{Au} / \mathrm{Fe}_{2} \mathrm{O}_{3}-\mathrm{PC}$ at $300{ }^{\circ} \mathrm{C}$. After annealing in $\mathrm{O}_{2}$ at high temperature, the $\mathrm{Au} 4 \mathrm{f}$ spectrum measured in the reaction gas mixture (Figure 3.35A(ii)) does not exhibit any changes in comparison with its state during annealing in $\mathrm{O}_{2}$. The $\mathrm{C}$ 1s peak totally vanishes (Figure $3.35 \mathrm{C}(\mathrm{ii})$ ). The absence of the $533.7 \mathrm{eV}$ peak in the $\mathrm{O} 1 \mathrm{~s}$ spectrum (Figure 3.35B(ii)) confirms the carbon removal. The two remaining $\mathrm{O}$ 1s peaks are assigned to lattice oxygen in $\mathrm{Fe}_{2} \mathrm{O}_{3}(\mathrm{BE}$ $530.0 \mathrm{eV}$ ) and copper oxides/hydroxides (BE $531.8 \mathrm{eV}$ ). Note, the increase of the intensity of $\mathrm{Fe}_{2} \mathrm{O}_{3}$ component in the $\mathrm{O}$ 1s spectrum (Figure $3.35 \mathrm{~B}$ (ii)) is a consequence of removing the carbon surface layer; however, the decrease of copper oxide contribution is a result of the presence of $\mathrm{CO}$, which is capable of reducing copper oxides/hydroxides to copper metal. $\mathrm{Fe}_{2} \mathrm{O}_{3}$ is more stable at low temperature than copper oxides/hydroxides, and cannot be reduced to metal at these temperatures.

Then the sample was cooled down to $100{ }^{\circ} \mathrm{C}$ in the reaction gas mixture. Cooling leads to immediate carbon accumulation on the sample surface, as shown in the $\mathrm{C}$ 1s spectrum (Figure 3.35C(iii)). The shape of the corresponding $\mathrm{O}$ 1s spectrum (Figure $3.35 \mathrm{~B}(\mathrm{iii})$ ) does not change. There is only an intensity decrease, as a consequence of the formation of the overlying carbon layer. As the Au loading is low, the Au 4f signal is quite weak, and consequently, after the accumulation of the carbonaceous layer at low temperature, the $\mathrm{Au} 4 \mathrm{f}$ signal attenuates so much that it can no longer be detected (Figure 3.35A(iii)). 


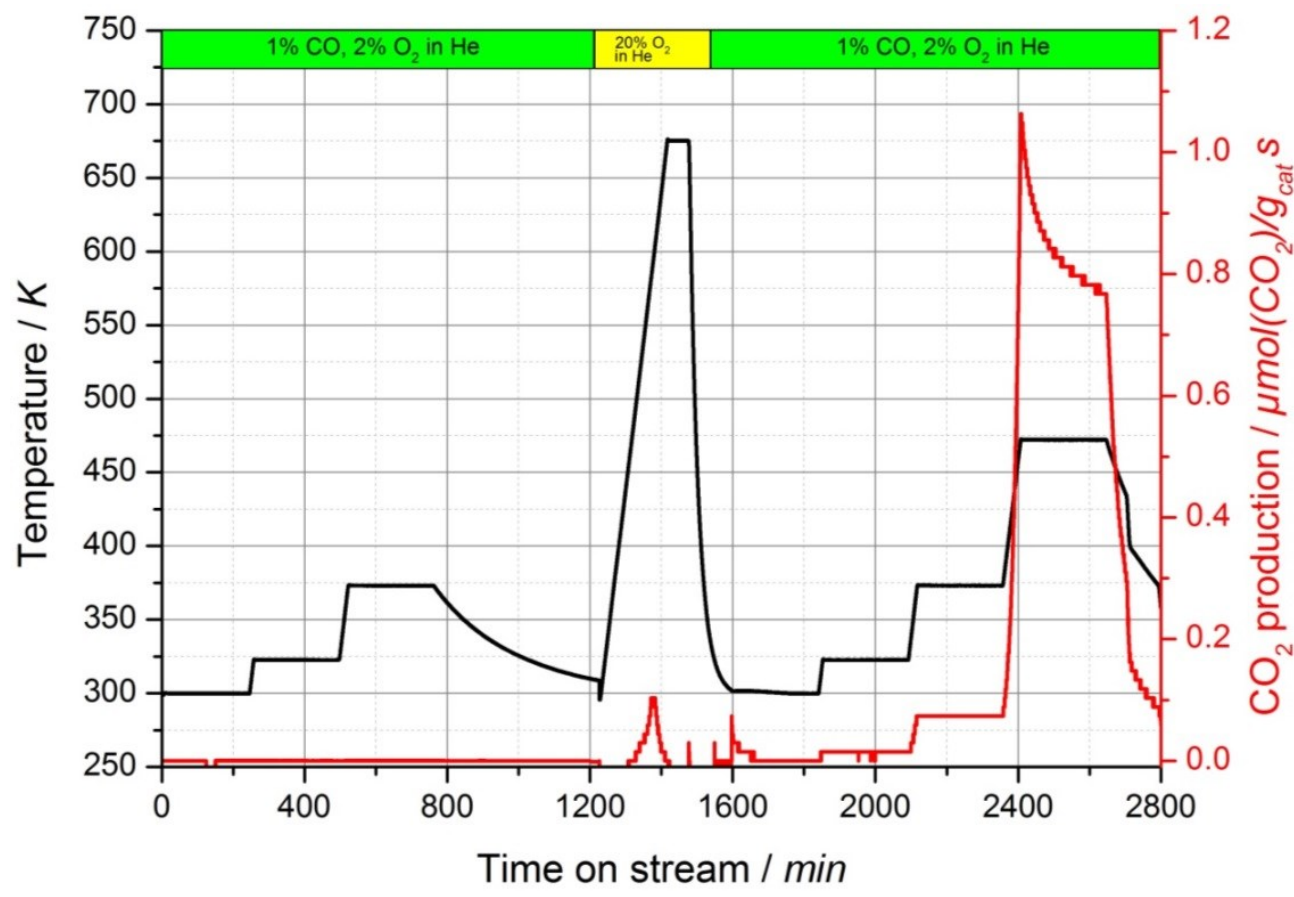

Figure 3.36. $\mathrm{CO}_{2}$ production of $\mathrm{Au} / \mathrm{Fe}_{2} \mathrm{O}_{3}-\mathrm{PC}$ in $\mathrm{CO}$-reactor at 1 bar and $\mathrm{CO}: \mathrm{O}_{2}=1: 2$.

Catalytic activity of $\mathrm{Au} / \mathrm{Fe}_{2} \mathrm{O}_{3}-\mathrm{PC}$ at 0.3 mbar was below the detection limit of the mass-spectrometer, so as-prepared $\mathrm{Au} / \mathrm{Fe}_{2} \mathrm{O}_{3}-\mathrm{PC}$ was tested in $\mathrm{CO}$ oxidation at atmospheric pressure in an oxygen-rich feed $\left(\mathrm{CO}: \mathrm{O}_{2}=1: 2\right)$ (Figure 3.36). Catalytic activity was monitored at RT, 323 and $373 \mathrm{~K}$ but the sample did not produce any $\mathrm{CO}_{2}$. Subsequent oxidation of the catalyst in synthetic air was performed at $673 \mathrm{~K}$ for 1 hour, showing the formation of some $\mathrm{CO}_{2}$ below $600 \mathrm{~K}$, probably originating from burning of (hydro)carbons from the surface, which may block active sites. However, after the oxidative treatment, the sample became active towards $\mathrm{CO}$ oxidation, with $\mathrm{CO}_{2}$ production already detectible at $323 \mathrm{~K}$. The activity increased with temperature, showing no sign of deactivation when held at 323 and $373 \mathrm{~K}$. However, when held at $473 \mathrm{~K}$ the production of $\mathrm{CO}_{2}$ decreased by ca. $28 \%$ over a period of $4 \mathrm{~h}$. The highest amount of $\mathrm{CO}_{2}$ observed at $473 \mathrm{~K}$ corresponds to a conversion of $\mathrm{CO}$ of about $7 \%$. 


\subsection{2 $\mathrm{Au} / \mathrm{Fe}_{2} \mathrm{O}_{3}-\mathrm{C}$ (co-precipitation) and $\mathrm{Au} / \mathrm{TiO}_{2}-\mathrm{DP}$ (deposition-precipitation).}

$200 \mathrm{~mL}$ of $0.1 \mathrm{M} \mathrm{Fe}\left(\mathrm{NO}_{3}\right)_{3}$ aqueous solution and $10 \mathrm{~mL} 0.05 \mathrm{M} \mathrm{HAuCl}_{4}$ aqueous solution were mixed and stirred constantly, then the mixture was precipitated at $80^{\circ} \mathrm{C}$ using $0.25 \mathrm{M} \mathrm{Na}_{2} \mathrm{CO}_{3}$ solution until a $\mathrm{pH}$ of 8.2 was reached. The gel-like precipitate was cooled, filtered and washed with hot deionized water (1 $\mathrm{L}, 80{ }^{\circ} \mathrm{C}$ ) three times and dried at $120^{\circ} \mathrm{C}$ for 16 hours in a muffle furnace under static air and a ramp rate of $15^{\circ} \mathrm{C}$. The final Au load was $5 \mathrm{wt} \%$.

$100 \mathrm{~mL}$ of $\mathrm{HAuCl}_{4}\left(8.4 \times 10^{-3} \mathrm{M}\right)$ aqueous solution was heated to $80{ }^{\circ} \mathrm{C}$. Then the $\mathrm{pH}$ value of the solution was adjusted to 8 by dropwise addition of $\mathrm{NaOH}(1 \mathrm{M})$. $4 \mathrm{~g}$ of $\mathrm{TiO}_{2}(\mathrm{P} 25)$ was dispersed in the solution and the $\mathrm{pH}$ value was re-adjusted to 8 . The suspension was then vigorously stirred at $80{ }^{\circ} \mathrm{C}$ for $2 \mathrm{~h}$. Solids were collected by centrifugation (10 $000 \mathrm{rpm}, 10 \mathrm{~min}$ ) and washed in $100 \mathrm{~mL}$ deionized water under stirring for $10 \mathrm{~min}$ at $50{ }^{\circ} \mathrm{C}$. The above procedure was repeated three times. The solids were dried in air at $80^{\circ} \mathrm{C}$ for $24 \mathrm{~h}$ and then calcined under a flow of synthetic air $\left(\mathrm{O}_{2}: \mathrm{N}_{2}=20: 80,100 \mathrm{~mL} \mathrm{~min}^{-1}\right)$ with a heating ramp of $2{ }^{\circ} \mathrm{C} \min ^{-1}$ and held at 300 ${ }^{\circ} \mathrm{C}$ for 4 hours. The final Au load was $1 \mathrm{wt} \%$.

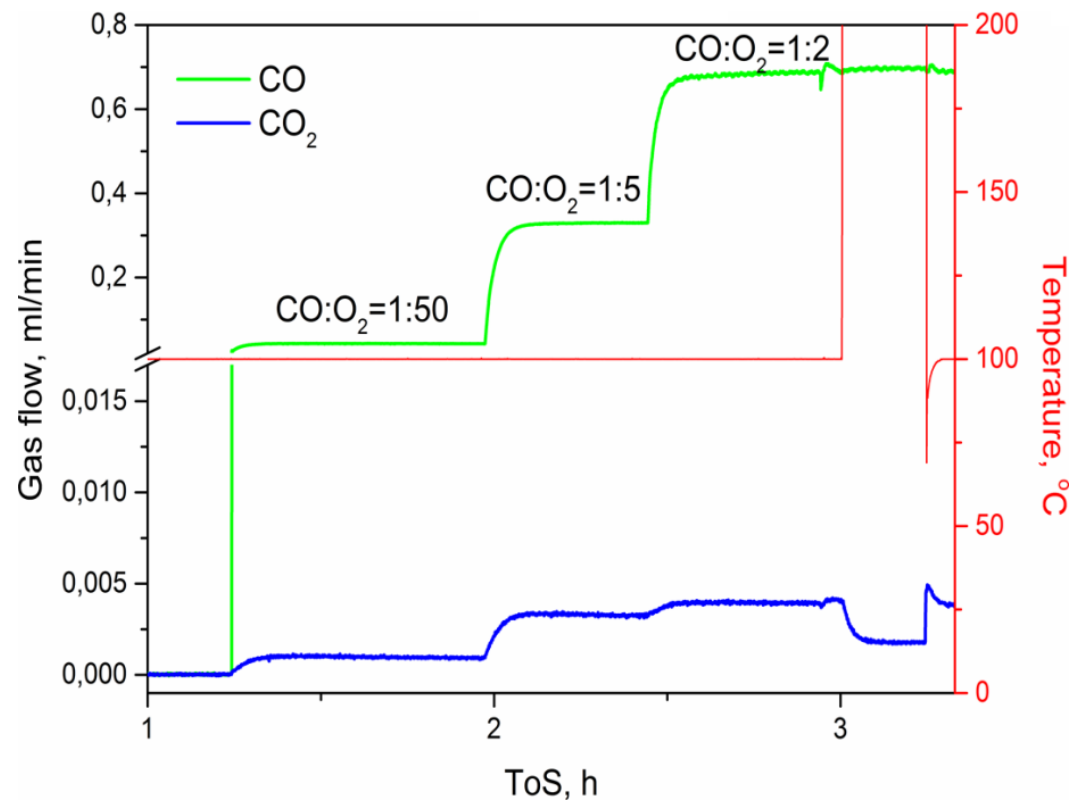

Figure 3.37. $\mathrm{CO}_{2}$ production of $\mathrm{Au} / \mathrm{Fe}_{2} \mathrm{O}_{3}-\mathrm{C}$ in NAP-XPS chamber at 0.3 mbar. 


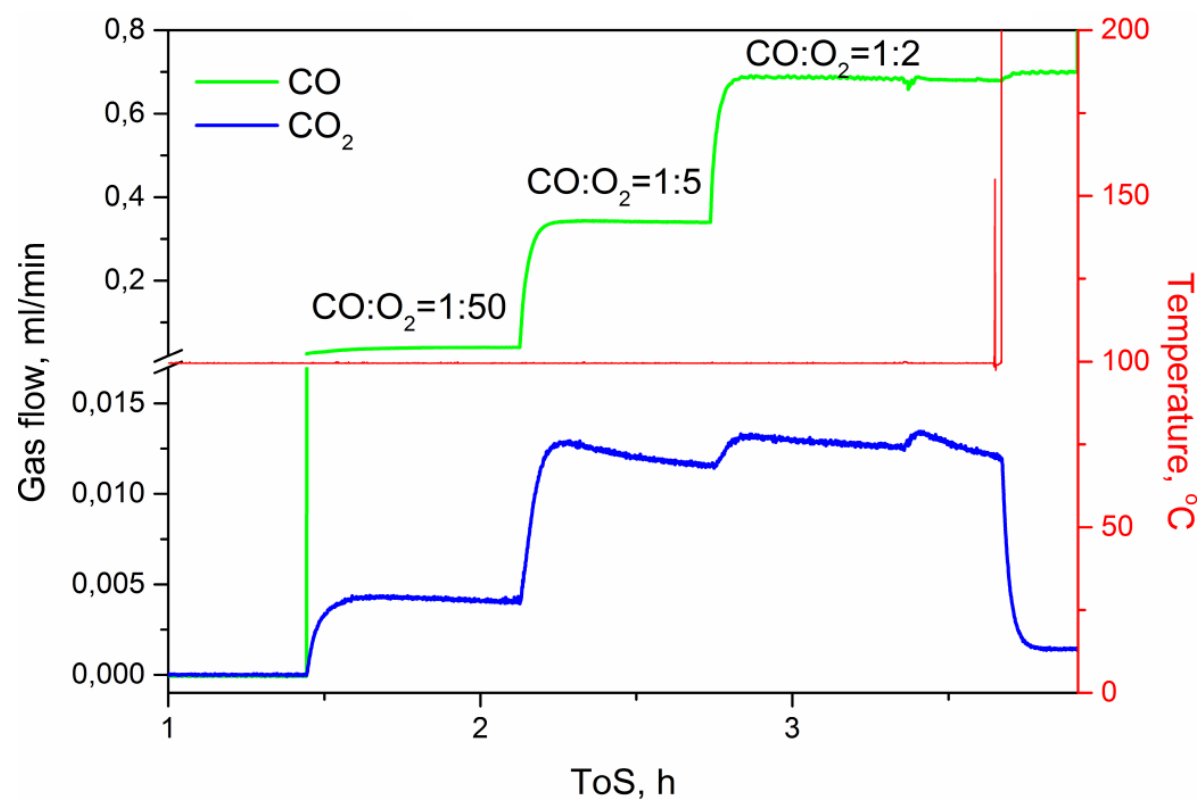

Figure 3.38. $\mathrm{CO}_{2}$ production of $\mathrm{Au} / \mathrm{TiO}_{2}-\mathrm{DP}$ in NAP-XPS chamber at $0.3 \mathrm{mbar}$.

In contrast to the sample prepared by photo-induced decomposition of the $\mathrm{Au}-$ azido-complex, both of the samples synthesized by precipitation methods $\left(\mathrm{Au} / \mathrm{Fe}_{2} \mathrm{O}_{3}\right.$ $\mathrm{C}$ and $\mathrm{Au} / \mathrm{TiO}_{2}$-DP) exhibited high $\mathrm{CO}_{2}$ yields at $100{ }^{\circ} \mathrm{C}$, without any pretreatment necessary (Figure 3.37 and 3.38, respectively). As shown in Figures 3.36 and 3.37, $\mathrm{CO}_{2}$ production increases with increasing $\mathrm{CO}: \mathrm{O}_{2}$ ratio. To exclude the possibility that some background reaction in the chamber was causing this reactivity, the samples were removed from the chamber without interrupting the gas flows. In Figures 3.36 and 3.37 these moments are apparent by the sharp jumps to infinity in the temperature signal (red line) - i.e. the apparent temperature becomes infinite due to breaking the contact between thermocouple and temperature control stageoccurring at a ToS of 3 hours in Figure 3.37 and at 3.7 hour in Figure 3.38. It is clear from the corresponding drop in $\mathrm{CO}_{2}$ signal that the reaction stops immediately once the sample is removed, and restarts once the sample is returned, as seen in Figure 3.37 . 


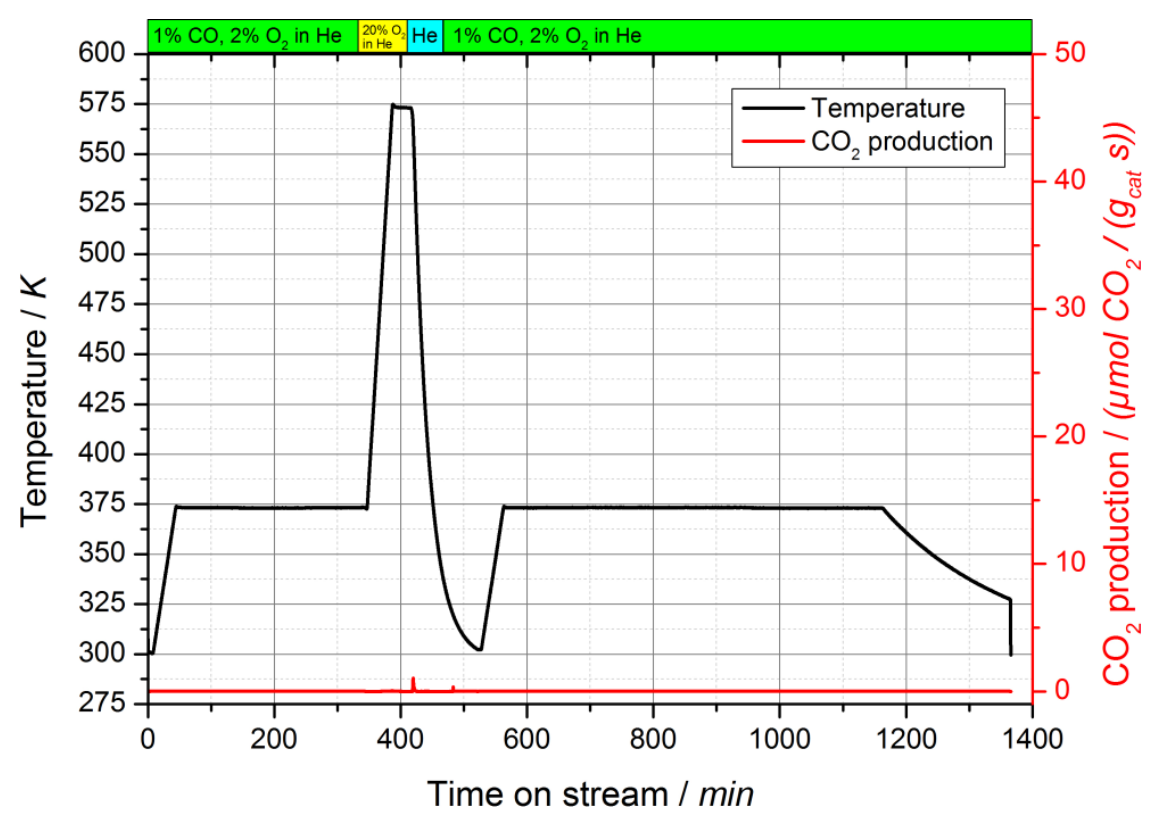

Figure 3.39. $\mathrm{CO}_{2}$ production of pure $\mathrm{Fe}_{2} \mathrm{O}_{3}$ in $\mathrm{CO}$-reactor at 1 bar $\left(\mathrm{CO}: \mathrm{O}_{2}=1: 2\right)$ and $373 \mathrm{~K}$.

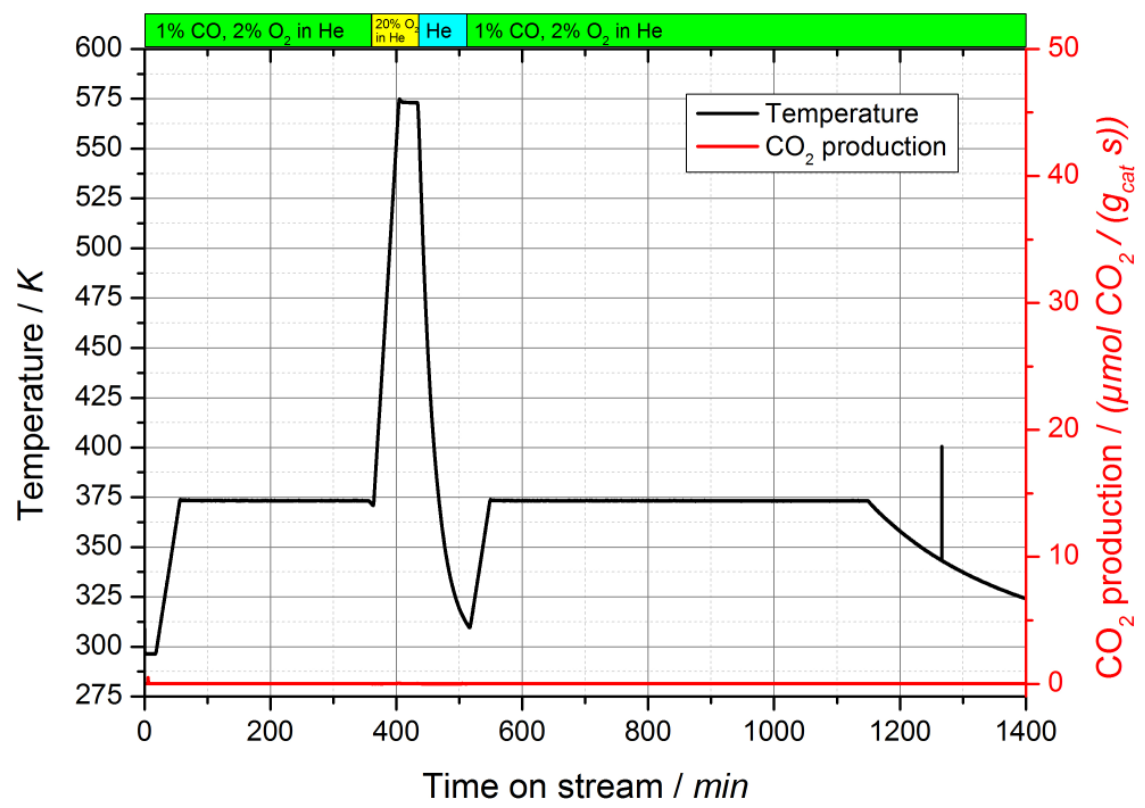

Figure 3.40. $\mathrm{CO}_{2}$ production of pure $\mathrm{TiO}_{2}$ in $\mathrm{CO}$-reactor at 1 bar $\left(\mathrm{CO}: \mathrm{O}_{2}=1: 2\right)$ and $373 \mathrm{~K}$.

Pure oxides (i.e. $\mathrm{Fe}_{2} \mathrm{O}_{3}$ and $\mathrm{TiO}_{2}$ without $\mathrm{Au}$ NPs) were also tested and did not show any significant activity at low temperature (Figures 3.39 and 3.40, respectively). Thus, catalytic CO oxidation was found to occur when Au NPs are supported on transition metal oxides. The catalytic performance of $\mathrm{Au} / \mathrm{Fe}_{2} \mathrm{O}_{3}-\mathrm{C}$ and 
$\mathrm{Au} / \mathrm{TiO}_{2}$-DP also were tested in a CO-reactor at 1 bar (Figure 3.41 and 3.42) and confirmed the results obtained at 0.3 mbar.

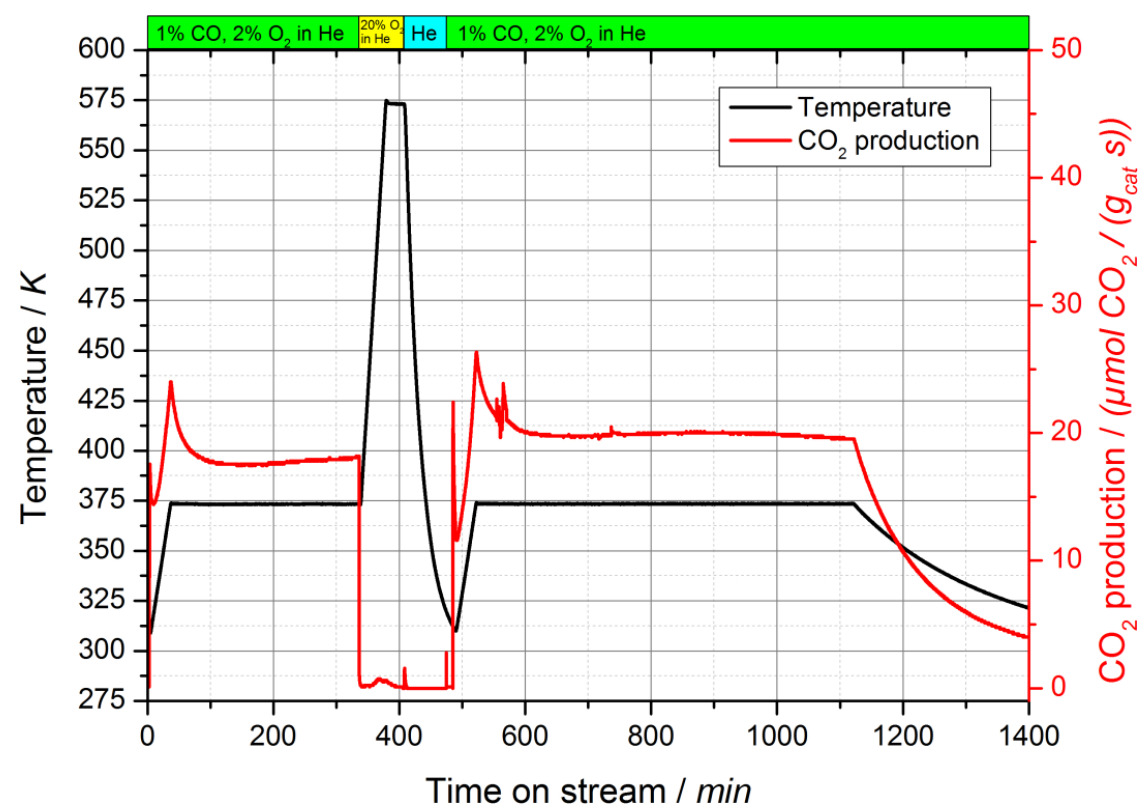

Figure 3.41. $\mathrm{CO}_{2}$ production of $\mathrm{Au} / \mathrm{Fe}_{2} \mathrm{O}_{3}-\mathrm{C}$ in $\mathrm{CO}$-reactor at 1 bar $\left(\mathrm{CO}: \mathrm{O}_{2}=1: 2\right)$ and $373 \mathrm{~K}$.

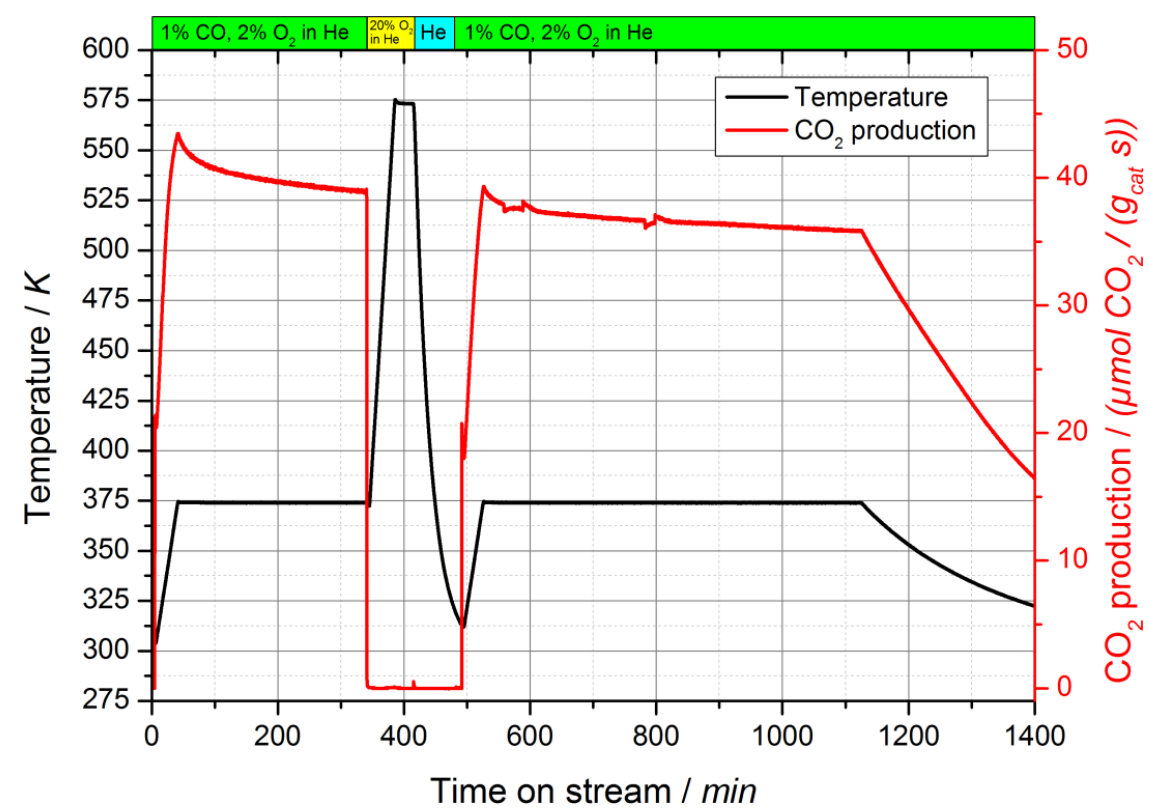

Figure 3.42. $\mathrm{CO}_{2}$ production of $\mathrm{Au} / \mathrm{TiO}_{2}-\mathrm{DP}$ in $\mathrm{CO}$-reactor at 1 bar $\left(\mathrm{CO}: \mathrm{O}_{2}=1: 2\right)$ and $373 \mathrm{~K}$. 


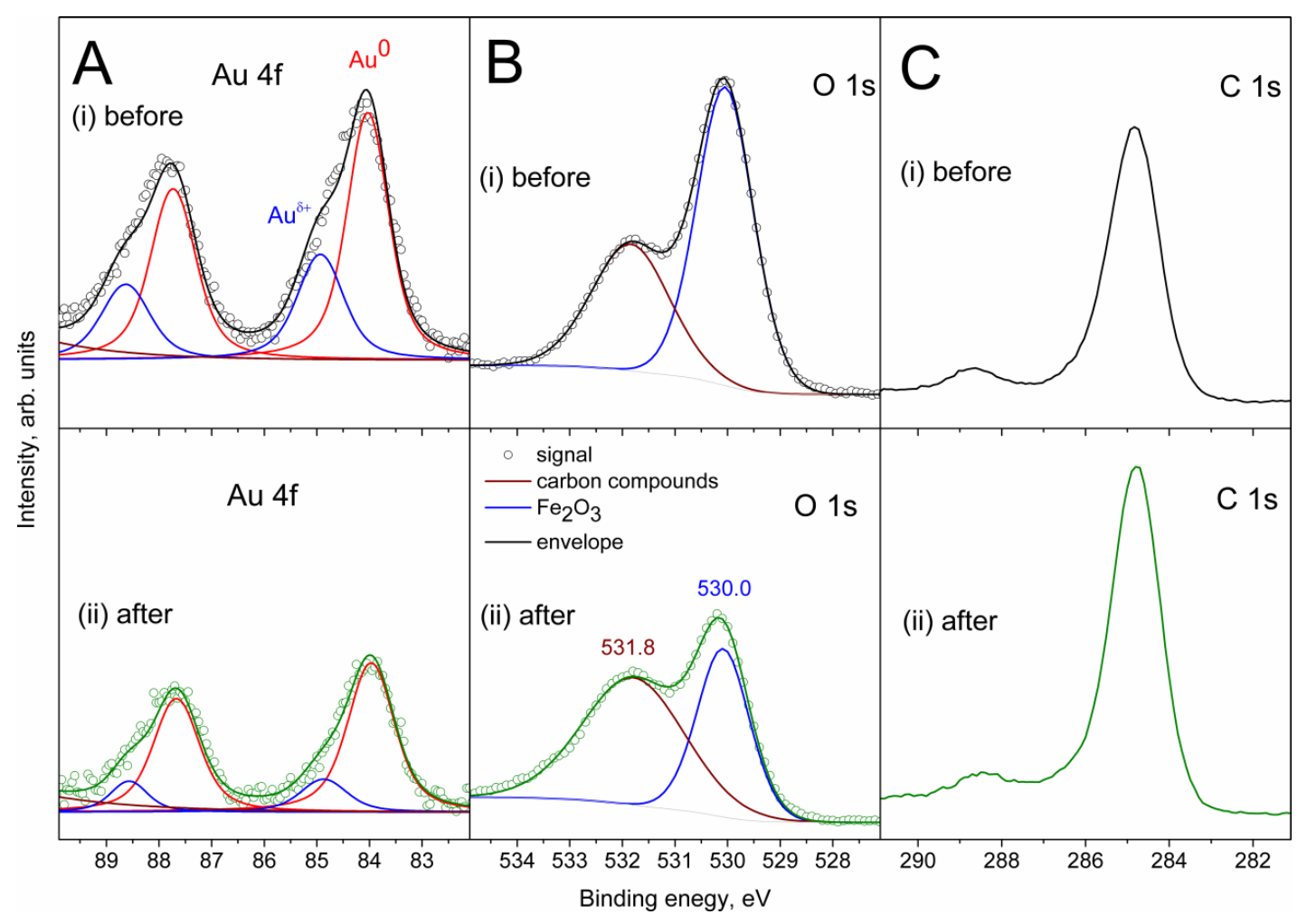

Figure 3.43. (A) $\mathrm{Au} 4 \mathrm{f}$, (B) $\mathrm{O} 1 \mathrm{~s}$ and (C) $\mathrm{C} 1 \mathrm{~s}$ XP spectra of $\mathrm{Au} / \mathrm{Fe}_{2} \mathrm{O}_{3}-\mathrm{C}$ before (top panel) and after (bottom panel) $\mathrm{CO}$ oxidation $\left(\mathrm{CO}: \mathrm{O}_{2}=1: 2\right)$ at $0.3 \mathrm{mbar}$ and $100{ }^{\circ} \mathrm{C}$. Photoelectrons with $160 \mathrm{eV}$ kinetic energy were used to collect $\mathrm{O} 1 \mathrm{~s}$ and $\mathrm{C}$ 1s spectra and photoelectrons with $900 \mathrm{eV}$ kinetic energy were used to collect $\mathrm{Au}$ 4f spectra.

To further examine the nature of the Au active sites, NAP-XPS was measured of the $\mathrm{Au} / \mathrm{Fe}_{2} \mathrm{O}_{3}-\mathrm{C}$ and $\mathrm{Au} / \mathrm{TiO}_{2}$-DP samples. The $\mathrm{Au} 4 \mathrm{f}$ core level spectrum of the fresh $\mathrm{Au} / \mathrm{Fe}_{2} \mathrm{O}_{3}-\mathrm{C}$, measured in $\mathrm{UHV}$ at $100^{\circ} \mathrm{C}$ before the reaction (Figure $3.43 \mathrm{~A}(\mathrm{i})$ ), exhibits a main metallic peak at a $\mathrm{BE}$ of $84.0 \mathrm{eV}$, with a second component shifted to higher BE by $0.9 \mathrm{eV}$ (Table 3.7). For proper fitting of $\mathrm{Au} 4 \mathrm{f}$ spectra the contribution from $\mathrm{Fe} 3 s$ peak (BE $93.7 \mathrm{eV}$ ) [113] has to be taken into account (wine line in Figure 3.43A). The high-binding-energy $\mathrm{Au} 4 \mathrm{f}$ peak is assigned to $\mathrm{Au}^{\delta+}$, which can be interpreted as perimeter $\mathrm{Au}$ atoms that interact with the metal oxide support via charge transport [26,114-117].

The corresponding $\mathrm{O}$ 1s spectrum (Figure 3.43B(i)) displays two peaks at $\mathrm{BE}$ of $530.0 \mathrm{eV}$ and $531.8 \mathrm{eV}$, respectively. The first peak is assigned to lattice oxygen of $\mathrm{Fe}_{2} \mathrm{O}_{3}$ [109] and the second one to oxygen from carbonates and other oxygencontaining (hydro)carbons [107]. The presence of carbonates and/or oxygencontaining (hydro)carbons on the surface is confirmed by the very intense $\mathrm{C} 1 \mathrm{~s}$ 
spectrum, which consists of a main peak $(\mathrm{BE}=284.8 \mathrm{eV})$ and a small peak $(\mathrm{C}=\mathrm{O}$ bonds) or satellite at $288.5 \mathrm{eV}$ (Figure 3.43C(i)).

Table 3.7. Fitting parameters of $\mathrm{Au} 4 \mathrm{f}_{7 / 2}$ and $\mathrm{O}$ 1s spectra of $\mathrm{Au} / \mathrm{Fe}_{2} \mathrm{O}_{3}-\mathrm{C}$.

\begin{tabular}{|c|c|c|c|c|c|c|c|c|}
\hline & \multicolumn{3}{|c|}{$\mathrm{Au} 4 \mathrm{f}_{7 / 2}$} & \multicolumn{3}{c|}{$\mathrm{O} 1 \mathrm{~s}$} \\
\hline & \multicolumn{2}{|c|}{$\mathrm{Au}^{0}$} & \multicolumn{2}{|c|}{$\mathrm{Au}^{\delta+}$} & \multicolumn{3}{c|}{ (hydro)carbon } & \multicolumn{2}{c|}{$\mathrm{Fe}_{2} \mathrm{O}_{3}$} \\
\hline & $\mathrm{BE}$ & $\mathrm{FWHM}$ & $\mathrm{BE}$ & $\mathrm{FWHM}$ & $\mathrm{BE}$ & $\mathrm{FWHM}$ & $\mathrm{BE}$ & $\mathrm{FWHM}$ \\
& $(\mathrm{eV})$ & $(\mathrm{eV})$ & $(\mathrm{eV})$ & $(\mathrm{eV})$ & $(\mathrm{eV})$ & $(\mathrm{eV})$ & $(\mathrm{eV})$ & $(\mathrm{eV})$ \\
\hline before $\mathrm{CO}$ & 84.03 & 0.95 & 84.93 & 1.05 & 531.8 & 1.8 & 530.0 & 1.3 \\
\hline After $\mathrm{CO}$ & 83.97 & 1.05 & 84.87 & 1.05 & 531.8 & 2.3 & 530.1 & 1.2 \\
\hline
\end{tabular}

Unfortunately, during the reaction, the sample was partially charging due to the low electrical conductivity of $\mathrm{Fe}_{2} \mathrm{O}_{3}$ in the presence of an $\mathrm{O}_{2}$-rich gas mixture at low temperature. Therefore, $\mathrm{Au} 4 \mathrm{f}, \mathrm{C} 1 \mathrm{~s}$ and $\mathrm{O} 1 \mathrm{~s}$ spectra had to be measured in UHV at $100{ }^{\circ} \mathrm{C}$ after the reaction (Figure 3.43(bottom panel)) in order to obtain a reliable binding energy scale.

Table 3.8. Surface composition of $\mathrm{Au} / \mathrm{Fe}_{2} \mathrm{O}_{3}-\mathrm{C}$ before and after $\mathrm{CO}$ oxidation $\left(\mathrm{CO}: \mathrm{O}_{2}=1: 2\right)$ at $100{ }^{\circ} \mathrm{C}$.

\begin{tabular}{|c|c|c|c|c|c|}
\hline & $\mathrm{Au}^{0}, \%$ & $\mathrm{Au}^{\delta+}, \%$ & $\mathrm{O}, \%$ & $\mathrm{C}, \%$ & $\mathrm{Fe}, \%$ \\
\hline before & 0.6 & 0.3 & 35.5 & 50.0 & 13.6 \\
\hline after & 0.4 & 0.1 & 29.1 & 64.6 & 5.8 \\
\hline
\end{tabular}

The $\mathrm{C}$ 1s peak after the reaction is more intense than before, which indicates carbon accumulation during $\mathrm{CO}$ oxidation. Corresponding $\mathrm{Au} 4 \mathrm{f}$ and $\mathrm{O}$ 1s spectra did not change their shapes, and only their intensities decreased due to carbon accumulation. Both, $\mathrm{Au}^{0}$ and $\mathrm{Au}^{\delta+}$, species remained even after reaction, only the ratio $\mathrm{Au}^{\delta+} / \mathrm{Au}^{0}$ decreases and was 0.5 and 0.25 before and after $\mathrm{CO}$ oxidation, respectively (Table 3.8).

The $\mathrm{Au} 4 \mathrm{f}, \mathrm{O} 1 \mathrm{~s}$ and $\mathrm{C}$ 1s XP spectra were also measured for $\mathrm{Au} / \mathrm{TiO}_{2}-\mathrm{DP}$ (Figure 3.44). A substantial amount of carbon is present on the surface of untreated 
$\mathrm{Au} / \mathrm{TiO}_{2}$-DP (Figure 3.44C(ii)). In comparison with the $\mathrm{C} 1 \mathrm{~s}$ XP spectra of $\mathrm{Au} / \mathrm{Fe}_{2} \mathrm{O}_{3}-\mathrm{C}$, the high-BE peak ( $\mathrm{BE} 288.5 \mathrm{eV}$ ) is less pronounced; however, the intensities of the main peak (BE $284.9 \mathrm{eV}$ ) are comparable. The obtained $\mathrm{O} 1 \mathrm{~s}$ spectrum consists of two main components (Table 3.9): the high-BE component has exactly the same position (BE $531.8 \mathrm{eV}$ ) as in case of $\mathrm{Au} / \mathrm{Fe}_{2} \mathrm{O}_{3}-\mathrm{C}$, and corresponds to oxygen-containing (hydro)carbons; the second $\mathrm{O}$ 1s peak differs from the $\mathrm{Au} / \mathrm{Fe}_{2} \mathrm{O}_{3}-\mathrm{C}$ sample, having a $\mathrm{BE}$ at $530.5 \mathrm{eV}$. This binding energy matches well the position of lattice oxygen of $\mathrm{TiO}_{2}$ [118]. The asymmetric $\mathrm{Au} 4 \mathrm{f}$ spectrum is composed of a metallic peak at a $\mathrm{BE}$ of $83.95 \mathrm{eV}$, and a second component shifted to the higher BE by $0.6 \mathrm{eV}$. The high-BE peak is assigned to an ionic $\mathrm{Au}$ species $\left(\mathrm{Au}^{\delta+}\right)$ [119], which also suggests a strong interaction between the Au NPs and the support material.

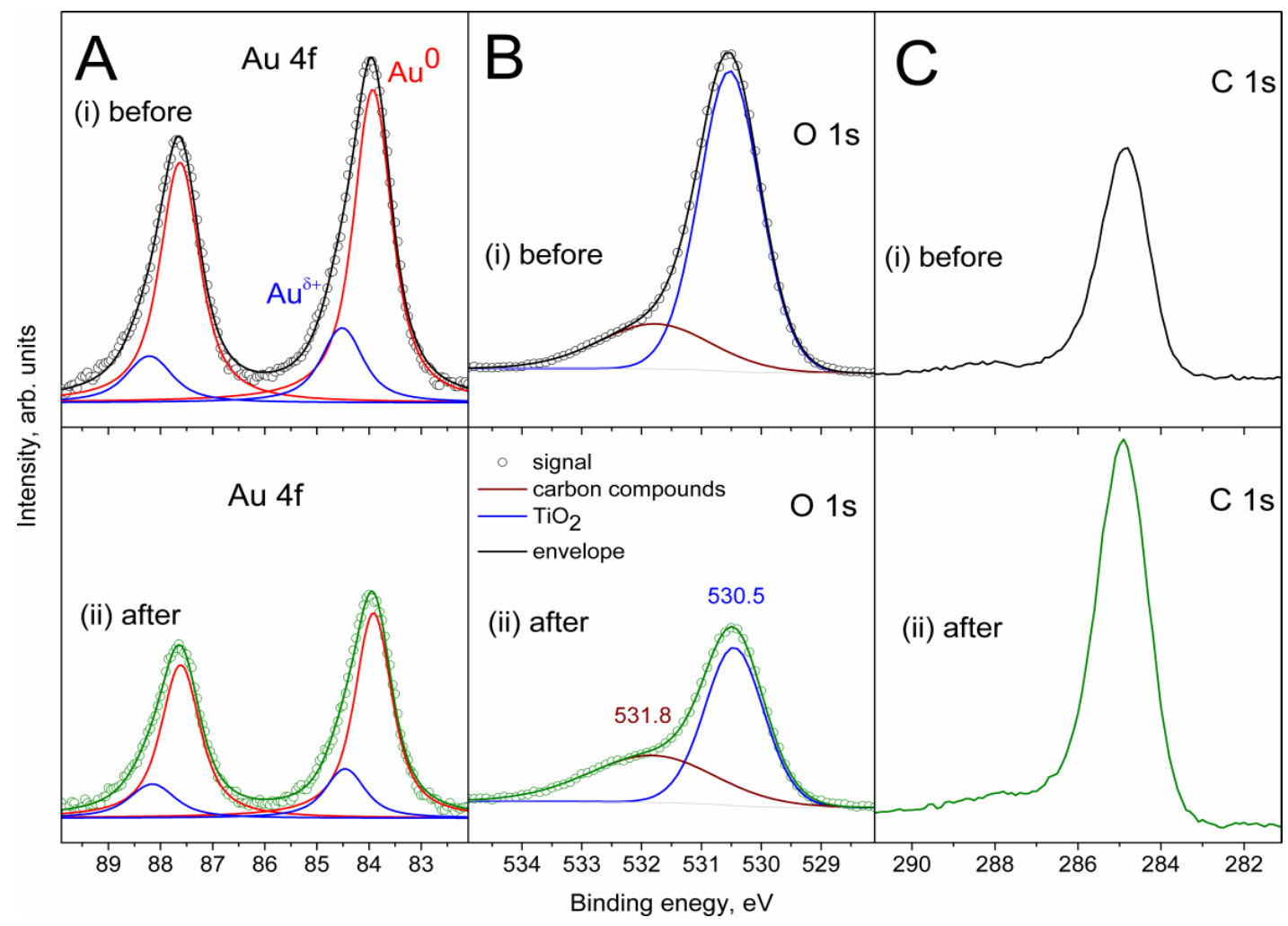

Figure 3.44. (A) $\mathrm{Au} 4 \mathrm{f}$, (B) $\mathrm{O} 1 \mathrm{~s}$ and (C) $\mathrm{C} 1 \mathrm{~s} \mathrm{XP}$ spectra of $\mathrm{Au} / \mathrm{TiO}_{2}-\mathrm{DP}$ before (top panel) and after (low panel) $\mathrm{CO}$ oxidation $\left(\mathrm{CO}: \mathrm{O}_{2}=1: 2\right)$ at $0.3 \mathrm{mbar}$ and $100{ }^{\circ} \mathrm{C}$. Photoelectrons with $160 \mathrm{eV}$ kinetic energy were used to collect $\mathrm{O}$ 1s, C 1s spectra and photoelectrons with $720 \mathrm{eV}$ kinetic energy were used to collect $\mathrm{Au}$ 4f spectra. 
Table 3.9. Fitting parameters of $\mathrm{Au} 4 \mathrm{f}_{7 / 2}$ and $\mathrm{O} 1 \mathrm{~s}$ spectra of $\mathrm{Au} / \mathrm{TiO}_{2}-\mathrm{DP}$.

\begin{tabular}{|c|c|c|c|c|c|c|c|c|}
\hline & \multicolumn{3}{|c|}{$\mathrm{Au} 4 \mathrm{f}_{7 / 2}$} & \multicolumn{3}{c|}{ O 1s } \\
\hline & \multicolumn{2}{|c|}{$\mathrm{Au}^{0}$} & \multicolumn{2}{|c|}{$\mathrm{Au}^{\delta+}$} & \multicolumn{2}{c|}{ (hydro)carbon } & \multicolumn{2}{c|}{$\mathrm{TiO}_{2}$} \\
\hline & $\mathrm{BE}$ & $\mathrm{FWHM}$ & $\mathrm{BE}$ & $\mathrm{FWHM}$ & $\mathrm{BE}$ & $\mathrm{FWHM}$ & $\mathrm{BE}$ & FWHM \\
& $(\mathrm{eV})$ & $(\mathrm{eV})$ & $(\mathrm{eV})$ & $(\mathrm{eV})$ & $(\mathrm{eV})$ & $(\mathrm{eV})$ & $(\mathrm{eV})$ & $(\mathrm{eV})$ \\
\hline Before CO & 83.93 & 0.86 & 84.52 & 0.95 & 531.8 & 2.2 & 530.5 & 1.2 \\
\hline After CO & 83.92 & 0.85 & 84.47 & 0.9 & 531.8 & 2.5 & 530.5 & 1.2 \\
\hline
\end{tabular}

Table 3.10. Surface composition of $\mathrm{Au} / \mathrm{TiO}_{2}-\mathrm{DP}$ before and after $\mathrm{CO}$ oxidation $\left(\mathrm{CO}: \mathrm{O}_{2}=1: 2\right)$ at $100{ }^{\circ} \mathrm{C}$.

\begin{tabular}{|c|c|c|c|c|c|}
\hline & $\mathrm{Au}^{0}, \%$ & $\mathrm{Au}^{\delta+}, \%$ & $\mathrm{O}, \%$ & $\mathrm{C}, \%$ & $\mathrm{Ti}, \%$ \\
\hline before & 1.1 & 0.16 & 48.0 & 34.7 & 16.0 \\
\hline after & 0.8 & 0.2 & 31.7 & 59.7 & 7.6 \\
\hline
\end{tabular}

After $\mathrm{CO}$ oxidation on $\mathrm{Au} / \mathrm{TiO}_{2}-\mathrm{DP}$, both, $\mathrm{Au}^{0}$ and $\mathrm{Au}^{\delta+}$, species remained as in case of $\mathrm{Au} / \mathrm{Fe}_{2} \mathrm{O}_{3}-\mathrm{C}$ (Table 3.8), but their ratio $\mathrm{Au}^{\delta+} / \mathrm{Au}^{0}$ has changed from 0.15 before to 0.25 after reaction (Table 3.10). It cannot be explained by continuing carbon accumulation during the reaction, which leads to an increase of the $\mathrm{C} 1 \mathrm{~s}$ peak intensity and a decrease of $\mathrm{O}$ 1s and $\mathrm{Au} 4 \mathrm{f}$ peak intensities (Figure 3.44(ii)).

The combination of XPS and TEM is a powerful approach, since it allows correlation of electronic structure and morphology. TEM images of a $\mathrm{Au} / \mathrm{TiO}_{2}-\mathrm{DP}$ sample are shown in Figure 3.45. In comparison with the photochemical decomposition preparation method, Au NPs synthesized by deposition precipitation, exhibit a higher degree of wetting, which indicates stronger interaction between the $\mathrm{Au}$ NPs and the support. More defects (for instance twins or symmetrical intergrowth of crystals, and low-coordinated atoms) are evident for the Au particles supported on titania. The NPs have a mean diameter of $15 \mathrm{~nm}$. 

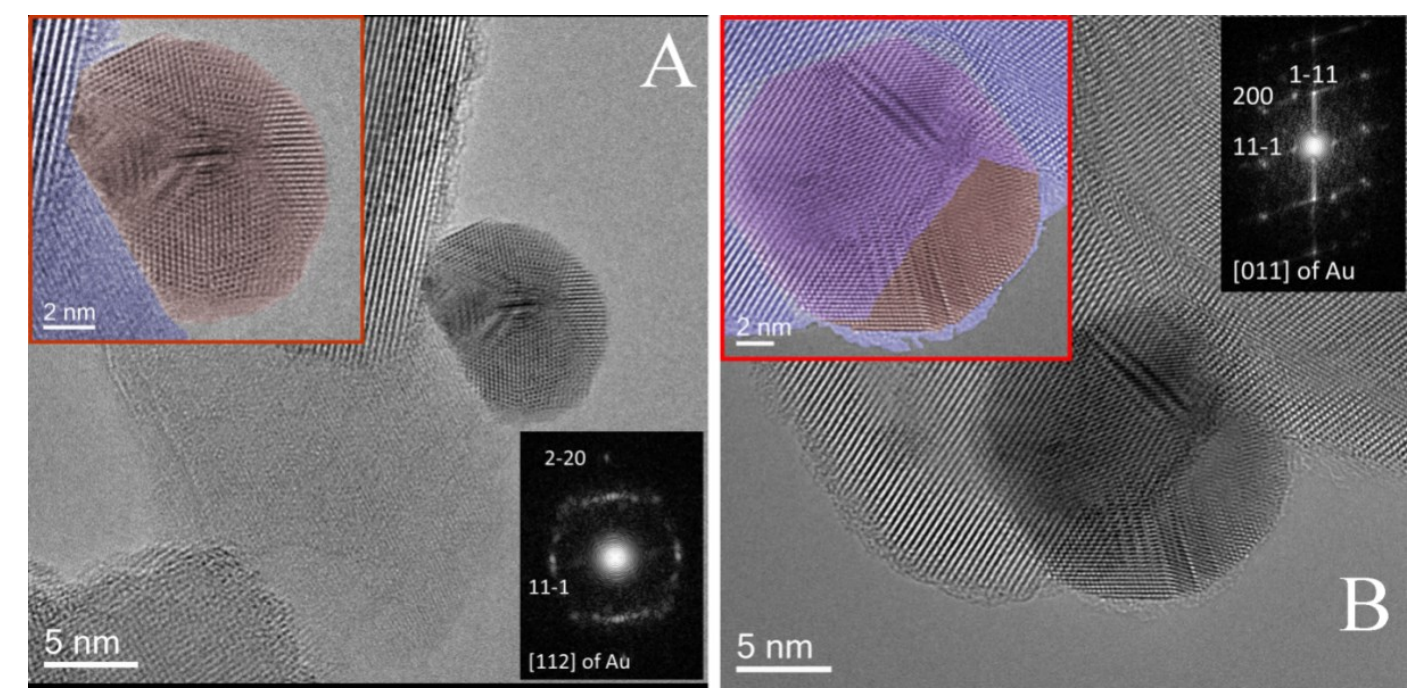

Figure 3.45. TEM images of $\mathrm{Au} / \mathrm{TiO}_{2}-\mathrm{DP}(\mathrm{A})$ before and (B) after $\mathrm{CO}$ oxidation $\left(\mathrm{CO}: \mathrm{O}_{2}=1: 2\right)$ at $0.3 \mathrm{mbar}$ and $100^{\circ} \mathrm{C}$. The insets in $(\mathrm{A})$ and $(\mathrm{B})$ represent power spectra of the $\mathrm{Au}$ nanoparticles. Images were colorized in order to highlight the differences between the two samples.

For fresh samples (i.e. prior to use in the $\mathrm{CO}$ oxidation reaction), no overgrowth of the support onto the NPs is visible. In contrast, after CO oxidation the $\mathrm{Au}$ NPs were covered by a thin layer of support material (Figure 3.45B). Similar results were obtained for $\mathrm{Au} / \mathrm{Fe}_{2} \mathrm{O}_{3}-\mathrm{C}$ sample, with overgrowth of the support forming a thin layer over the Au NPs after the CO oxidation reaction; however, the overgrowth layer is not as extensive as in case of $\mathrm{Au} / \mathrm{TiO}_{2}$-DP (Figure 3.46). Therefore increasing of the $\mathrm{Au}^{\delta+} / \mathrm{Au}^{0}$ ratio of the $\mathrm{Au} / \mathrm{TiO}_{2}-\mathrm{DP}$ sample after $\mathrm{CO}$ oxidation detected by XPS is associated with an overlayer formation observed in TEM due to charge transfer between Au NPs and transition metal oxide. This observation confirms the assumption that a strong metal support interaction (SMSI) is occurring, which may play a key role in the activation mechanism of $\mathrm{Au}$ for $\mathrm{CO}$ oxidation. 


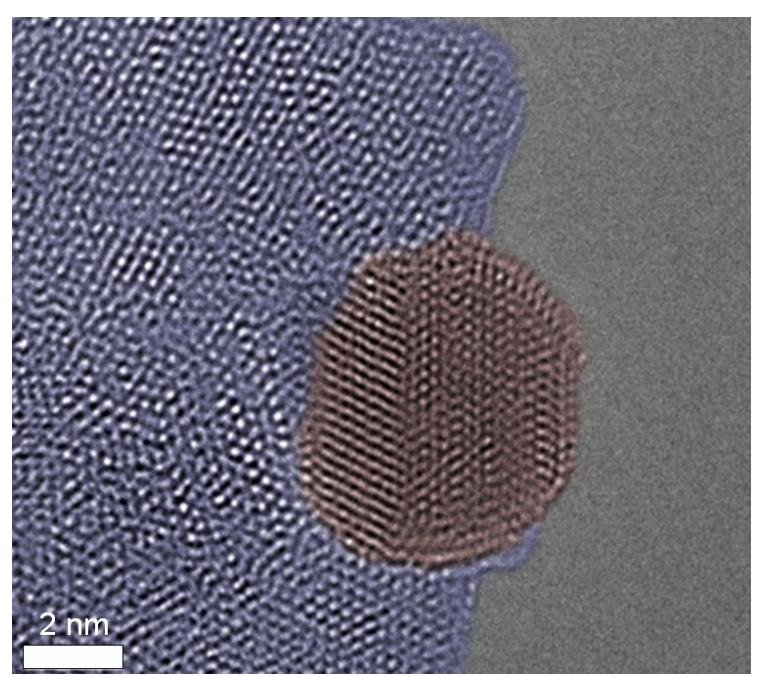

Figure 3.46. TEM image of $\mathrm{Au} / \mathrm{Fe}_{2} \mathrm{O}_{3}-\mathrm{C}$ after $\mathrm{CO}$ oxidation at 0.3 mbar $\left(\mathrm{CO}: \mathrm{O}_{2}=1: 2\right)$ and $100^{\circ} \mathrm{C}$. Image was colorized in order to highlight the differences between $\mathrm{Au}$ and $\mathrm{Fe}_{2} \mathrm{O}_{3}$.

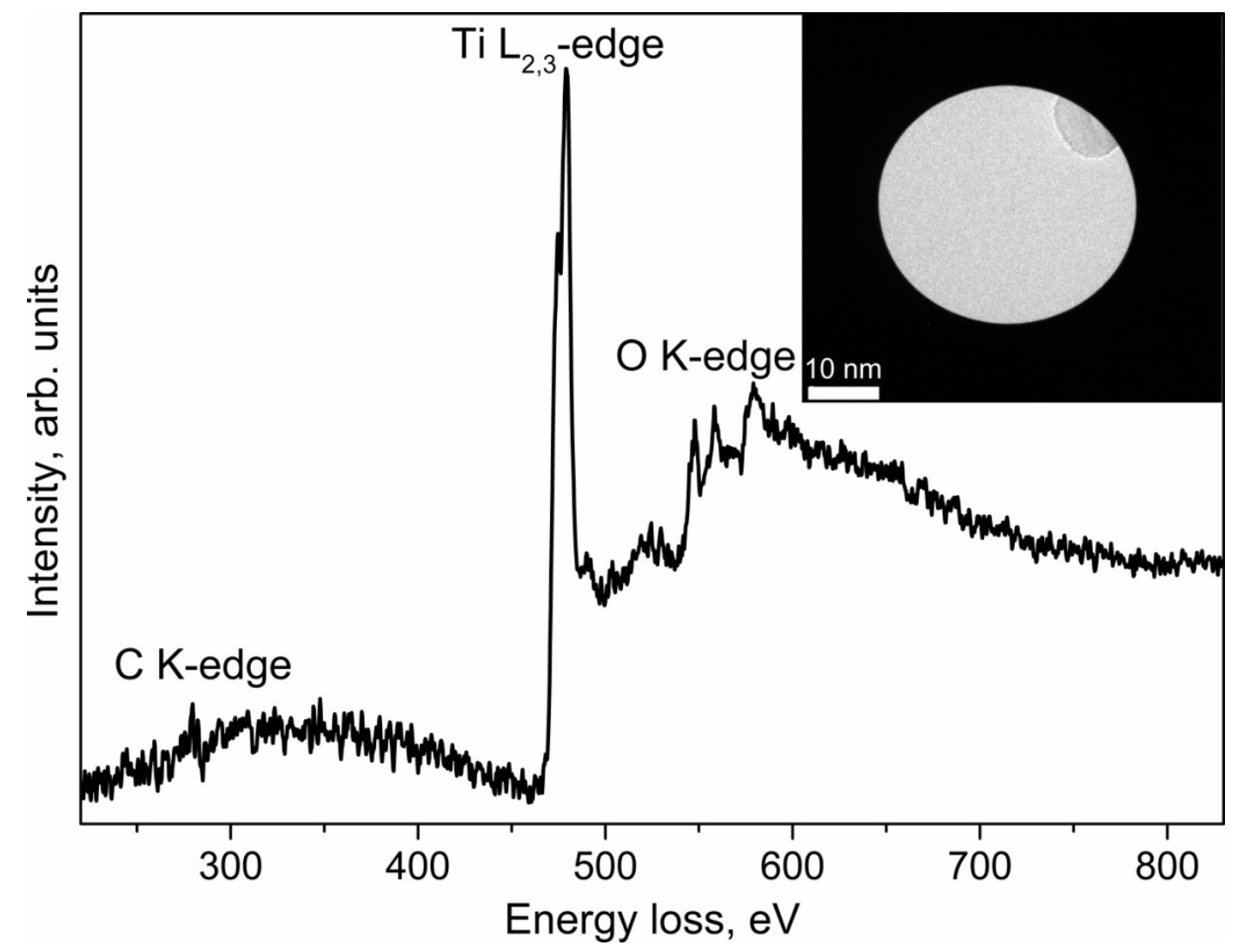

Figure 3.47. EELS spectra of $\mathrm{Au} / \mathrm{TiO}_{2}$-DP after $\mathrm{CO}$ oxidation at 0.3 mbar $\left(\mathrm{CO}: \mathrm{O}_{2}=1: 2\right)$ and $100^{\circ} \mathrm{C}$. The inset represents a TEM image of a single Au NP in front of the aperture. 
The spot size in our XPS measurements is $150 \times 200 \mu \mathrm{m}$, which provides information about electronic structure averaged over this area; however, it does not allow one to judge unequivocally the origin of the overgrowth. Therefore, we use EELS to clarify the nature of overgrowth layer after reaction, and confirm whether it indeed originates from the support material. A single Au NP was placed in front of the aperture, as shown in the inset of Figure 3.47, to reduce the signal contribution from support. The obtained EELS spectrum is presented in Figure 3.47. Here one clearly sees $\mathrm{Ti} \mathrm{L}_{2,3-}$ and $\mathrm{O} \mathrm{K}$-edges. Therefore, the EELS measurements confirms that the overlayer arises from overgrowth of the oxide support onto the Au NPs, and that there is indeed an SMSI between Au NPs and these transition metal oxides.

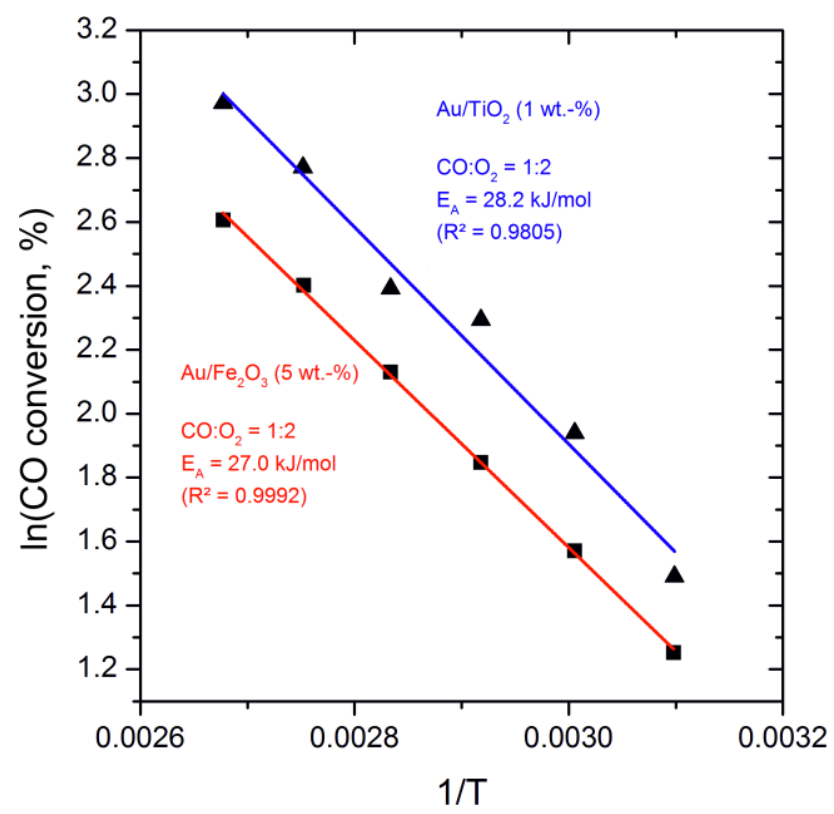

Figure 3.48. Arrhenius plot of $\mathrm{Au} / \mathrm{TiO}_{2}-\mathrm{DP}$ (blue line) and $\mathrm{Au} / \mathrm{Fe}_{2} \mathrm{O}_{3}-\mathrm{C}$ (red line).

In order to estimate activation energies for $\mathrm{CO}$ oxidation on $\mathrm{Au} / \mathrm{Fe}_{2} \mathrm{O}_{3}-\mathrm{C}$ and $\mathrm{Au} / \mathrm{TiO}_{2}$-DP, samples were placed in a $\mathrm{CO}$ oxidation reactor. $\mathrm{CO}$ conversion was measured at six different temperatures without any pre-treatment, yielding the Arrhenius plot shown in Figure 3.48. While the $\mathrm{Au} / \mathrm{TiO}_{2}$-DP sample shows higher conversion rates than $\mathrm{Au} / \mathrm{Fe}_{2} \mathrm{O}_{3}-\mathrm{C}$ at all temperatures, the activation energies of both samples are similar $\left(27.0 \mathrm{~kJ} / \mathrm{mol}\right.$ and $28.3 \mathrm{~kJ} / \mathrm{mol}$ for $\mathrm{Au} / \mathrm{Fe}_{2} \mathrm{O}_{3}-\mathrm{C}$ and $\mathrm{Au} / \mathrm{TiO}_{2}-\mathrm{DP}$, respectively). Thus one may conclude that $\mathrm{Au} / \mathrm{TiO}_{2}-\mathrm{DP}$ had more active sites than $\mathrm{Au} / \mathrm{Fe}_{2} \mathrm{O}_{3}-\mathrm{C}$, but that $\mathrm{CO}$ oxidation on both systems may occur via similar mechanisms. 
Comparison of the activities at $373 \mathrm{~K}$ yields about $7 \mu \mathrm{mol} \mathrm{CO}_{2} \mathrm{~g}_{[\mathrm{Au}]}{ }^{-1} \mathrm{~s}^{-1}$ for photo-chemically prepared $\mathrm{Au} / \mathrm{Fe}_{2} \mathrm{O}_{3}-\mathrm{PC}$ after oxidative pre-treatment $(673 \mathrm{~K})$ and $20 \mu \mathrm{mol} \mathrm{CO}_{2} \mathrm{~g}_{[\mathrm{Au}]}{ }^{-1} \mathrm{~s}^{-1} \mathrm{Au} / \mathrm{Fe}_{2} \mathrm{O}_{3}-\mathrm{C}$ by co-precipitation without any pre-treatment. The most active sample was $\mathrm{Au} / \mathrm{TiO}_{2}-\mathrm{DP}$, with a yield of $35 \mu \mathrm{mol} \mathrm{CO} \mathrm{CO}_{[\mathrm{Au}]}{ }^{-1} \mathrm{~s}^{-1}$. The most important results about Au-based samples on transition metal oxides are summarized in Table 3.11.

Table 3.11. Main finding of Au NPs supported on transition metal oxides.

\begin{tabular}{|l|c|c|c|}
\hline & $\begin{array}{c}\mathrm{Au} / \mathrm{Fe}_{2} \mathrm{O}_{3} \\
-\mathrm{PC}\end{array}$ & $\begin{array}{c}\mathrm{Au} / \mathrm{Fe}_{2} \mathrm{O}_{3} \\
-\mathrm{C}\end{array}$ & $\begin{array}{c}\mathrm{Au} / \mathrm{TiO}_{2} \\
-\mathrm{DP}\end{array}$ \\
\hline $\mathrm{BE}$ difference betweeen $\mathrm{Au}^{\delta+}$ and $\mathrm{Au}^{0}, \mathrm{eV}$ & - & +0.9 & +0.6 \\
\hline degree of wetting & low & high & high \\
\hline overlayer formation & no & low & high \\
\hline activation energy for $\mathrm{CO}$ oxidation, $\mathrm{kJ} / \mathrm{mol}$ & - & 27.0 & 28.3 \\
\hline $\mathrm{CO}_{2}$ yield, $\mu \mathrm{mol} \mathrm{CO}_{2} \mathrm{~g}_{[\mathrm{Au}]}^{-1} \mathrm{~s}^{-1}$ & $<7$ & 20 & 35 \\
\hline
\end{tabular}

Our experiments reveal that activity of $\mathrm{Au}$ on transition metal oxides, such as $\mathrm{Fe}_{2} \mathrm{O}_{3}$ and $\mathrm{TiO}_{2}$, depends on the method of synthesis. Only samples prepared by the precipitation method showed high $\mathrm{CO}_{2}$ production at low temperature, independent of the metal oxide. It is known that the method of synthesis is crucial for controlling the activity of a catalyst [120]. Au NPs synthesized by photo-induced decomposition do not possess any significant catalytic activity because of minimal interaction with the metal oxide support, and therefore such samples retain the inertness of bulk gold. Most preparation methods produce large NPs that are inactive for CO oxidation, but deposition precipitation provides good control over particle size. The preparation of $\mathrm{Au} / \mathrm{TiO}_{2}$ by deposition precipitation has been studied in detail by Moreau et al. [121] and they outline that the method allows one to control many experimental parameters (concentration, temperature, $\mathrm{pH}$, time, etc.).

As is apparent from the XPS results, two Au species are formed on the active catalysts. TEM images of these samples reveal the formation of an extended interface 
between the Au NPs and the oxide support. Therefore, it is possible that the $\mathrm{Au}^{\delta^{+}}$ component seen in the XP spectra is from a species formed by a strong interaction between the surface $\mathrm{Au}$ atoms and overgrowth layer from the oxide supports. In the literature there is much debate concerning the nature of the active site for Au-based catalysts. Various factors - such as quantum size effects [122], low coordinated atoms, surface ions and the support interactions [25] - have been proposed as factors that influence Au activity. Some authors consider metallic gold $[123,124]$ to be the active site, while others suggest positive $(\delta+)[125,126]$ or negative $(\delta-)[127,128]$ low-charged gold or oxidized $(1+, 3+)$ states [129]. Some years ago Bond and Thomson [26] proposed a model where Au atoms at the interface between Au and the oxide are the active oxidation centers; however, they focus on a mechanistic debate, while the electronic structure of active Au remained unclear.

Our present findings suggest that, on the active catalyst's surface, gold is present in both cationic and metallic forms, where the atoms at the triple-phase boundary are cationic in nature. These results are in a good agreement with previous works of Costello et al. [130] and Kung et al. [116], where a chemical model that involves an ensemble of metallic Au atoms and Au cations with hydroxyl ligands has been suggested.

It must also be noted that XP spectra of Au NPs are markedly affected by finalstate effects, and furthermore, the binding energy of the $\mathrm{Au}^{0}$ is highly size-dependent for small nanoparticles [131]. When the electron leaves the system, a core hole is made and is stabilized to a varying degree depending on the chemical environment. If this core hole decay occurs before the emitted photoelectron is completely decoupled from the system, then the electron binding energy is affected. The ionization of a single atom will result in a localized hole with little ability for the atom to electronically relax, while in a cluster of many atoms, the hole produced after ionization may be delocalized over the cluster lowering the final state energy. It was shown that Au NPs containing less than 70 atoms $(0.5 \mathrm{~nm})$ have a BE shift of the $\mathrm{Au} 4 \mathrm{f}$ peak by $0.25 \mathrm{eV}$ to higher region independently on the substrates [132]. However, BE value decreases with increasing number of atoms and approaches value of bulk Au, when NPs reach size about $5 \mathrm{~nm}$ (1800 atoms). In our case, because of rather large Au NPs (15 nm) and simultaneously observed shifted and none shifted 
$\mathrm{Au}$ species, the contribution from final-state effects to BE shift can be excluded, so the positive binding energy shifts are the result of the interaction between Au and the oxide support. The similarity in the high-BE shift values of $\mathrm{Au} / \mathrm{TiO}_{2}-\mathrm{DP}$ and $\mathrm{Au} / \mathrm{Fe}_{2} \mathrm{O}_{3}-\mathrm{C}$ suggests the same origin for both samples, i.e. SMSI. The small difference in chemical shift arises due to different interaction strengths (charge transfer) between $\mathrm{Au}$ and the oxides. The high-BE shift value $(0.9 \mathrm{eV})$ for $\mathrm{Au} / \mathrm{TiO}_{2}-$ DP correlates well with Chusuei's work [133]. Yang and Wu [134] showed that the high-BE shift is caused by the interaction of gold with oxygen vacancies and not by final-state effects. DFT calculations also identify the importance of Au-transition metal oxide interaction in $\mathrm{CO}$ oxidation [135].

The obtained TEM images reliably show that the formation of an overgrowth layer can be observed only after the reaction. $\mathrm{Au}^{\delta+}$ peak observed in XPS before reaction shows initial interaction between $\mathrm{Au}$ NPs and underlying oxide. The overgrowth layer from the support is evidence of a SMSI. Furthermore, the higher $\mathrm{CO}_{2}$ production rate of $\mathrm{Au} / \mathrm{TiO}_{2}-\mathrm{DP}$ than $\mathrm{Au} / \mathrm{Fe}_{2} \mathrm{O}_{3}-\mathrm{C}$ may be explained by different interaction strengths between $\mathrm{Au}$ and the support. Indeed, Grunwald et al. [136] showed higher activity of $\mathrm{Au} / \mathrm{TiO}_{2}$ in comparison with $\mathrm{Au} / \mathrm{ZrO}_{2}$ even though the particle sizes were identical. They believe that the support affects the ability of Au to dissociate oxygen. Also Au-based catalysts supported on 'non-reducible' metal oxide supports $\left(\mathrm{Au} / \mathrm{Al}_{2} \mathrm{O}_{3}\right)$ have considerably less activity than those supported on 'reducible' metal oxide supports $\left(\mathrm{Au} / \mathrm{Fe}_{2} \mathrm{O}_{3}, \mathrm{Au} / \mathrm{TiO}_{2}\right)$ [137]. Au-assisted Mars-van Krevelen mechanism of reducible support [138] was discussed to be the origin of the overgrowth layer. Based on quantitative temporal analysis of products reactor measurements, which allow the detection and quantification of active species even at the extremely low concentrations at RT and above, Behm's group [139] has shown that he active oxygen species for $\mathrm{CO}$ oxidation on $\mathrm{Au} / \mathrm{TiO}_{2}$ at temperature above 80 ${ }^{\circ} \mathrm{C}$ is formed only at the perimeter of the Au-oxide interface. In-situ infrared spectroscopy confirms the interaction of $\mathrm{CO}$ molecules with the partly reduced titania support surface under reduction atmosphere [140]. Indeed, locally reduced $\mathrm{TiO}_{2}$ near Au NPs may have higher mobility, which could lead to the formation of an overlayer. 
The activation energy values calculated from Arrhenius plots for $\mathrm{CO}$ oxidation and specific surface area measurements $\left(\mathrm{S}_{\mathrm{BET}}\right)$ of our samples, $\mathrm{Au} / \mathrm{Fe}_{2} \mathrm{O}_{3}-\mathrm{C}$ and $\mathrm{Au} / \mathrm{TiO}_{2}$-DP, prepared by precipitation methods are shown in Table 3.13 together with a comparison with other works. Despite the similarity of activation energy values and sizable difference in specific surface area, $27.0 \mathrm{~kJ} / \mathrm{mol}$ and $28.2 \mathrm{~kJ} / \mathrm{mol}$, $206.8 \mathrm{~m}^{2} / \mathrm{g}$ and $54.8 \mathrm{~m}^{2} / \mathrm{g}$ for $\mathrm{Au} / \mathrm{Fe}_{2} \mathrm{O}_{3}-\mathrm{C}$ and $\mathrm{Au} / \mathrm{TiO}_{2}-\mathrm{DP}$, respectively, the intrinsic activity of $\mathrm{Au} / \mathrm{TiO}_{2}$-DP is much higher (Table 3.12), which suggests higher numbers of active sites on the surface. Because of the existence of numerous defects on the surface of active samples, SMSI also enables stabilization of low-coordinated Au atoms.

Table 3.12. Activation energies for $\mathrm{CO}$ oxidation and specific surface area of $\mathrm{Au} / \mathrm{Fe}_{2} \mathrm{O}_{3}$ and $\mathrm{Au} / \mathrm{TiO}_{2}$ prepared by different methods.

\begin{tabular}{|l|c|c|c|c|}
\hline Catalysts & Preparation method & $\mathrm{S}_{\mathrm{BET}}\left[\mathrm{m}^{2} / \mathrm{g}\right]$ & $\mathrm{E}_{\mathrm{a}}[\mathrm{kJ} / \mathrm{mol}]$ & Ref. \\
\hline $\mathrm{Au} / \mathrm{Fe}_{2} \mathrm{O}_{3}$ & DP & & 29 & {$[137]$} \\
\hline & DP & & 35 & {$[141]$} \\
\hline & DP with phosphine & & 21 & {$[142,143]$} \\
\hline & co-precipitation & 206.8 & 27.0 & This work \\
\hline & co-precipitation & 73 & & {$[41]$} \\
\hline & co-precipitation & 45 & & {$[144]$} \\
\hline $\mathrm{Au} / \mathrm{TiO}_{2}$ & DP & 196.1 & & {$[145]$} \\
\hline & DP with phosphine & & 12 & {$[142,143]$} \\
\hline & impregnation & & 21 & {$[137]$} \\
\hline & impregnation & & 29 & {$[148]$} \\
\hline & DP & 54.8 & 28.2 & This work \\
\hline & DP & 44 & & {$[144]$} \\
\hline & DP & 81.8 & & {$[149]$} \\
\hline & colloidal deposition & 47 & & {$[150]$} \\
\hline
\end{tabular}

Our results agree well with the proposed reaction pathway (Scheme 3.1) for the $\mathrm{CO}$ oxidation reaction over supported Au catalysts, as described by Schubert et al. [137] Oxygen adsorbs in large quantities on reducible metal oxides and then migrates 
to the Au NPs. Dissociation of the mobile oxygen is suggested to take place at the metal-support interface, after which atomic oxygen reacts with $\mathrm{CO}$ adsorbed on the gold and/or at the interface. Therefore, the formation of an overlayer increases triple phase boundary, which leads to increases in $\mathrm{CO}_{2}$ yield. An increase in interface area can be achieved by decreasing the particle size, which also leads to a significant increase of $\mathrm{CO}_{2}$ production $[122,142,151]$.

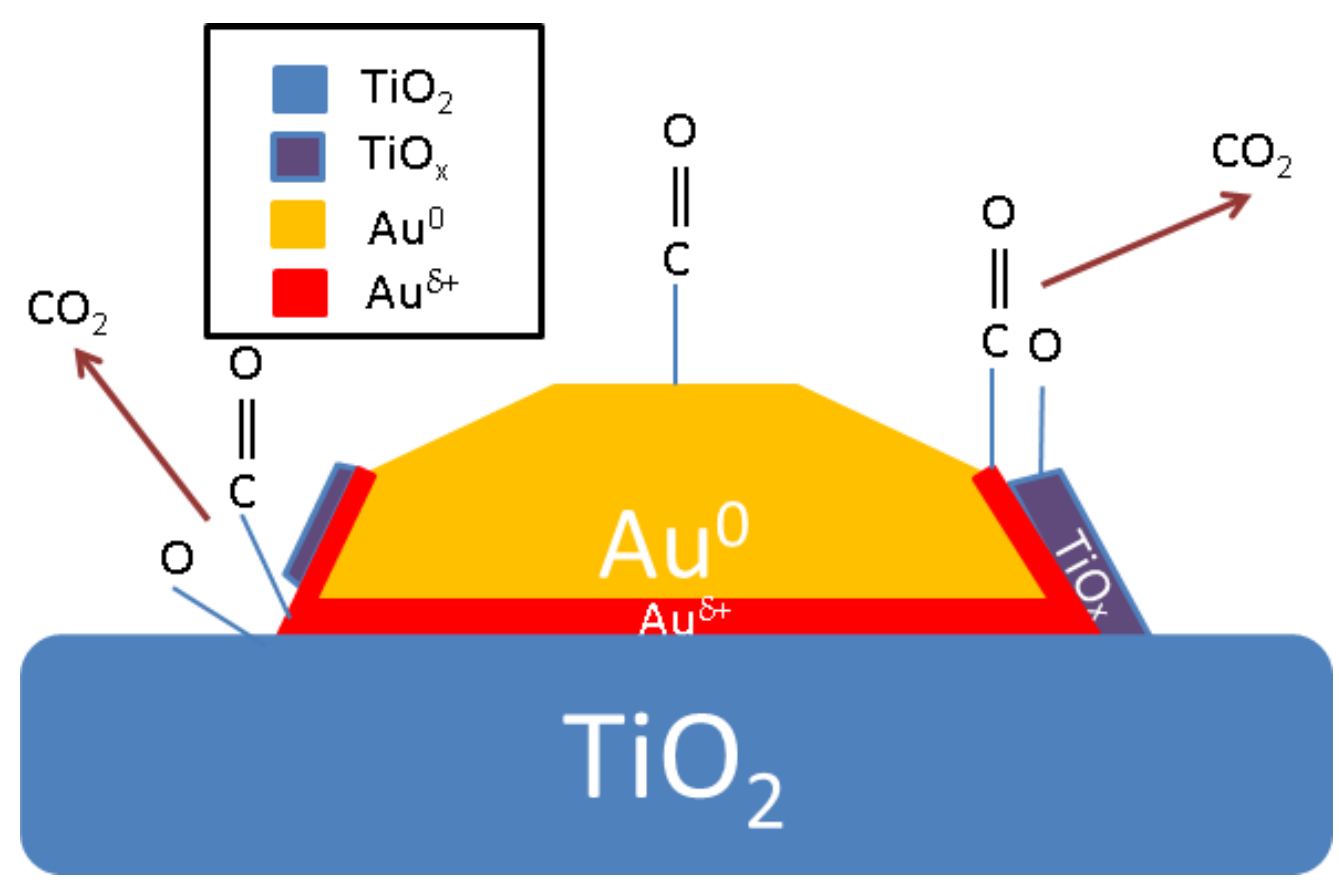

Scheme 3.1. Suggested $\mathrm{CO}$ oxidation pathway on $\mathrm{Au} / \mathrm{TiO}_{2}$.

\subsubsection{Conclusions.}

The results presented here indicate that the Au NPs on transition metal oxides show high catalytic activity, which depends on the method of preparation, and can be associated with the formation of positively charged $\mathrm{Au}$ species. Indeed, only the samples prepared by precipitation methods showed significant CO conversion at low temperature. XPS revealed the presence of two $\mathrm{Au}$ species $\left(\mathrm{Au}^{0}\right.$ and $\left.\mathrm{Au}^{\delta+}\right)$ on the surface of active $\mathrm{Au} / \mathrm{TiO}_{2}-\mathrm{DP}$ and $\mathrm{Au} / \mathrm{Fe}_{2} \mathrm{O}_{3}-\mathrm{C}$ samples. The energy shift of the $\mathrm{Au}^{\delta+}$ peak, relative to bulk gold $\left(\mathrm{Au}^{0}\right)$, depends on the support, and is $0.6 \mathrm{eV}$ and $0.9 \mathrm{eV}$ to higher binding energy for $\mathrm{Au} / \mathrm{TiO}_{2}-\mathrm{DP}$ and $\mathrm{Au} / \mathrm{Fe}_{2} \mathrm{O}_{3}-\mathrm{C}$, respectively. TEM images indicate the formation of overlayers on Au particles. EELS spectra confirm that the 
overlayers consist of support material - i.e. transition metal oxide overlayers on top of the Au NPs.

Tiny activity of $\mathrm{Au} / \mathrm{Fe}_{2} \mathrm{O}_{3}-\mathrm{PC}$ at higher temperature shows that there are some active sites, but their amount is very little. Sample synthesized by photo-induced decomposition of an Au-Azido complex is characterized by small contact angle between $\mathrm{Au}$ and $\mathrm{Fe}_{2} \mathrm{O}_{3}$ and spherical shape of NPs. These features do not allow forming strong interaction between Au NPs and metal oxide. Therefore the correct strategy to activate $\mathrm{Au}$ is to form Au-support interaction via charge transfer, which can be realized by the method of synthesis. 


\section{Summary.}

The discovery that gold nanoparticles (Au NPs) supported on metal oxides are active in low-temperature $\mathrm{CO}$ oxidation has inspired a considerable amount of research focused on understanding the basis of activity of $\mathrm{Au}$ catalysts Various factors - such as quantum size effects, low coordinated atoms, surface ions and the support interaction have been proposed as factors that influence Au activity. In this thesis a systematical study of the catalytic properties of oxidized Au and Au NPs on various supports in $\mathrm{CO}$ oxidation reaction were conducted.

All measurements were performed in the near ambient pressure X-ray photoelectron spectroscopy (NAP-XPS) endstation at the ISISS beamline at HZB/BESSY II (Berlin, Germany). Gold containing samples (Au foil, Au NPs supported on carbon and transition metal oxides) were characterized using in-situ XPS and ex-situ techniques, such as electron energy loss spectroscopy (EELS), scanning and transmission electron microscopy (SEM and TEM). CO and $\mathrm{O}_{2} / \mathrm{O}_{3}$ were introduced to the chamber at different ratios, keeping the pressure and temperature constant, at $0.3 \mathrm{mbar}$ and $100^{\circ} \mathrm{C}$, respectively.

The procedure, used to prepare the $\mathrm{Au} / \mathrm{HOPG}$ (highly oriented pyrolytic graphite) model catalysts, involves forming defects on the HOPG surface via soft $\mathrm{Ar}^{+}$ sputtering, followed by Au deposition and surface annealing at $300^{\circ} \mathrm{C}$ in UHV (for Au NPs stabilization). Au NPs supported on functionalized carbon nanotubes (CNTs) were prepared using immobilization and incipient impregnation methods. Nanoscopic Au was electrochemically deposited on Au foil. Au NPs on transition metal oxides were synthesized by precipitation $\left(\mathrm{Au} / \mathrm{Fe}_{2} \mathrm{O}_{3}, \mathrm{Au} / \mathrm{TiO}_{2}\right)$ and photochemical decomposition of intermediate gold-azido complexes $\left(\mathrm{Au} / \mathrm{Fe}_{2} \mathrm{O}_{3}\right.$, $\mathrm{Au} / \mathrm{Cr}_{2} \mathrm{O}_{3}$ ) methods.

Our in-situ measurements show that the oxidation of extended Au surfaces by $\mathrm{O}_{3}$ treatment is accompanied by the formation of meta-stable surface oxide(s). It was found that $\mathrm{Au}$ oxide does not directly participate in $\mathrm{CO}$ oxidation on Au-based catalysts. Our experiments on $\mathrm{Au}$ foil allow us to conclude that low-coordinated $\mathrm{Au}$ atoms, present on the surface after oxidation, do not possess catalytic activity for $\mathrm{CO}$ oxidation at room temperature. Similar to oxidized Au foil, Au NPs on oxygen-free 
supports (HOPG, functionalized CNTs, Au foil) do not show any catalytic activity, regardless of the NPs' size, the type of the support and the method of synthesis. Therefore, NP size only reduction and/or oxidation are not sufficient to activate $\mathrm{Au}$ (Table 4.1).

Table 4.1 CO oxidation on Au-based catalysts.

\begin{tabular}{|c|c|c|}
\hline & $\begin{array}{c}\text { Stoichiometric } \\
\text { reaction } \\
\end{array}$ & $\begin{array}{l}\text { Catalytic } \\
\text { reaction }\end{array}$ \\
\hline Clean Au foil & $\mathbf{x}$ & 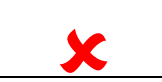 \\
\hline Oxidized Au foil & $x$ & $x$ \\
\hline Clean $\mathrm{Au}$ powder & $x$ & $x$ \\
\hline Oxidized $\mathrm{Au}$ powder & $x$ & $x$ \\
\hline Au@HOPG & $x$ & $x$ \\
\hline OxidizedAu@HOPG & & $x$ \\
\hline $\mathrm{Au} @ \mathrm{~N}-\mathrm{CNTs}$ & $x$ & $x$ \\
\hline OxidizedAu@N-CNTs & & $x$ \\
\hline $\mathrm{Au} @ \mathrm{O}-\mathrm{CNTs}$ & $x$ & $x$ \\
\hline OxidizedAu@O-CNTs & & $x$ \\
\hline Au@Au foil & $x$ & $x$ \\
\hline OxidizedAu@Au foil & & $x$ \\
\hline $\mathrm{Au} @ \mathrm{Fe}_{2} \mathrm{O}_{3}$ (photo-induced & - & \\
\hline $\mathrm{Au} @ \mathrm{Cr}_{2} \mathrm{O}_{3}$ (photo-induced & - & 1 \\
\hline $\mathrm{Au} / \mathrm{Fe}_{2} \mathrm{O}_{3}$ (coprecipitation) & - & $v$ \\
\hline $\mathrm{Au} / \mathrm{TiO}_{2}$ (deposition-precipitation) & & \\
\hline
\end{tabular}

In contrast, $\mathrm{Au}$ NPs on oxygen containing supports show high catalytic activity, which depends on the method of preparation, and can be associated with the formation of positively charged $\mathrm{Au}$ species (Figure 4.1). Indeed, only samples prepared by precipitation methods showed significant $\mathrm{CO}$ conversion at low temperature. XPS revealed the presence of only two $\mathrm{Au}$ species $\left(\mathrm{Au}^{0}\right.$ and $\left.\mathrm{Au}^{\delta+}\right)$ on the surface of active samples, $\mathrm{Au}$ NPs of inactive sample have 'bulk'-like $\left(\mathrm{Au}^{0}\right)$ nature. The energy shift of the $\mathrm{Au}^{\delta+}$ peak, relatively to bulk gold $\left(\mathrm{Au}^{0}\right)$, depends on 
the support, and is $0.6 \mathrm{eV}$ and $0.9 \mathrm{eV}$ to higher binding energy for $\mathrm{Au} / \mathrm{TiO}_{2}$ and $\mathrm{Au} / \mathrm{Fe}_{2} \mathrm{O}_{3}$, respectively. TEM and EELS spectra show the formation of transition metal oxide overlayers on top of the Au NPs.

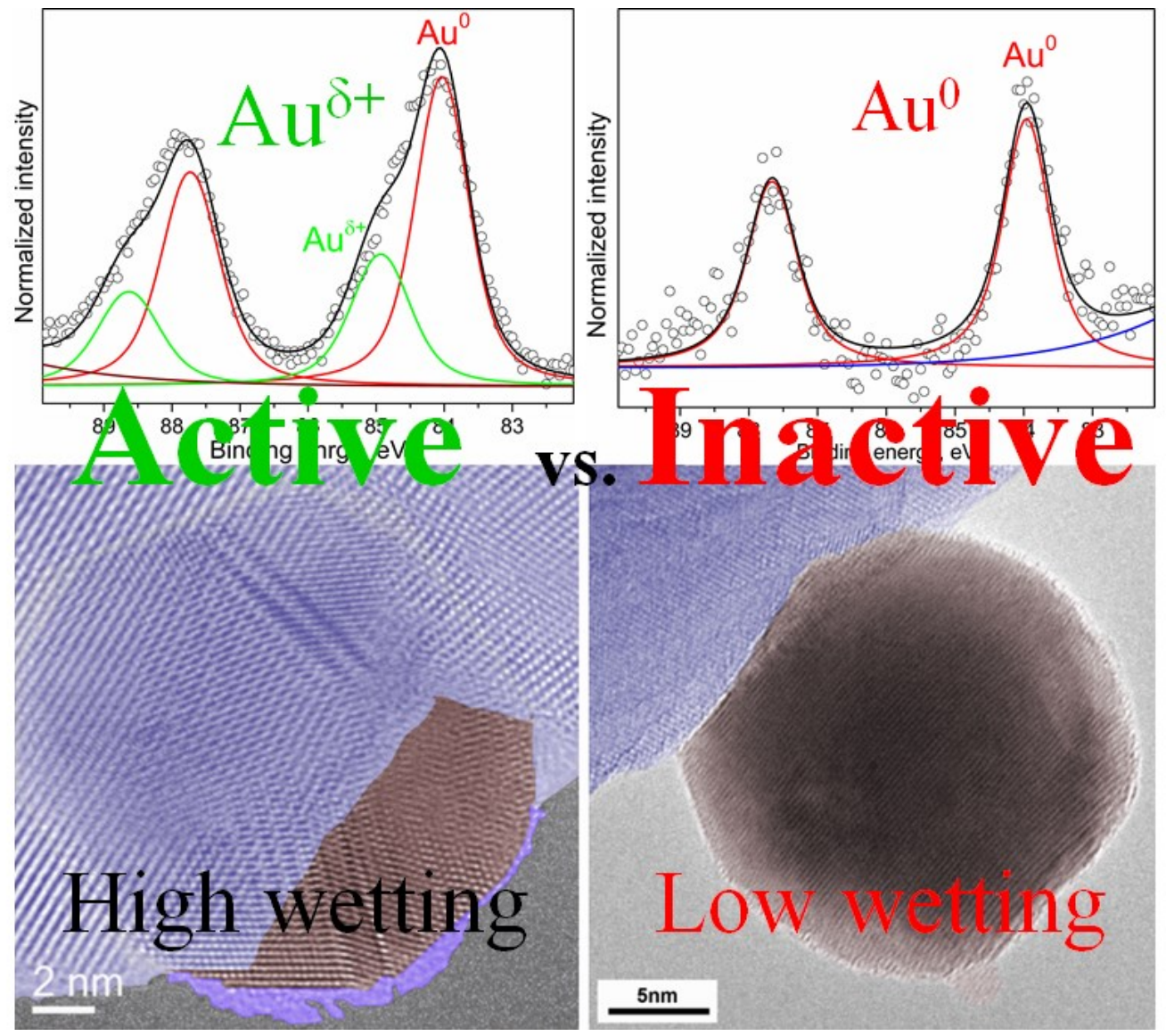

Figure 4.1. $\mathrm{Au}$ 4f XP spectrum and TEM image of sample synthesized by deposition-precipitation (left) and photochemical decomposition of intermediate gold-azido complex (right) method.

Our results suggest a mechanism of $\mathrm{Au}$ activation in $\mathrm{CO}$ oxidation via Strong Metal Support Interaction, assuming a strong influence of the support on the electronic structure of the gold through charge transfer and stabilization of lowcoordinated $\mathrm{Au}$ atoms. Therefore SMSI plays key role in $\mathrm{Au}$ activation for $\mathrm{CO}$ oxidation and is more important than size reduction. 


\section{Bibliography.}

1. G. C. Bond, Heterogeneous Catalysis: Principles and Applications, Oxford U.P, Oxford, 1987.

2. G. C. Bond, C. Louis, D. T. Thompson, Catalysis by Gold, Imperial College Pr., London, 2007.

3. B. Hinnemann, J. K. Nørskov, Top. Catal. 2006, 37, 55-70.

4. R. Schlögl, in Handbook of Heterogeneous Catalysis, ed. G. Ertl, H. Knozinger, F. Schuth, J. Weitkamp, Wiley-VCH Verlag, GmbH \& Co. KGaA, Weinheim, 2008, Chapter 12.1, pp. 2501-2575.

5. F. Haber, G. van Oordt, Z. Anorg. Allg. Chem. 1905, 44, 341-378.

6. A. M. Trzeciak, J. J. Ziolkowski, Coord. Chem. Rev. 1999, 190-192, 883-900.

7. K. Klier, Adv.Catal. 1982, 30, 243-313.

8. G. P. Van der Laan, A. A. C. M. Beenackers, Catal. Rev. -Sci. Eng. 1999, 41, 255-318.

9. L. Glasser, J. Chem. Educ. 1979, 56, 22.

10. A. Couper, D. D. Eley, Discuss. Faraday Soc. 1950, 8, 172-184.

11. B. L. M. Hendriksen, J. W. M. Frenken, Phys. Rev. Lett. 2002, 89, 046101.

12. A. Hoffman, T. Maniv, M. Folman, Surf. Sci. 1987, 183, 484-502.

13. A. Atli, M. Abon, P. Beccat, J.C. Bertolini, B. Tardy, Surf. Sci. 1994, 302, $121-125$.

14. H. Hirano, T. Yamada, K. I. Tanaka, J. Siera, P. Cobden, B. E. Nieuwenhuys, Surf. Sci. 1992, 262, 97-112.

15. K.S. Kim, M. A. Barteau, Surf. Sci. 1989, 223, 13-32.

16. J. H. McCreery, G. Wolken Jr., J. Chem. Phys. 1976, 64, 2845-2853.

17. R. A. Barker, P. J. Estrup, F. Jona, P. M. Marcus, Solid State Commun. 1978, $25,375-379$.

18. M. Bäumer, H.-J. Freund, Prog. Surf. Sci. 1999, 61, 127-198.

19. L. Aballe, A. Barinov, A. Locatelli, S. Heun, M. Kiskinova, Phys. Rev. Lett. 2004, 93, 196103.

20. D. W. Goodman. Chem. Rev. 1995, 95, 523-536. 
21. A. Böttcher, H. Nirhus, S. Schwegmann, H. Over, G. Ertl. J. Phys. Chem. B 1997, 101, 11185-11191.

22. T. C. R. Rocha, M. Hävecker, A. Knop-Gericke, R.Schlögl, J. Catal. 2014, 312, 12-16.

23. P. A. Sermon, Gold Bull. 1976, 9, 129-131.

24. M. Haruta, N. Yamada, T. Kobayashi, S. Iijima, J. Catal. 1989, 115, 301-309.

25. B. K. Min, C. M. Friend, Chem. Rev. 2007, 107, 2709-2724.

26. G.C. Bond, D. T. Thompson, Gold Bull. 2000, 33, 41-51.

27. T. Hayashi, K. Tanaka, M. Haruta, J.Catal. 1998, 178, 566-575.

28. A. K. Sinha, S. Seelan, S. Tsubota, M. Haruta, Top. Catal. 2004, 29, 95-102.

29. I. Andreeva, T. Tabakova, A. Andreev, J. Catal. 1996, 158, 354-355.

30. A. S. K. Hashmi, G. J. Hutchings, Angew. Chem. Int. Ed. 2006, 45, 7896-7936.

31. C. González-Arellano, A. Corma, M. Iglesias, F. Sánchez, Chem. Commun. 2005, 27, 3451-3453.

32. N. Dimitratos, J. A. Lopez-Sanchez, G. J. Hutchings, Chem. Sci. 2012, 3, 2044.

33. M. C. Kung, J.-H. Lee, A. Chu-Kung, H. H. Kung, Stud. Surf. Sci. Catal. 1996, 101, 701-710.

34. A. Ueda, T.Oshima, M. Haruta, Appl. Catal. B 1997, 12, 81-93.

35. R. M. T. Sanchez, A. Ueda, K.Tanaka, M. Haruta, J. Catal. 1997, 168, 125127.

36. G. K. Bethke, H. H. Kung, Appl. Catal. A 2000, 194, 43-53.

37. Y. A. Kalvachev, T. Hayashi, S. Tsubota, M. Haruta, J. Catal. 1999, 186, 228233.

38. T. Hayashi, K. Tanaka, M. Haruta, J. Catal. 1998, 178, 566-575.

39. J. F. Jia, K. Haraki, J. N. Kondo, K. Domen, K. Tamaru, J. Phys. Chem. B 2000, 104, 11153-11156.

40. M. Okumura, T. Akita, M. Haruta, Catal. Today 2002, 74, 265-269.

41. M. Haruta, M. Daté, Appl. Catal. A 2001, 222, 427-437.

42. J.-L. Lu, H.-J. Gao, S. Shaikhudinov, H.-J. Freund, Catal. Lett. 2007, 114, 816.

43. F. Boccuzzi, A. Chiorino, M. Manzoli, Surf. Sci. 2000, 454-456, 942-946. 
44. Y. Iizuka, T. Tode, T. Takao, K. Yatsu, T. Takeuchi, S. Tsubota, M. Haruta, J. Catal. 1999, 187, 50-58.

45. K. Mallick, M. S. Scurrell, Appl. Catal. A Gen. 2003, 253, 527-536.

46. J.-D. Grunwaldt, M. Maciejewski, O. S. Becker, P. Fabrizioli, A. Baiker, J. Catal. 1999, 186, 458-469.

47. J. T. Calla, R. J. Davis, J. Phys. Chem. B 2004, 109, 2307-2314.

48. A. K. Tripathi, V. S. Kamble, N. M. Gupta, J. Catal. 1999, 187, 332-342.

49. D. E. Starr, Sh. K. Shaikhutdinov, H.-J. Freund, Top. Catal. 2005, 36, 33-41.

50. M. Valden, S. Pak, X. Lai, D. W. Goodman, Catal. Lett. 1998, 56, 7-10.

51. G. Glaspell, L. Fuoco, M. S. El-Shall, J. Phys. Chem. B 2005, 109, 1735017355.

52. W.-C. Li. M. Comotti, F.Schüth, J. Catal. 2006, 237, 190-196.

53. V. Schwartz, D. R. Mullins, W. Yan, B. Chen, S. Dai, S. H. Overbury, J. Phys. Chem. B 2004, 108, 15782-15790.

54. A. Bongiorno, U. Landman, Phys. Rev. Lett. 2005, 95, 106102.

55. B. K. Min, A. R. Alemozafar, D. Pinnaduwage, X. Deng, C. M. Friend. J. Phys Chem B 2006, 110, 19833-19838.

56. J.-D. Grunwaldt, A. Baiker. J. Phys. Chem. B 1999, 103, 1002-1012.

57. N. Lopez, J. Norskov. J. Am. Chem. Soc. 2002, 124, 11262-11263.

58. H. Robinson, W. F. Rawlison, Phil. Mag. 1914, 28, 277-281.

59. M. de Broglie, Compt. Rend. Acad. Sci. 1921, 172, 274-275.

60. C. S. Fadley, in Electron Spectroscopy: Theory, Techniques and Applications, ed. C.R. Brundle and A.D. Baker, Academic Press, New York, 1978, Vol.2, Chapter 1, pp. 2-157.

61. K. Siegbahn, C. Nordling, G. Johansson, J. Hedman, P.-F.Heden, K. Hamrin, U. Gelius, T. Bergmark, L. O. Werme, R. Manne, Y. Baer, ESCA applied to free molecules, Amsterdam, North-Holland, 1969.

62. D.A. Shirley, Phys. Rev. B 1972, 5, 4709-4714.

63. S. Tougaard, Surf. Interface Anal. 1997, 25, 137-154.

64. J. Stöhr, NEXAFS Spectroscopy, Springer, Berlin, 1992.

65. M. H. Carpenter, Helium Atmosphere Chamber for Soft X-ray Spectroscopy of Biomolecules, MS Thesis, University of California, Davis, 2010. 
66. L. Reimer, Scanning Electron Microscopy Physics of Image Formation and Microanalysis, Springer, Berlin, 1984.

67. B. Fultz, J.M. Howe, Transmission Electron Microscopy and Diffractometry of Materials, Springer, Berlin, 2001

68. W. Paul, M. Raether, Z. Physik 1955, 140, 262-273.

69. J. B. Farmer, in Mass Spectroscopy, ed. C.A. McDowell, McGraw-Hill Book Company, New York, 1963, Chapter 2, pp. 7-45.

70. S. Tanuma, C.J. Powell, and D.R. Penn,. Surf. Interface Anal., 1991, 17, 911926.

71. N. D. S Canning, D. Outka, R. J. Madix, Surf. Sci. 1984, 141, 240-254.

72. D. E. King, J. Vac. Sci. Technol. A 1995, 13, 1247-1253.

73. B. Koslowski, H.-G. Boyen, C. Wilderotter, G. Kästle, P. Ziemann, R. Wahrenberg, P. Oelhafen, Surf. Sci. 2001, 475, 1-10.

74. P. H Citrin, G. K. Wertheim,Y. Baer, Phys. Rev. Lett. 1978, 41, 1425-1428.

75. P. Heimann, J. F. van der Veen, D. E. Eastman, Solid State Commun. 1981, 38, 595-598.

76. H. Tsai, E. Hu, K. Perng, M. Chen, J.-C. Wu, Y.-S.Chang, Surf. Sci. 2003, 537, L447-L450.

77. C. J. Weststrate, E. Lundgren, J. N. Andersen, E. D. L. Rienks, A. C. Gluhoi, J. W. Bakker, I. M. N. Groot, B. E. Nieuwenhuys, Surf. Sci. 2009, 603, 21522157.

78. K. A. Mills, R. F. Davis, S. D. Kevan, G. Thornton, D.A. Shirley, Phys. Rev. B 1980, 22,581 .

79. H.-G. Zimmer, A. Goldmann, R. Courths, Surf. Sci. 1986, 176, 115-124.

80. R. Courths, H.-G. Zimmer, A. Goldmann, H. Saalfeld, Phys. Rev. B 1986, 34, 3577-3585.

81. A. Cimino, D. Gazzoli, M. Valigi, J. Electron. Spectrosc. Relat. Phenom. 1999, 104, 1-29.

82. H. Shi, R. Asahi, C. Stampfl, Phys. Rev. B 2007, 75, 205125.

83. A. Knop-Gericke, M. Hävecker, T. Schedel-Niedrig, R. Schlögl. Topics Catal. 2001, 15, 27-34. 
84. X. Deng, B. K. Min, A. Guloy, C. M. Friend, J. Am. Chem. Soc. 2005, 127, 9267-9270.

85. A. Krozer, M. Rodalh, J. Vac. Sci. Technol. A 1997, 15, 1704-1709.

86. J. T. Miller, A. J. Kropf, Y. Zha, J. R. Regalbuto, L. Delannoy, C. Louis, E. Bus, J. A. van Bokhoven, J.Catal. 2006, 240, 222-234.

87. M. C. Kung, R. J. Davis, H. H. Kung, J. Phys. Chem. C 2007, 111, 1176711775.

88. B. K. Min, A. R. Alemozafar, M. M. Biener, J. Biener, C. M. Friend, Top. Catal. 2005, 36, 77-90.

89. K. Juodkazis, J. Juodkazyte, V. Jasulaitiene, A. Lukinskas, B. Sebeka, Electrochem. Commun. 2000, 2, 503-507.

90. H. Ron, I. Rubinstein, Langmuir 1994, 10, 4566-4573.

91. P. Jiang, S. Porsgaard, F. Borondics, M. Köber, A. Caballero, H. Bluhm, F.Besenbacher, M. Salmeron, J. Am. Chem. Soc. 2010, 132, 2858-2859.

92. W. X. Li, C. Stampfl, M. Scheffler, Phys. Rev. B 2003, 67, 045408.

93. J. Schnadt, J. Knudsen, X. L. Hu, A. Michaelides, R. T. Vang, K. Reuter, Z. Li, E. Lægsgaard, M. Scheffler, F. Besenbacher, Phys. Rev. B: Condens. Matter Mater. Phys., 2009, 80, 075424.

94. T. C. R. Rocha, A. Oestereich, D. V. Demidov, M. Hävecker, S. Zafeiratos, G. Weinberg, V. I. Bukhtiyarov, A. Knop-Gericke, R. Schlögl, Phys. Chem. Chem. Phys. 2012, 14, 4554-4564.

95. B. K. Min, X. Deng, D. Pinnaduwage, R. Schalek, C.M. Friend, Phys. Rev. B 2005, 72,121410 .

96. E. I. Intezarova, V. N. Kondrat'ev. B. Acad Sci. USSR Ch+ 1967, 16, 23262331.

97. M. Haruta, Chemical Records 2003, 3, 75-87.

98. Hutchings, G.J.; Edwards, J.K. In Frontiers of Nanoscience, eds. L.J. Roy, J.P. Wilcoxon, Elsevier, Amsterdam, 2012, Vol. 3, Chapter 6, pp. 249-293.

99. R. Meyer, C. Lemire, Sh. K. Shaikhutdinov, H.-J. Freund, Gold Bull. 2004, 37, $72-124$.

100. D. V. Demidov, I. P. Prosvirin, A. M. Sorokin, T. Rocha, A. Knop-Gericke, V. I. Bukhtiyarov, Catal. Sci. Technol. 2011, 1, 1432-1439. 
101. E. Desimoni, G. I. Casella, A. Morone, A. M. Salvi, Surf. Interface Anal. 1990, $15,627-634$.

102. S. Kundu, Y. Wang, W. Xia, M. Muhler, J. Phys. Chem. C 2008, 112, 1686916878.

103. G. Witek, M. Noeske, G. Mestl, S. Shaikhutdinov, R. J. Behm, Catal. Lett. 1996, 37, 35-39.

104. T. Dickinson, A. F. Povey, P. M. A. Sherwood, J. Chem. Soc. Faraday Trans.1975, 71, 298-311.

105. A. Yu. Klyushin, T.C.R Rocha, M. Hävecker, A. Knop-Gericke, R. Schlögl, Phys. Chem. Chem. Phys. 2014, 16, 7881-7886.

106. D. Tandon, E. J. Hippo, H. Marsh, E. Sebok, Carbon 1997, 35, 35-44.

107. A. Schaefer, D. Ragazzon, A. Wittstock, L. E. Walle, A. Borg, M. Bäumer, A. Sandell, J. Phys. Chem C 2012, 116, 4564-4571.

108. N. Saliba, D. H. Parker, B. E. Koel, Surf. Sci. 1998, 410, 270-282.

109. A.P. Grosvenor, B.A. Kobe, N.S. McIntyre, Surf. Sci. 2004, 572, 217-227.

110. G. Ertl, R. Hierl, H. Knozinger, N. Thiele, H. P. Urbach, Appl. Surf. Sci. 1980, $5,49-64$.

111. E. Cano, C. L. Torres, J. M. Bastidas, Mater. Corros. 2001, 52, 667-676.

112. A. N. Mansour, Surf. Sci. Spectra 1994, 3, 202-210.

113. G. C. Allen, S. J. Harris, J. A. Jutson, J. M. Dyke, Appl. Surf. Sci. 1989, 37, 111-134.

114. I. X. Green, W. Tang, M. McEntee, M. Neurock, J.T. Yates, J. Am. Chem. Soc. 2012, 134, 12717-12723.

115. A. K. Sinha, S. Seelan, S.Tsubota, M. Haruta, Angew. Chem. Int. Ed. 2004, 43, 1546-1548.

116. H. H. Kung, M. C. Kung, C. K. Costello, J. Catal. 2003, 216, 425-432.

117. D. W. Goodman, J. Phys. Chem. 1996, 100, 13090-13102.

118. P. Stefanov, M. Shipochka, P. Stefchev, Z. Raicheva, V. Lazarova, L. Spassov, J. Phys. Conf. Ser. 2008, 100, 012039.

119. C. Chusuei, X. Lai, K. Luo, D. W. Goodman, Top. Catal. 2001, 14, 71-83.

120. R. Zanella, L. Delannoy, C. Louis, Appl. Catal. A Gen. 2005, 291, 62-72.

121. F. Moreau, G. C. Bond, A. O. Taylor, J. Catal. 2005, 231, 105-114. 
122. M. Valden, X. Lai, D. W. Goodman, Science 1998, 281, 1647-1650.

123. A. K. Tripathi, V. S. Kamble, N. M. Gupta, J. Catal. 1999, 187, 332-342.

124. T. Bär, T. Visart de Bocarmé, B. E. Nieuwenhuys, N. Kruse, Catal. Lett. 2001, $74,127-131$.

125. D. Guillemot, V. Yu.Borovkov, V. B. Kazansky, M. Polisset-Thfoin, J. Fraissard, J. Chem. Soc. Faraday Trans. 1997, 93, 3587-3591.

126. F. Boccuzzi, A. Chiorino, M. Manzoli, P. Lu, T. Akita, S. Ichikawa, M. Haruta, J. Catal. 2001, 202, 256-267.

127. M. S. Chen, D. W. Goodman, Science 2004, 306, 252-255.

128. B. Yoon, H. Häkkinen, U. Landman, A. S. Wörz, J.-M. Antonietti, S. Abbet, K. Judai, U. Heiz, Science 2005, 307, 403-407.

129. S. Minicò, S. Scirè, C. Crisafulli, A. M. Visco, S. Galvagno, Catal. Lett. 1997, 47, 273-276.

130. C. K. Costello, J.H. Yang, H. Y. Law, Y. Wang, J.-N. Lin, L. D. Marks, M. C. Kung, H. H. Kung, Appl. Catal. A Gen. 2003, 243, 15-24.

131. M. G.Mason, Phys. Rev. B 1983, 27, 748-762.

132. Y. Kitsudo, A. Iwamoto, H. Matsumoto, K. Mitsuhara, T. Nishimura, M. Takizawa, T. Akita, Y. Maeda, Y. Kido, Surf. Sci 2009, 603, 2108-2114.

133. C.Chusuei, X. Lai, K. Luo, D. W. Goodman, Top. Catal. 2001, 14, 71-83.

134. Z. Yang, R. Wu, Phys. Rev. B 2003, 67, 081403.

135. Z.-P. Liu, X.-Q. Gong, J. Kohanoff, C. Sanchez, P. Hu, Phys. Rev. Lett. 2003, 91, 266102.

136. J.-D. Grunwaldt, C. Kiener, C. Wögerbauer, A. Baiker, J. Catal. 1999, 181, 223-232.

137. M. M. Schubert, S. Hackenberg, A. C. van Veen, M. Muhler, V. Plzak, R. J. Behm, J. Catal. 2001, 197, 113-122.

138. D. Widmann, R. J. Behm, Angew. Chem. Int. Ed. 2011, 50, 10241-10245.

139. D. Widmann, R. J. Behm, Acc. Chem. Res. 2014, 47, 740-749.

140. T. Diemant, Z. Zhao, H. Rauscher, J. Bansmann, R. J. Behm, Top. .Catal. 2007, 44, 83-93.

141. M. Haruta, S. Tsubota, T. Kobayashi, H. Kageyama, M. J. Genet, B. Delmon, J. Catal. 1993, 144, 175-192. 
142. A. I. Kozlov, A. P. Kozlova, H. Liu, Y. Iwasawa, Appl. Catal. A 1999, 182, 928.

143. Y. Yuan, K. Asakura, H. Wan, K. Tsai, Y. Iwasawa, Catal. Lett. 1996, 42, 1520.

144. B. E. Solsona, T. Garcia, C. Jones, S. H. Taylor, A. F. Carley, G. J. Hutchings, Appl. Catal. A 2006, 312, 67-76.

145. R. Liu, N. Gao, F. Zhen, Y. Zhang, L. Mei, X. Zeng, Chem. Eng. J. 2013, 225, 245-253.

146. M. Haruta, Catal. Today 1997, 36, 153-166.

147. G.R. Bamwenda, S. Tsubota, T. Nakamura, M. Haruta, Catal. Lett. 1997, 44, 83-87.

148. M. A. Bollinger, M. A. Vannice, Appl. Catal. B 1996, 8, 417-443.

149. J. Liu, R. Si, H. Zheng, Q. Geng, W. Dai, X. Chen, X. Fu, Catal. Commun. 2012, 26, 136-139

150. D. Widmann, Y. Liu, F. Schüth, R. J. Behm, J. Catal. 2010, 276, 292-305.

151. N. Lopez, T. V. W. Janssens, B. S. Clausen, Y. Xu, M. Mavrikakis, T. Bligaard, J. K. Nørskov, , J. Catal. 2004, 223, 232-235. 